\title{
Ethnopharmacology of Medicinal Plants of the Pantanal Region (Mato Grosso, Brazil)
}

\author{
Isanete Geraldini Costa Bieski, ${ }^{1}$ Fabrício Rios Santos, ${ }^{1}$ Rafael Melo de Oliveira, ${ }^{1}$ \\ Mariano Martinez Espinosa, ${ }^{2}$ Miramy Macedo, ${ }^{3}$ Ulysses Paulino Albuquerque, ${ }^{4}$ \\ and Domingos Tabajara de Oliveira Martins ${ }^{1}$ \\ ${ }^{1}$ Department of Basic Sciences in Health, Faculty of Medicine, Federal University of Mato Grosso, Cuiabá, \\ Avenida Fernando Correa da Costa, No. 2367, University Campus, 78060-900 Cuiabá, MT, Brazil \\ ${ }^{2}$ Department of Statistics, Institute of Exact and Earth Sciences, Federal University of Mato Grosso, 78060-900 Cuiabá, MT, Brazil \\ ${ }^{3}$ Faculty of Biological Sciences, University of Cuiabá, Mato Grosso, Avenida Beira Rio, No. 3100, University Campus, \\ 78020-590 Cuiabá, MT, Brazil \\ ${ }^{4}$ Department of Biology, Botany Area, Laboratory of Applied Ethnobotany, Federal University of Rural de Pernambuco, \\ 52171-900 Recife, PE, Brazil
}

Correspondence should be addressed to Domingos Tabajara de Oliveira Martins, taba@terra.com.br

Received 16 August 2011; Accepted 3 October 2011

Academic Editor: Maria Franco Trindade Medeiros

Copyright ( $) 2012$ Isanete Geraldini Costa Bieski et al. This is an open access article distributed under the Creative Commons Attribution License, which permits unrestricted use, distribution, and reproduction in any medium, provided the original work is properly cited.

\begin{abstract}
Traditional knowledge is an important source of obtaining new phytotherapeutic agents. Ethnobotanical survey of medicinal plants was conducted in Nossa Senhora Aparecida do Chumbo District (NSACD), located in Poconé, Mato Grosso, Brazil using semistructured questionnaires and interviews. 376 species of medicinal plants belonging to 285 genera and 102 families were cited. Fabaceae (10.2\%), Asteraceae (7.82\%) and Lamaceae (4.89\%) families are of greater importance. Species with the greater relative importance were Himatanthus obovatus (1.87), Hibiscus sabdariffa (1.87), Solidago microglossa (1.80), Strychnos pseudoquina (1.73) and Dorstenia brasiliensis, Scoparia dulcis L., and Luehea divaricata (1.50). The informant consensus factor (ICF) ranged from 0.13 to 0.78 encompassing 18 disease categories, of which 15 had ICF greater than 0.50 , with a predominance of disease categories related to injuries, poisoning and certain other consequences of external causes (ICF $=0.78$ ) having 65 species cited while 20 species were cited for mental and behavioral disorders (ICF $=0.77$ ). The results show that knowledge about medicinal plants is evenly distributed among the population of NSACD. This population possesses medicinal plants for most disease categories, with the highest concordance for prenatal, mental/behavioral and respiratory problems.
\end{abstract}

\section{Introduction}

Despite the fact that modern medicine, on the basis of the complex pharmaceutical industry, is well developed in most part of the world, the World Health Organization (WHO) through it Traditional Medicine Program recommends its Member States to formulate and develop policies for the use of complementary and alternative medicine (CAM) in their national health care programmes [1]. Among the components of CAM, phytotherapy practiced by the greater percentage of the world population through the use of plants or their derivatives, occupies a significant and unique position [2].
In this sense, documentation of the indigenous knowledge through ethnobotanical studies is important in the conservation and utilization of biological resources [3].

Brazil is a country with floral megadiversity, possessing six ecological domains, namely, Amazonian forest, Caatinga, Pampas, Cerrado, Atlantic Forest, and the Pantanal [4]. Mato Grosso region is noteworthy in this regard, as it occupies a prominent position both in the national and international settings, for it presents three major Brazilian ecosystems (the Pantanal, Cerrado, and Amazonian rainforest). Besides this, it also hosts diverse traditional communities in its territories, namely, the Indians descents (Amerindians), African descents, and the white Europeans. However, due to the mass 
migration from the rural areas and technological development, coupled with globalization of knowledge by the dominant nations, cultural tradition concerning the use of medicinal plants is in the major phase of declining [5].

The Pantanal is distinguishably the largest wetland ecosystem of the world, according to the classification by UNESCO World Heritage Center (Biosphere Reserve) [4]. The Pantanal vegetation is a mosaic consisting of species of the Amazonian rainforest, Cerrado, Atlantic forest, and Bolivian Chaco, adapted to special conditions, where there is alternations of both high humidity and pronounced dryness during the time of the year [4]. The presence in the Pantanal of the traditional populations that use medicinal plants for basic health care makes this region an important field for the ethnobotanical and ethnopharmacological studies $[6,7]$.

Because of the fact that the Pantanal communities are relatively isolated, they have developed private lives that involved much reliance on profound knowledge of the biological cycles, utilization of natural resources, and traditional technology heritage [8].

As a result of the aforementioned, this study aimed to systematically and quantitatively evaluate the information gathered from these Pantanal communities, highlight the relevance of the ethnobotanical findings, and cite and discuss relevant literatures related to medicinal plants with greater relative importance (RI) and high informant consensus factor (ICF) values obtained in the study.

\section{Materials and Methods}

2.1. Study Area. For the choice of study area, literature search was conducted to identify the Pantanal region in Mato Grosso, consisting of traditional communities where such studies have not yet been conducted and/or there were no ethnobotanical survey publications. The study design was cross-sectional and was conducted between the period of November, 2009 and February, 2010. The study setting chosen was NSACD located in the Poconé municipality, Mato Grosso State, Central West of Brazil (Figure 1) with coordinates of $16^{\circ} 02^{\prime} 90^{\prime \prime} \mathrm{S}$ and $056^{\circ} 43^{\prime} 49^{\prime \prime} \mathrm{W}$. Poconé is located within the region of Cuiabá River valley, with an altitude of $142 \mathrm{~m}$, occupies a territorial area of $17,260.86 \mathrm{~km}^{2}$, and of tropical climate. The mean annual temperature is $24^{\circ} \mathrm{C}\left(4-42^{\circ} \mathrm{C}\right)$ and the mean annual rainfall is $1,500 \mathrm{~mm}$ with rainy season occurring between December and February. The municipality is composed of 2 Districts (NSAC and Cangas), 5 villages, 11 settlements, 14 streets, and 72 communities (countryside) [9]. The population of NSACD is estimated to be 3,652 inhabitants, representing $11.5 \%$ of Poconé municipality [10]. The principal economic activities are mainly livestock farming, mining, and agriculture with great tourism potentials, because Poconé municipality is the gateway to the Pantanal region [9].

2.2. Consent and Ethical Approval. Authorization and ethical clearance were sought from the relevant government (Health authority of Poconé and the National Council of Genetic Heritage of the Ministry of Environment (CGEN/MMA),
Resolution 247 published in the Federal Official Gazette, in October, 2009, on access to the traditional knowledge for scientific research and Federal University of Mato Grosso and Júlio Muller Hospital Research Ethical Committees, Protocol 561/CEP-HUJM/08 authorities. Previsits were made to each community of NSACD to present the research project as well as to seek the consent of each potential informant.

2.3. Data Collection and Analysis. In this present study, sampling was done using probabilistic simple randomization and stratified sampling techniques $[10,11]$.

The population studied consists of inhabitants of 13 communities of NSACD, Mato Grosso State, considering an informant per family. The criteria for each informant chosen were age of 40 and above, residing in NSACD for more than 5 years (because there is large migration into the area because of the presence of ethanol producing factory).

These criteria are in line with the study objective coupled with the information gathered from the local authority [12].

In order to determine the estimated sample size $(n)$, in this case, the number of families to be sampled per communities being considered, the following formula was utilized $[11,13]$ :

$$
n=\frac{N p(1-p)}{(N-1)\left(d / z_{\alpha / 2}\right)^{2}+p(1-p)} .
$$

This study considered the population size of 1,179 families $(N=1,179)$, confidence coefficient of $95 \%(z / 2=$ 1.96), sampling error of $0.05(d=0.05)$, a proportion of 0.5 $(P=0.5)$. It should be noted that the $P=0.5$ was assigned due to nonexistence of previous information about this value as is usual in practice, to obtain conservative sample size which is representative at the same time.

In determining the sample size for the microarea, 5\% error and $10 \%$ loss in sample were considered. To determine the sample size in each microarea, the sample size (290) was multiplied by the sampling fraction of each microarea and dividing the total number of families of the same microarea with the total number of families of all the microareas $(1,179)$, thereby arriving at the sample sizes for each area as shown in Table 1.

The interviews were conducted with the help of 12 trained applicators, under the supervision of the respective investigator. Data collected included sociodemographic details, vernacular names of the plant species with their medicinal uses, methods of drug preparation, and other relevant information. The ethnobotanical data were organized using the Microsoft Office Access 2003 program and statistically analyzed using SPSS, version 15 for Windows (SPSS Inc., Chicago, Illinois, USA).

2.4. Plant Collection, Identification, and Herborization. The collection of plant materials were done in collaboration with the local specialists, soon after the interviews. Both indigenous and scientific plant names were compiled. The plant materials collected during the study period were herborized, mounted as herbarium voucher specimens, and deposited for taxonomic identification and inclusion in the 

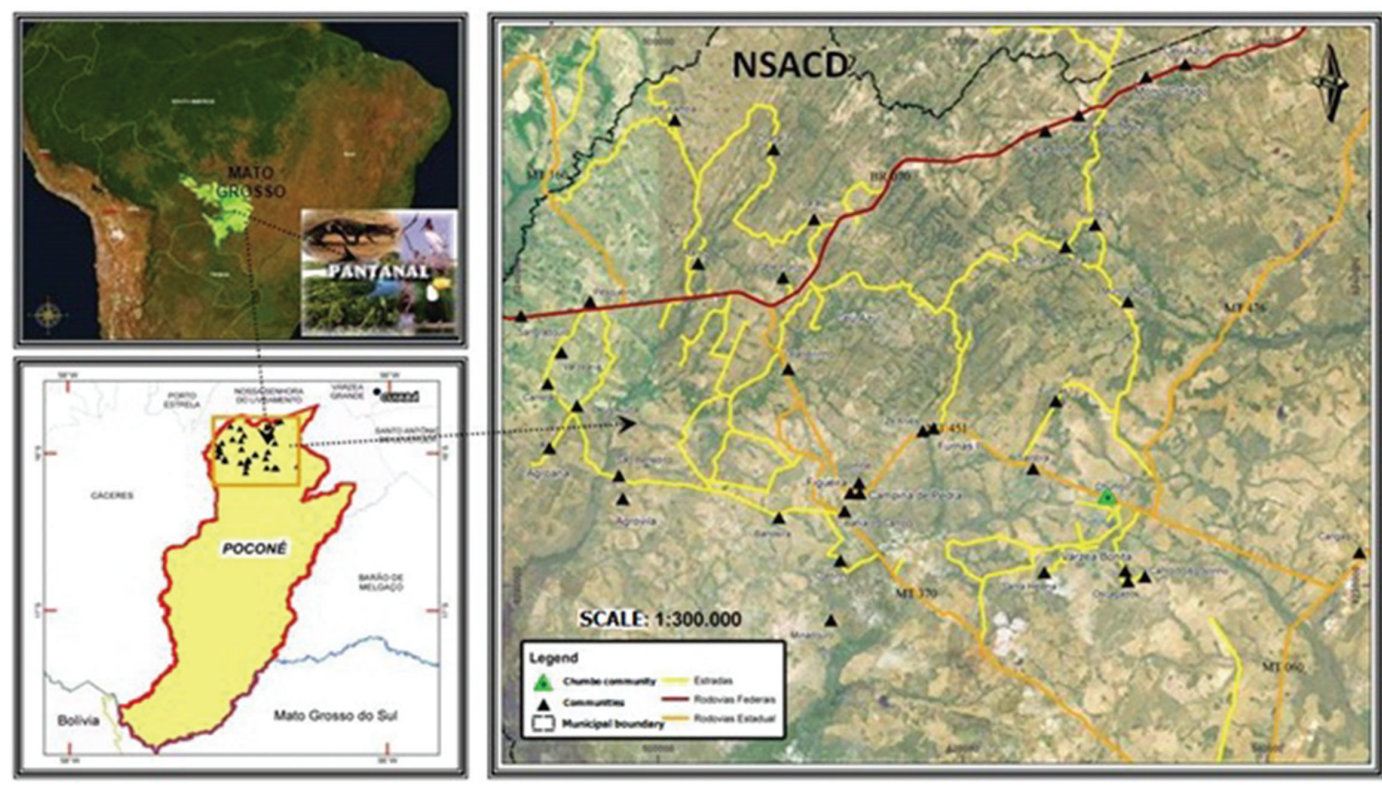

Figure 1: Location of the study area. Poconé, Mato Grosso, in Midwest of Brazil.

Table 1: Distribution of the 13 communities of Nossa Senhora Aparecida do Chumbo District.

\begin{tabular}{|c|c|c|c|c|c|}
\hline ID & COMMUNITY & $\begin{array}{c}\text { Total number of } \\
\text { individuals }\end{array}$ & $\begin{array}{c}\text { Total number of } \\
\text { families }\end{array}$ & $\begin{array}{l}\text { Sample } \\
\text { fraction }\end{array}$ & $\begin{array}{c}\text { Sample } \\
\text { size }\end{array}$ \\
\hline 1 & Chumbo & 946 & 216 & 0.1832 & 52 \\
\hline 2 & Canto do Agostinho, Santa Helena, Os Cagados, Várzea bonita & 179 & 52 & 0.0441 & 15 \\
\hline 3 & Furnas II, Salobra, Zé Alves & 165 & 59 & 0.0500 & 15 \\
\hline 4 & Campina II, Furnas I, Mundo Novo, Rodeio & 279 & 81 & 0.0687 & 20 \\
\hline 5 & Campina de Pedra, Imbé & 188 & 67 & 0.0568 & 16 \\
\hline 6 & Barreirinho, Coetinho, Figueira & 253 & 95 & 0.0806 & 23 \\
\hline 7 & Bahia de Campo & 257 & 74 & 0.0628 & 18 \\
\hline 8 & Agrovila, São Benedito & 184 & 66 & 0.0560 & 16 \\
\hline 9 & Agroana & 372 & 178 & 0.1510 & 44 \\
\hline 10 & Bandeira, Minadouro & 248 & 82 & 0.0696 & 20 \\
\hline 11 & Carretão, Deus Ajuda, Sangradouro, Pesqueiro, Varzearia & 216 & 77 & 0.0653 & 19 \\
\hline 12 & Chafariz, Ramos, Sete Porcos, Urubamba & 208 & 67 & 0.0568 & 16 \\
\hline \multirow[t]{2}{*}{13} & Céu Azul, Capão Verde, Morro Cortado, Passagem de Carro, Varal & 157 & 65 & 0.0551 & 16 \\
\hline & Total & 3,652 & 1,179 & 1.0000 & 290 \\
\hline
\end{tabular}

ID = identification of the microarea.

collection of Federal University of Mato Grosso and CGMS Herbarium of Federal University of Mato Grosso do Sul, Brazil.

Plant species were identified according to standard taxonomic methods, based on floral morphological characters, analytical keys, and using, where possible, samples for comparison, as well as consultations with experts and literature $[6,7,14-19]$. The plant species obtained were grouped into families according to the classification system of Cronquist [20], with the exception of the Pteridophyta and Gymnospermae. For corrections of scientific names and families, the official website of the Missouri Botanical Garden was consulted [21].
2.5. Quantitative Ethnobotany. The relative importance (RI) of each plant species cited by the informants was calculated according to a previously proposed method [22]. In order to calculate RI, the maximum obtainable by a species is two was calculated using (2) according to Oliveira et al. [23]

$$
\mathrm{RI}=\mathrm{NCS}+\mathrm{NP}
$$

where RI: relative importance; NCS: number of body systems. It is given by the number of body systems, treated by a species (NSCS) over the total number of body system treated by the most versatile species (NSCSV): NCS = NSCS/NSCSV; NP: number of properties attributed to a specific species 
(NPS) over the total number of properties attributed to the most versatile species (NPSV): NP $=$ NPS/NPSV.

We sought to identify the therapeutic indications which were more important in the interviews to determine the informant consensus factor (ICF), which indicates the homogenity of the information [23].

The ICF will be low (close to 0), if the plants are chosen randomly, or if the informants do not exchange information about their uses. The value will be high (close to 1), if there is a well defined criterion of selection in the community and/or if the information is exchanged among the informants [23].

ICF was calculated using the number of use citations in each category of plant disease $\left(n_{\mathrm{ur}}\right)$, minus the number of species used $\left(n_{t}\right)$ divided by the number of use citations in each category minus one on the basis of (3):

$$
\mathrm{ICF}=\frac{n_{\mathrm{ur}}-n_{t}}{n_{\mathrm{ur}}-1}
$$

The citations for therapeutic purposes were classified using the 20 categories of the International Classification of Diseases and Related Health Problems, 10th editionCID [24]: injuries, certain infectious, and parasitic diseases (I); neoplasms-tumors (II), diseases of blood and bloodforming organs and certain disorders involving the immune mechanism (III), endocrine, nutritional and metabolic diseases (IV) mental and behavioral disorders (V), nervous system (VI), diseases of eye and adnexa (VII), diseases of the ear and mastoid process (VIII), diseases of the circulatory system (IX), respiratory diseases (X), digestive diseases (XI), diseases of the skin and subcutaneous tissue (XII), diseases of the musculoskeletal system and connective tissue (XIII), genitourinary diseases (XIV), pregnancy, childbirth and $(\mathrm{XV})$, certain conditions originating during the perinatal period (XVI), symptoms, signs and abnormal clinical and laboratory findings, not elsewhere classified (XVIII) and injury, poisoning and certain other consequences of external causes (XIX).

We selected for further discussion species that presented $\mathrm{RI} \geq 1.5$, and are in a category with high ICF. We conducted literature review using among others, the databases of Web of Science, MEDLINE, SciELO and including nonindexed works. We also searched national data bases for dissertations and theses.

\section{Results}

A total of 262 informants were interviewed, representing $7.17 \%$ of the population of NSACD, $22.22 \%$ of the population aged $\geq 40$ years and residing in the District for over five years. Of the respondents, $69 \%$ were female and $31 \%$ male, aged 40-94 years (median 55). 68\% were born in the city of Poconé, and $62 \%$ have been residents for over 20 years in the District (Table 2).

Of the 262 respondents, 259 (99.0\%) reported the use of medicinal plants in self health care, with a minimum of 1 plant and a maximum of 250 plants among the female respondents and a minimum of 2 plants and a maximum of 54 among the male respondents. A total of 3,289 citations were recorded corresponding to 376 different plant species which belong to 285 genera and 102 families. Fabaceae (10.2\%), Asteraceae (7.82\%), and Lamaceae (4.89\%) families were the most representative in this study (Table 3 ).

3.1. Relative Importance (RI). The RI of the species cited by 262 respondents from NSACD ranged from 0.17 to 1.87 . A total of 261 species had RI $\leq 0.5 ; 80$ species, RI from 0.51 to $1.0 ; 30$ species, RI from 1.1 to 1.5 , and 4 species with RI from 1.51 to 2.0 , among the latter, three species were native to Brazil. The species with RI $\geq 1.5$, were Himatanthus obovatus (Müll. Arg.) Woodson (1.87), Hibiscus sabdariffa L. (1.87), Solidago microglossa DC. (1.80), Strychnos pseudoquina A. St.-Hil. (1.73), Dorstenia brasiliensis Lam., Scoparia dulcis L., and Luehea divaricata Mart. (1.50 each), as shown in Table 4.

3.2. Informant Consensus Factor (ICF). In the disease categories according to CID, 10th ed., we observed that ICF values ranged from 0.43 to 0.77 , with the exception of disease category included in CID VI (diseases of the nervous system), which was 0.13 . The ICF for CID VI ranged between 0.13 and 0.78 (mean $=0.62, \mathrm{SD}=0.16,95 \% \mathrm{CI}: 0.53-0.70)$. The highest consensus value obtained was for the category related to injuries, poisoning, and some other consequences of external causes (ICF $=0.78$ ), with 65 species and 286 citations. Three species were more common, namely, S. dulcis and S. microglossa ("Brazilian arnica"), with 49 citations each and L. pacari (manga-brava) with 42 citations. The main ailments addressed in this category were inflammation, pain, and gastric disorders.

Out of 20 disease categories, there were citations for 18 therapeutic indications, as shown in Table 5.

\section{Discussion}

In the present study, almost all the respondents (99\%) claimed to know and use medicinal plants. Surveys conducted in other countries had reported values ranging from $42 \%$ to $98 \%$ depending on the region and country of the study [25-27]. Due to the low level of knowledge of traditional medicine in national capitals, ethnobotanical surveys in many developing countries including Brazil, primarily prefer to evaluate small communities or rural hometowns, whose population having knowledge and practical experience with traditional medicine are proportionately higher (between 80 and 100\%) [28-30].

The high percentage of folk knowledge of medicinal plants identified in Brazil may be due to factors such as lower influence of the contemporary urban lifestyle and the strength of cultural traditions in the rural communities [31]. In fact, with the process of industrialization and migration to the cities, a significant part of traditional culture is maintained more in the communities farther from the metropolis via oral transmission of the knowledge of CAM and family traditions. Transmission and conservation of CAM knowledge is more pronounced in Brazil due to high degree of biodiversity.

One of the most important aspects of this research is the documentation of high number of taxa (285 genera and 
Table 2: Distribution of the 13 communities of Nossa Senhora Aparecida do Chumbo District, Poconé, Mato Grosso, Brazil.

\begin{tabular}{|c|c|c|c|c|c|c|c|}
\hline ID & Comunity & Population & $\begin{array}{l}\text { Number of } \\
\text { individuals }{ }^{\mathrm{a}}\end{array}$ & $\begin{array}{l}\text { Sample } \\
\text { fraction }\end{array}$ & $\begin{array}{l}\text { Sample } \\
\text { size }\end{array}$ & $N$ & $\begin{array}{c}\text { Plant } \\
\text { citations }\end{array}$ \\
\hline 1 & Chumbo & 946 & 216 & 0.1832 & 52 & 50 & 827 \\
\hline 2 & $\begin{array}{l}\text { Canto do Agostinho, Santa Helena, Os } \\
\text { Cagados, Várzea bonita }\end{array}$ & 179 & 52 & 0.0441 & 15 & 10 & 131 \\
\hline 3 & Furnas II, Salobra, Zé Alves & 165 & 59 & 0.050 & 15 & 10 & 99 \\
\hline 4 & $\begin{array}{l}\text { Campina II, Furnas I, Mundo Novo, } \\
\text { Rodeio }\end{array}$ & 279 & 81 & 0.0687 & 20 & 11 & 179 \\
\hline 5 & Campina de Pedra, Imbé & 188 & 67 & 0.0568 & 16 & 12 & 173 \\
\hline 6 & Barreirinho, Coetinho, Figueira & 253 & 95 & 0.0806 & 23 & 23 & 213 \\
\hline 7 & Bahia de Campo & 257 & 74 & 0.0628 & 18 & 13 & 461 \\
\hline 8 & Agrovila, São Benedito & 184 & 66 & 0.056 & 16 & 16 & 141 \\
\hline 9 & Agroana & 372 & 178 & 0.151 & 44 & 38 & 349 \\
\hline 10 & Bandeira, Minadouro & 248 & 82 & 0.0696 & 20 & 22 & 171 \\
\hline 11 & $\begin{array}{l}\text { Carretão, Deus Ajuda, Sangradouro, } \\
\text { Pesqueiro, Varzearia }\end{array}$ & 216 & 77 & 0.0653 & 19 & 23 & 180 \\
\hline 12 & Chafariz, Ramos, Sete Porcos, Urubamba & 208 & 67 & 0.0568 & 16 & 16 & 200 \\
\hline \multirow[t]{2}{*}{13} & $\begin{array}{l}\text { Céu Azul, Capão Verde, Morro Cortado, } \\
\text { Passagem de Carro, Varal }\end{array}$ & 157 & 65 & 0.0551 & 16 & 18 & 165 \\
\hline & $N$ & 3,652 & 1,179 & 1.000 & 290 & 262 & 3,289 \\
\hline
\end{tabular}

ID: Identification of the microarea; $N$ : Sample size; ${ }^{\mathrm{a}}$ Informants with age $\geq 40$ years and period of residing $\geq 5$ years.

102 families) and species (376) mentioned by the informants as medicinal. These findings confirmed the existence of the great diversity of plants used for therapeutic purpose and preserved traditional culture, as stated by Simbo [32]. It is worth mentioning here the presence of 8 (eight) local medicinal plant expert informants/healers among the 262 respondents in this study. These local expert informants/healers account for a significant number of citations (43 to 250) in this study. In Brazil, as in other countries, rural communities have developed knowledge about the medicinal and therapeutic properties of natural resources and have contributed to the maintenance and transmission of the ethnopharmacological knowledge within the communities.

The most representative plant families are Fabaceae (10.2\%), Asteraceae (7.82\%), and Lamiaceae (4.89\%). These results are in accordance with other ethnobotanical surveys conducted in the tropical regions $[33,34]$ including Brazil $[7,35]$. Furthermore, the results from our study are also in conformity with the findings of the most comprehensive ethnobotanical survey conducted by V. J. Pott and A. Pott in the Brazilian Pantanal region [19].

Featuring greater potential for bioprospecting are 231 $(61.6 \%)$ species indicated for the treatment of at least two diseases, and RI between 0.17 and 1.87 (mean $=0.46$, SD $=0.357$, 95\% CI: 0.4250-0.4973). The seven species with the highest RI were $H$. obovatus (Müll. Arg.) Woodson (13 therapeutic indications and $\mathrm{RI}=1.87, H$. sabdariffa $\mathrm{L}$. $(12$ therapeutic indications and $\mathrm{RI}=1.87)$; S. microglossa DC. (9 therapeutic indications and $\mathrm{RI}=1.80$ ) S. pseudoquina A. St. - Hil. (14 therapeutic indications and RI = 1.73) and D. brasiliensis Lam., S. dulcis L., and L. divaricata Mart. $(12,10$, and 12 therapeutic indications respectively with RI = 1.50) (Table 4). For the sake of brevity, we will focus most of our discussion on these seven most cited medicinal plants highlighting the most important available literature on them and including L. pacari. It should be noted that although 146 (39\%) species presented RI below 0.17, with just a single indication, they cannot be considered as of lower pharmacological potential or importance, because as Albuquerque et al. [36] have noted elsewhere, these may be species of recent introduction in the culture of the community under study but might have been validated by the customary use in other social groups.

A total of 105 different folkways, including 18 disease categories, according to Brasil [24], were codified as shown in Table 5. The highest frequencies in decreasing magnitude were indications for the treatment of pain and inflammation (10.8\%), kidney disease (7.6\%), and wound healing $(6.8 \%)$. In part, these data can be explained by the characteristics of the informants (elderly, rural activity, low level of education, and poor sanitation at home) with higher frequency of chronic, inflammatory, and infectious diseases. In addition, the search for natural treatments for infected wounds is very common in populations of agrarian labor or menial worker as stated by Akerreta et al. [37]. As ICF values were generally close to 1.0, it may be presumed that there is certain homogeneity in knowledge of medicinal plants among the population of NSACD.

4.1. Literature Survey and Discussions on the Selected Species with Higher Relative Importance. Himatanthus obovatus, var. obovatus had the highest relative importance, being cited for 13 different ailments that fall into 11 categories of CID, 10 th ed. with a total of 29 citations. The most commonly mentioned of these indications for this plant were its 
TABle 3: Relation of the relative importance of the plant species mentioned by informants of Nossa Senhora Aparecida do Chumbo District, Poconé, Mato Grosso, Brazil.

\begin{tabular}{cccc}
\hline Family/species & $\begin{array}{c}\text { Vernacular } \\
\text { name }\end{array}$ & Application & $\begin{array}{c}\text { Preparation } \\
\text { (administration) listed }\end{array}$ \\
\hline
\end{tabular}

\section{ACANTHACEAE}

1.1. Justicia pectoralis Jacq.

\section{ADOXACEAE}

2.1. Sambucus australis Cham. \& Schltdl.

\section{ALISMATACEAE}

\subsection{Echinodorus macrophyllus (Kuntze.) Micheli}

\section{AMARYLLIDACEAE \\ 4.1. Allium cepa $\mathrm{L}$. \\ 4.2. Allium fistulosum L. \\ 4.3. Allium sativum L. \\ 5. AMARANTHACEAE}

5.1. Alternanthera brasiliana (L.) Kuntze

5.2. Alternanthera dentata(Moench) Stuchlik ex R.E. Fr.

\subsection{Alternanthera ficoide (L.) P. Beauv.}

5.4. Amaranthus aff. viridis $\mathrm{L}$.

5.5. Beta vulgaris L.

5.6. Celosia argentea L.

\subsection{Chenopodium ambrosioides $\mathrm{L}$.}

5.8. Pfaffia glomerata (Spreng.) Pedersen

\section{ANACARDIACEAE}

6.1. Anacardium humile A. St.- Hil.

6.2. Anacardium occidentale L.

6.3. Astronium fraxinifolium Schott ex Spreng
Anador

pain, fever,

laxative, and

muscle relaxant

Sabugueiro Fever and measles

$\begin{array}{cc}\text { Chapéu-de- } & \begin{array}{c}\text { blood cleanser, } \\ \text { stomach, } \\ \text { couro } \\ \text { rheumatism, and } \\ \text { kidneys }\end{array}\end{array}$

Cebola
Cebolinha
Alho

wound healing

Flu

hypertension

wound healing,

itching, diabetes, pain, bone

Terramicina

fractures, throat,

flu, inflammation

uterine, and

relaxative

muscular

Ampicilina

wound healing

and kidneys

Doril

Caruru-de-

porco

Beterraba

Crista-de-galo

Erva-de-santamaria

Ginseng-

brasileiro

Cajuzinho-docampo

muscula relaxative

wound healing, pain, and kidneys

anemia

kidneys

wound healing,

heart, diabetes,

bone fractures,

flu, kidneys,

cough, and worms

Obesity

diabetes,

dysentery, and $\quad$ Infusion (I, E) $\quad \begin{array}{lllll}5 & 3 & 3 & 0.50\end{array}$ hepatitis

abortive, wound healing,

cholesterol, teeth, blood cleanser,

diabetes, diarrhea, dysentery, and pain

flu, hemorrhoids, and cough

Infusion (I) $\quad 36 \quad 2 \quad 3 \quad 0.40$

Infusion (I, E) $\quad 24 \quad 2 \quad 2 \quad 0.33$

$\begin{array}{lllll}\text { Infusion (I) } & 1 & 1 & 1 & 0.17\end{array}$

$\begin{array}{lllll}\text { Infusion (I) } & 1 & 1 & 1 & 0.17\end{array}$

$\begin{array}{lllll}\text { Infusion (I) } & 7 & 1 & 1 & 0.17\end{array}$

Infusion (I, E) $\quad 41 \quad 6 \quad 9 \quad 1.20$

$\begin{array}{lllll}\text { Infusion (I, E) } & 7 & 2 & 2 & 0.33\end{array}$

$\begin{array}{lllll}\text { Infusion (I, E) } & 3 & 1 & 1 & 0.17\end{array}$

Infusion (I) $\quad 4 \quad 3 \quad 3 \quad 0.50$

$\begin{array}{lllll}\text { Infusion (I) } & 1 & 1 & 1 & 0.17\end{array}$

$\begin{array}{llll}5 & 3 & 3 & 0.50\end{array}$

$\begin{array}{lllll}\text { Infusion (I, E) } & 102 & 7 & 8 & 1.23\end{array}$

$\begin{array}{lllll}\text { Infusion (I) } & 2 & 1 & 1 & 0.17\end{array}$

Infusion (I, E) $\quad 30 \quad 6 \quad 9 \quad 1.20$

Cajueiro

Gonçaleiro
Infusion and maceration (I, $\quad \begin{array}{lllll}8 & 3 & 3 & 0.50\end{array}$ E) 
Table 3: Continued.

\begin{tabular}{|c|c|c|c|c|c|c|c|}
\hline Family/species & $\begin{array}{l}\text { Vernacular } \\
\text { name }\end{array}$ & Application & $\begin{array}{c}\text { Preparation } \\
\text { (administration) }\end{array}$ & $\begin{array}{c}\text { Uses } \\
\text { listed }\end{array}$ & NCS & NP & RI \\
\hline 6.4. Mangifera indica L. & Mangueira & $\begin{array}{l}\text { Bronchitis, flu, } \\
\text { and cough }\end{array}$ & $\begin{array}{l}\text { Infusion and } \\
\text { maceration (I, } \\
\text { E) }\end{array}$ & 11 & 2 & 3 & 0.40 \\
\hline 6.5. Myracrodruon urundeuva (Allemão) Engl. & Aroeira & $\begin{array}{l}\text { anemia, bladder } \\
\text { bronchitis cancer, } \\
\text { wound healing, } \\
\text { blood cleanser, } \\
\text { bone fractures, } \\
\text { hernia, uterine } \\
\text { inflammation, } \\
\text { muscular } \\
\text { relaxative, and } \\
\text { cough }\end{array}$ & $\begin{array}{c}\text { Infusion, } \\
\text { maceration, and } \\
\text { decoction }(\mathrm{I}, \mathrm{E})\end{array}$ & 84 & 7 & 11 & 1.43 \\
\hline 6.6. Spondias dulcis Parkinson & Caja-manga & scabies & Infusion (I, E) & 2 & 1 & 1 & 0.17 \\
\hline 6.7. Spondias purpurea L. & Seriguela & $\begin{array}{l}\text { wound healing } \\
\text { and hepatitis }\end{array}$ & Infusion (I, E) & 2 & 2 & 2 & 0.33 \\
\hline \multicolumn{8}{|l|}{ 7. ANNONACEAE } \\
\hline 7.1. Annona cordifolia Poepp. ex Maas \& Westra & $\begin{array}{l}\text { Araticum- } \\
\text { abelha }\end{array}$ & $\begin{array}{l}\text { Diabetes and bone } \\
\text { fractures }\end{array}$ & $\begin{array}{c}\text { Infusion and } \\
\text { decoction (I, E) }\end{array}$ & 3 & 2 & 2 & 0.33 \\
\hline 7.2. Annona crassiflora Mart. & Graviola & diabetes & Infusion (I, E) & 11 & 1 & 1 & 0.17 \\
\hline 7.3. Duguetia furfuracea (A. St.- Hil.) Saff. & $\begin{array}{l}\text { Beladona-do- } \\
\text { cerrado }\end{array}$ & pain & Infusion (I, E) & 1 & 1 & 1 & 0.17 \\
\hline \multicolumn{8}{|l|}{ 8. APIACEAE } \\
\hline 8.1. Coriandrum sativum L. & Coentro & flu & Infusion (I) & 1 & 1 & 1 & 0.17 \\
\hline 8.2. Eryngium aff. pristis Cham. \& Schltdl. & $\begin{array}{l}\text { Lingua-de- } \\
\text { tucano }\end{array}$ & $\begin{array}{l}\text { Tooth and } \\
\text { muscular } \\
\text { relaxative }\end{array}$ & Infusion (I) & 3 & 2 & 2 & 0.33 \\
\hline 8.3. Petroselinum crispum ((Mill) Fuss & Salsinha & flu & Infusion (I) & 1 & 1 & 1 & 0.17 \\
\hline 8.4. Pimpinella anisum $\mathrm{L}$. & Erva-doce & $\begin{array}{l}\text { pain soothing, } \\
\text { constipation, and } \\
\text { kidneys }\end{array}$ & Infusion (I, E) & 12 & 3 & 3 & 0.50 \\
\hline \multicolumn{8}{|l|}{ 9. APOCYNACEAE } \\
\hline 9.1. Aspidosperma polyneuron (Müll.) Arg. & Péroba & $\begin{array}{l}\text { Stomach and } \\
\text { laxative }\end{array}$ & $\begin{array}{c}\text { Infusion and } \\
\text { decoction (I, E) }\end{array}$ & 5 & 1 & 2 & 0.23 \\
\hline 9.2. Aspidosperma tomentosum Mart. & Guatambu & gastritis & Infusion (I) & 4 & 1 & 1 & 0.17 \\
\hline 9.3. Catharanthus roseus (L.) G. Don & Boa-noite & $\begin{array}{l}\text { mumps fever and } \\
\text { kidneys }\end{array}$ & Infusion (I) & 8 & 3 & 3 & 0.50 \\
\hline 9.4. Geissospermum laeve (Vell.) Miers & Pau-tenente & Diabetes and pain & Infusion (I) & 6 & 2 & 2 & 0.33 \\
\hline 9.5. Hancornia speciosa var. gardneri (A. DC.) Müll. Arg. & $\begin{array}{l}\text { Mangava- } \\
\text { mansa }\end{array}$ & $\begin{array}{l}\text { itching, diarrhea, } \\
\text { and stomach }\end{array}$ & $\begin{array}{l}\text { Decoction and } \\
\text { maceration (I, } \\
\text { E) }\end{array}$ & 8 & 3 & 3 & 0.50 \\
\hline 9.6. Himatanthus obovatus (Müll. Arg.) Woodson & Angélica & $\begin{array}{l}\text { anemia, wound } \\
\text { healing, } \\
\text { cholesterol, blood } \\
\text { cleanser, pain, } \\
\text { nose bleeding, } \\
\text { hypertension, } \\
\text { uterine } \\
\text { inflammation, } \\
\text { labyrinthitis, } \\
\text { pneumonia, } \\
\text { relaxative } \\
\text { muscular, worms, } \\
\text { and vitiligo }\end{array}$ & Maceration (I) & 45 & 10 & 13 & 1.87 \\
\hline
\end{tabular}


Table 3: Continued.

\begin{tabular}{|c|c|c|c|c|c|c|c|}
\hline Family/species & $\begin{array}{c}\text { Vernacular } \\
\text { name }\end{array}$ & Application & $\begin{array}{c}\text { Preparation } \\
\text { (administration) }\end{array}$ & $\begin{array}{c}\text { Uses } \\
\text { listed }\end{array}$ & NCS & NP & RI \\
\hline 9.7. Macrosiphonia longiflora (Desf.) Müll. Arg. & $\begin{array}{l}\text { Velame-do- } \\
\text { campo }\end{array}$ & $\begin{array}{l}\text { hearth, blood } \\
\text { cleanser, stroke, } \\
\text { diuretic, pain, } \\
\text { throat, muscular } \\
\text { relaxative, and } \\
\text { vitiligo }\end{array}$ & Decoction (I) & 5 & 6 & 8 & 1.13 \\
\hline 9.8. Macrosiphonia velame (A. St.-Hil.) Müll. Arg. & Velame-branco & flu & Decoction (I) & 73 & 1 & 1 & 0.17 \\
\hline \multicolumn{8}{|l|}{ 10. ARACEAE } \\
\hline 10.1 Dieffenbachia picta Schott & $\begin{array}{c}\text { Comigo- } \\
\text { ninguém-pode }\end{array}$ & pain & Maceration (E) & 2 & 1 & 1 & 0.17 \\
\hline 10.2. Dracontium sp. & Jararaquinha & snakebite & Infusion (I) & 10 & 1 & 1 & 0.17 \\
\hline \multicolumn{8}{|l|}{ 11. ARECACEAE } \\
\hline 11.1. Acrocomia aculeata Lodd. ex. Mart. & Bocaiuveira & $\begin{array}{l}\text { heart, hepatitis, } \\
\text { hypertension, and } \\
\text { kidneys }\end{array}$ & $\begin{array}{l}\text { Decoction and } \\
\text { syrup (I) }\end{array}$ & 20 & 4 & 4 & 0.67 \\
\hline 11.2. Cocos nucifera L. & Cocô-da-bahia & kidneys & Maceration (I) & 2 & 1 & 1 & 0.17 \\
\hline 11.3. Orbignya phalerata Mart. & Babaçu & inflammation & Decoction (I) & 8 & 1 & 1 & 0.17 \\
\hline 11.4. Syagrus oleracea (Mart.) Becc. & Guariroba & kidneys & Maceration (I) & 2 & 1 & 1 & 0.17 \\
\hline \multicolumn{8}{|l|}{ 12. ARISTOLOCHIACEAE } \\
\hline 12.1. Aristolochia cymbifera Mart \& Zucc. & $\begin{array}{l}\text { Cipó-de-mil- } \\
\text { homem }\end{array}$ & $\begin{array}{l}\text { dengue, blood } \\
\text { cleanser, stomach, } \\
\text { kidneys, and } \\
\text { digestive }\end{array}$ & Infusion (I) & 11 & 4 & 5 & 0.73 \\
\hline 12.2. Aristolochia esperanzae Kuntze & Papo-de-peru & wound healing & Infusion (I) & 3 & 1 & 1 & 0.17 \\
\hline \multicolumn{8}{|l|}{ 13. ASTERACEAE } \\
\hline 13.1. Acanthospermum australe (Loefl.). Kuntze & $\begin{array}{l}\text { Carrapicho, } \\
\text { beijo-de-boi }\end{array}$ & $\begin{array}{l}\text { colic, kidneys, and } \\
\text { runny cough }\end{array}$ & Infusion (I) & 31 & 2 & 3 & 0.40 \\
\hline 13.2. Acanthospermum hispidum DC. & $\begin{array}{l}\text { Chifre-de- } \\
\text { garrotinho }\end{array}$ & $\begin{array}{l}\text { Gonorrhea and } \\
\text { kidneys }\end{array}$ & Infusion (I) & 5 & 2 & 3 & 0.40 \\
\hline 13.3. Achillea millefolium $\mathrm{L}$. & $\begin{array}{l}\text { Dipirona, } \\
\text { Novalgina, }\end{array}$ & $\begin{array}{l}\text { pain, flu, and } \\
\text { muscular } \\
\text { relaxative }\end{array}$ & Infusion (I) & 13 & 3 & 4 & 0.57 \\
\hline 13.4. Achyrocline satureioides (Lam.) DC. & $\begin{array}{l}\text { Macela-do- } \\
\text { campo }\end{array}$ & $\begin{array}{c}\text { diarrhea, pain, } \\
\text { stomach, gastritis, } \\
\text { flu, and } \\
\text { hypertension }\end{array}$ & Infusion (I) & 13 & 5 & 6 & 0.90 \\
\hline 13.5. Ageratum conyzoides L. & Mentrasto & $\begin{array}{l}\text { pain, labor pain, } \\
\text { stomach, swelling } \\
\text { in pregnant } \\
\text { woman, } \\
\text { rheumatism, and } \\
\text { cough }\end{array}$ & Infusion (I) & 18 & 5 & 6 & 0.90 \\
\hline 13.6. Artemisia vulgaris L. & Artemisia & insomnia & Infusion (I) & 3 & 1 & 1 & 0.17 \\
\hline 13.7. Artemisia absinthium L. & $\begin{array}{c}\text { Losna, } \\
\text { nor-vômica }\end{array}$ & $\begin{array}{l}\text { pain, stomach, } \\
\text { liver, hernia, and } \\
\text { muscular } \\
\text { relaxative }\end{array}$ & Infusion (I) & 39 & 4 & 5 & 0.73 \\
\hline 13.8. Baccharis trimera (Less.) DC. & Carqueja & $\begin{array}{c}\text { cancer, } \\
\text { cholesterol, } \\
\text { diabetes, diuretic, } \\
\text { stomach, flu, and } \\
\text { obesity }\end{array}$ & Infusion (I) & 31 & 5 & 7 & 0.97 \\
\hline 13.9. Bidens pilosa L. & Picão-preto & $\begin{array}{l}\text { hepatitis, enteric, } \\
\text { and kidneys }\end{array}$ & Infusion (I, E) & 20 & 3 & 3 & 0.50 \\
\hline
\end{tabular}


TABle 3: Continued.

\begin{tabular}{|c|c|c|c|c|c|c|c|}
\hline Family/species & $\begin{array}{c}\text { Vernacular } \\
\text { name }\end{array}$ & Application & $\begin{array}{c}\text { Preparation } \\
\text { (administration) }\end{array}$ & $\begin{array}{c}\text { Uses } \\
\text { listed }\end{array}$ & NCS & NP & RI \\
\hline 13.10. Brickellia brasiliensis (Spreng.) B.L. Rob. & $\begin{array}{l}\text { Arnica-do- } \\
\text { campo }\end{array}$ & $\begin{array}{l}\text { wound healing, } \\
\text { uterine } \\
\text { inflammation, } \\
\text { and kidneys }\end{array}$ & Infusion (I) & 13 & 2 & 3 & 0.40 \\
\hline 13.11. Calendula officinalis $\mathrm{L}$. & Calêndula & anxiety & Infusion (I) & 6 & 1 & 1 & 0.17 \\
\hline 13.12. Centratherum aff. punctatum Cass. & Perpétua-roxa & $\begin{array}{c}\text { muscular } \\
\text { relaxative, and } \\
\text { hearth }\end{array}$ & Infusion (I) & 3 & 2 & 2 & 0.33 \\
\hline 13.13. Chamomilla recutita (L.) Rauschert. & Camomila & $\begin{array}{l}\text { soothing colic, } \\
\text { pain, stomach, } \\
\text { fever, and flu }\end{array}$ & Infusion (I) & 78 & 5 & 6 & 0.90 \\
\hline 13.14. Chaptalia integerrima (Vell.) Burkart & Lingua-de-vaca & worms & Infusion (I) & 6 & 1 & 1 & 0.17 \\
\hline 13.15. Chromolaena odorata (L.) R.M. King \& H. Rob & Cruzeirinho & $\begin{array}{l}\text { colic, pain, bone } \\
\text { fractures, pain, } \\
\text { bone fractures, } \\
\text { and kidneys }\end{array}$ & Infusion (I) & 7 & 3 & 4 & 0.57 \\
\hline 13.16. Conyza bonariensis (L.) Cronquist & Voadeira & $\begin{array}{c}\text { cancer itching, } \\
\text { blood cleanser, } \\
\text { leukemia, and } \\
\text { worms }\end{array}$ & Infusion (I) & 15 & 4 & 5 & 0.73 \\
\hline 13.17. Elephantopus mollis Kunth & Sussuaiá & $\begin{array}{l}\text { blood cleanser, } \\
\text { pain, and uterine } \\
\text { inflammation }\end{array}$ & Infusion (I) & 11 & 2 & 3 & 0.40 \\
\hline 13.18. Emilia fosbergii Nicolson & Serralha & conjunctivitis & Infusion (I) & 6 & 1 & 1 & 0.17 \\
\hline 13.19. Eremanthus exsuccus (DC.) Baker & $\begin{array}{l}\text { Bácimo-do- } \\
\text { campo }\end{array}$ & $\begin{array}{l}\text { wound healing, } \\
\text { stomach, bone } \\
\text { fractures, and skin }\end{array}$ & $\begin{array}{l}\text { Infusion and } \\
\text { maceration (I, } \\
\text { E) }\end{array}$ & 11 & 3 & 4 & 0.57 \\
\hline 13.20. Eupatorium odoratum L. & Arnicão & $\begin{array}{l}\text { wound healing, } \\
\text { muscular } \\
\text { relaxative, and } \\
\text { kidneys }\end{array}$ & Infusion (I, E) & 10 & 3 & 3 & 0.50 \\
\hline 13.21. Mikania glomerata Spreng. & Guaco & bronchitis cough & Infusion (I) & 14 & 2 & 2 & 0.33 \\
\hline 13.22. Mikania hirsutissima DC. & Cipó-cabeludo & diabetes & Infusion (I) & 10 & 1 & 1 & 0.17 \\
\hline 13.23. Pectis jangadensis S. Moore & $\begin{array}{l}\text { Erva-do- } \\
\text { carregador }\end{array}$ & $\begin{array}{l}\text { blood cleanser } \\
\text { and diabetes }\end{array}$ & Infusion (I) & 4 & 2 & 2 & 0.33 \\
\hline 13.24. Porophyllum ruderale (Jacq.) Cass. & Picão-branco & $\begin{array}{l}\text { Hepatitis and } \\
\text { kidneys }\end{array}$ & Infusion (I) & 11 & 2 & 2 & 0.33 \\
\hline 13.25. Solidago microglossa DC. & $\begin{array}{l}\text { Arnica- } \\
\text { brasileira }\end{array}$ & $\begin{array}{l}\text { wound healing, } \\
\text { blood cleanser, } \\
\text { pain, bone } \\
\text { fractures, } \\
\text { hypertension, } \\
\text { uterine } \\
\text { inflammation, } \\
\text { muscular } \\
\text { relaxative, } \\
\text { kidneys, worms, } \\
\text { pain, stomach, } \\
\text { hypertension, } \\
\text { pneumonia, } \\
\text { constipation, and } \\
\text { relaxative } \\
\text { muscular }\end{array}$ & Infusion (I, E) & 82 & 8 & 15 & 1.80 \\
\hline 13.26. Spilanthes acmella (L.) Murray & Jambú & liver & Infusion (I) & 5 & 1 & 1 & 0.17 \\
\hline 13.27. Tagetes minuta L. & $\begin{array}{l}\text { Cravo-de- } \\
\text { defunto }\end{array}$ & Dengue and flu & Infusion (I) & 3 & 2 & 2 & 0.33 \\
\hline
\end{tabular}


Table 3: Continued.

\begin{tabular}{|c|c|c|c|c|c|c|c|}
\hline Family/species & $\begin{array}{c}\text { Vernacular } \\
\text { name }\end{array}$ & Application & $\begin{array}{c}\text { Preparation } \\
\text { (administration) }\end{array}$ & $\begin{array}{c}\text { Uses } \\
\text { listed }\end{array}$ & NCS & NP & RI \\
\hline 13.28. Taraxacum officinale L. & Dente-de-leão & blood cleanser & Infusion (I) & 18 & 1 & 1 & 0.17 \\
\hline 13.29. Tithonia diversifolia (Hemsl.) A. Gray & $\begin{array}{l}\text { Flor-da- } \\
\text { amazônia }\end{array}$ & $\begin{array}{l}\text { alcoholism, } \\
\text { stomach, kidney, } \\
\text { and constipation }\end{array}$ & Infusion (I) & 16 & 3 & 3 & 0.50 \\
\hline 13.30.Vernonia condensata Baker & $\begin{array}{l}\text { Figatil- } \\
\text { caferana }\end{array}$ & $\begin{array}{l}\text { cancer stomach } \\
\text { and liver }\end{array}$ & Infusion (I) & 48 & 2 & 3 & 0.40 \\
\hline 13.31. Vernonia scabra Pers. & Assa-peixe & $\begin{array}{l}\text { bronchitis blood } \\
\text { cleanser, fever, flu, } \\
\text { pneumonia, cold, } \\
\text { and cough }\end{array}$ & $\begin{array}{l}\text { Infusion and } \\
\text { syrup (I) }\end{array}$ & 38 & 2 & 7 & 0.67 \\
\hline 13.32. Zinnia elegans Jacq. & Jacinta & pain & Infusion (I) & 1 & 1 & 1 & 0.17 \\
\hline \multicolumn{8}{|l|}{ 14. BERBERIDACEAE } \\
\hline 14.1. Berberis laurina Billb. & $\begin{array}{l}\text { Raiz-de-são- } \\
\text { joão }\end{array}$ & $\begin{array}{l}\text { blood cleanser } \\
\text { and diarrhea }\end{array}$ & $\begin{array}{l}\text { Decoction and } \\
\text { bottle (I, E) }\end{array}$ & 6 & 2 & 2 & 0.33 \\
\hline \multicolumn{8}{|l|}{ 15. BIGNONIACEAE } \\
\hline 15.1. Anemopaegma arvense (Vell.) Stellfeld \& J.F. Souza & $\begin{array}{l}\text { Verga-teso, } \\
\text { Alecrim-do- } \\
\text { campo, } \\
\text { Catuaba }\end{array}$ & $\begin{array}{l}\text { anxiety soothing } \\
\text { kidneys }\end{array}$ & $\begin{array}{l}\text { Decoction and } \\
\text { bottle (I, E) }\end{array}$ & 13 & 2 & 3 & 0.40 \\
\hline 15.2. Arrabidaea chica (Humb. \& Bonpl.) B. Verl. & Crajirú & $\begin{array}{l}\text { wound healing } \\
\text { and blood } \\
\text { cleanser }\end{array}$ & Infusion (I) & 6 & 2 & 2 & 0.33 \\
\hline 15.3. Cybistax antisyphilitica (Mart.) Mart. & Pé-de-anta & $\begin{array}{l}\text { fever, flu, } \\
\text { relaxative } \\
\text { muscular, and } \\
\text { worms }\end{array}$ & Infusion (I) & 13 & 4 & 4 & 0.67 \\
\hline 15.4. Jacaranda caroba (Vell.) A. DC. & Caroba & wound healing & $\begin{array}{l}\text { Decoction and } \\
\text { bottle (I, E) }\end{array}$ & 3 & 1 & 1 & 0.17 \\
\hline 15.5. Jacaranda decurrens Cham. & Carobinha & $\begin{array}{c}\text { allergy cancer } \\
\text { wound healing, } \\
\text { blood cleanser, } \\
\text { diabetes, leprosy, } \\
\text { hemorragia no } \\
\text { nariz, } \\
\text { inflammation } \\
\text { uterina, and } \\
\text { kidneys }\end{array}$ & $\begin{array}{l}\text { Decoction and } \\
\text { bottle (I, E) }\end{array}$ & 94 & 8 & 9 & 1.40 \\
\hline 15.6. Tabebuia aurea (Silva Manso) B. \& H. f. ex S. Moore & Ipê-amarelo & worms & $\begin{array}{l}\text { Decoction and } \\
\text { bottle (I) }\end{array}$ & 2 & 1 & 1 & 0.17 \\
\hline 15.7. Tabebuia caraiba (Mart.) Bureau & Para-tudo & $\begin{array}{l}\text { prostate cancer } \\
\text { anemia, bronchitis } \\
\text { cancer blood } \\
\text { cleanser, diarrhea, } \\
\text { pain, stomach, } \\
\text { cough, and worms }\end{array}$ & $\begin{array}{c}\text { Decoction and } \\
\text { bottle }(\mathrm{I}, \mathrm{E})\end{array}$ & 67 & 6 & 10 & 1.27 \\
\hline 15.8. Tabebuia impetiginosa (Mart. ex DC.) Standl. & Ipê-roxo & $\begin{array}{c}\text { prostate cancer } \\
\text { cough }\end{array}$ & $\begin{array}{l}\text { Decoction and } \\
\text { bottle (I) }\end{array}$ & 8 & 2 & 2 & 0.33 \\
\hline 15.9. Tabebuia serratifolia Nicholson & Piúva & prostate cancer & $\begin{array}{l}\text { Decoction and } \\
\text { bottle (I, E) }\end{array}$ & 3 & 1 & 1 & 0.17 \\
\hline 15.10. Zeyhera digitalis (Vell.) Hochn. & $\begin{array}{l}\text { Bolsa-de- } \\
\text { pastor }\end{array}$ & Stomach & $\begin{array}{l}\text { Decoction and } \\
\text { bottle (I) }\end{array}$ & 9 & 1 & 1 & 0.17 \\
\hline \multicolumn{8}{|l|}{ 16. BIXACEAE } \\
\hline 16.1. Bixa orellana $\mathrm{L}$. & Urucum & $\begin{array}{c}\text { cholesterol, } \\
\text { stroke, bone } \\
\text { fractures, and } \\
\text { measles }\end{array}$ & Infusion (I) & 11 & 4 & 4 & 0.67 \\
\hline
\end{tabular}


TABle 3: Continued.

\begin{tabular}{|c|c|c|c|c|c|c|c|}
\hline Family/species & $\begin{array}{c}\text { Vernacular } \\
\text { name }\end{array}$ & Application & $\begin{array}{c}\text { Preparation } \\
\text { (administration) }\end{array}$ & $\begin{array}{l}\text { Uses } \\
\text { listed }\end{array}$ & NCS & NP & RI \\
\hline 16.2. Cochlospermum regium (Schrank) Pilg. & $\begin{array}{l}\text { Algodãozinho- } \\
\text { do-campo }\end{array}$ & $\begin{array}{l}\text { blood cleanser, } \\
\text { stomach, bone } \\
\text { fractures, } \\
\text { inflammation } \\
\text { uterina, syphilis, } \\
\text { vitiligo, } \\
\text { gonorrhea, and } \\
\text { ringworm }\end{array}$ & Infusion (I) & 37 & 6 & 9 & 1.20 \\
\hline \multicolumn{8}{|l|}{ 17. BOMBACACEAE } \\
\hline 17.1. Pseudobombax longiflorum (Mart. Et Zucc.) Rob. & $\begin{array}{l}\text { Embiriçu-do- } \\
\text { cerrado }\end{array}$ & $\begin{array}{l}\text { pneumonia, } \\
\text { cough, and } \\
\text { tuberculosis }\end{array}$ & Infusion (I) & 17 & 3 & 3 & 0.50 \\
\hline 17.2. Eriotheca candolleana (K. Schum.) & Catuaba & prostate cancer & & 1 & 1 & 1 & 0.17 \\
\hline \multicolumn{8}{|l|}{ 18. BORAGINACEAE } \\
\hline 18.1. Cordia insignis Cham. & $\begin{array}{l}\text { Calção-de- } \\
\text { velho }\end{array}$ & cough & Infusion (I) & 5 & 1 & 1 & 0.17 \\
\hline 18.2. Heliotropium filiforme Lehm. & Sete-sangria & $\begin{array}{l}\text { thooth, blood } \\
\text { cleanser, } \\
\text { hypertension, and } \\
\text { tuberculosis }\end{array}$ & Infusion (I) & 43 & 4 & 4 & 0.67 \\
\hline 18.3. Symphytum asperrimum Donn ex Sims & Confrei & $\begin{array}{l}\text { wound healing, } \\
\text { heart, throat, and } \\
\text { obesity }\end{array}$ & Infusion (I, E) & 10 & 4 & 4 & 0.67 \\
\hline \multicolumn{8}{|l|}{ 19. BRASSICACEAE } \\
\hline 19.1. Nasturtium officinale R. Br. & Agrião & bronchitis & Infusion (I) & 2 & 1 & 1 & 0.17 \\
\hline \multicolumn{8}{|l|}{ 20. BROMELIACEAE } \\
\hline 20.1. Ananas comosus (L.) Merr. & Abacaxi & $\begin{array}{l}\text { diuretic and } \\
\text { cough }\end{array}$ & Infusion (I) & 9 & 2 & 2 & 0.33 \\
\hline 20.2. Bromelia balansae $\mathrm{Mez}$ & Gravatá & $\begin{array}{l}\text { cough and } \\
\text { bronhitis }\end{array}$ & Infusion (I) & 2 & 2 & 2 & 0.33 \\
\hline \multicolumn{8}{|l|}{ 21. BURSERACEAE } \\
\hline 21.1. Commiphora myrrha (T. Nees) Engl. & Mirra & $\begin{array}{l}\text { Menstruation and } \\
\text { rheumatism }\end{array}$ & Infusion (I) & 3 & 2 & 2 & 0.33 \\
\hline 21.2. Protium heptaphyllum (Aubl.) Marchand & Almésica & $\begin{array}{l}\text { blood cleanser, } \\
\text { stroke, pain, } \\
\text { muscular } \\
\text { relaxative, } \\
\text { rheumatism, and } \\
\text { cough }\end{array}$ & & 23 & 3 & 6 & 0.70 \\
\hline \multicolumn{8}{|l|}{ 22. CACTACEAE } \\
\hline 22.1. Cactus alatus Sw. & Cacto & $\begin{array}{c}\text { Colic and guard } \\
\text { delivery }\end{array}$ & Infusion (I, E) & 10 & 2 & 2 & 0.33 \\
\hline 22.2. Opuntia sp. & Palma & column & & 2 & 1 & 1 & 0.17 \\
\hline 22.3. Pereskia aculeata Mill. & Oro-pro-nobis & anemia & Infusion (I) & 2 & 1 & 1 & 0.17 \\
\hline \multicolumn{8}{|l|}{ 23. CAPPARACEAE } \\
\hline 23.1. Crataeva tapia L. & Cabaça & cough & Infusion (I) & 2 & 1 & 1 & 0.17 \\
\hline 23.2. Cleome affinis DC. & Mussambé & diarrhea & & 1 & 1 & 1 & 0.17 \\
\hline \multicolumn{8}{|l|}{ 24. CARICACEAE } \\
\hline 24.1. Carica papaya L. & Mamoeiro & $\begin{array}{l}\text { worms, thooth, } \\
\text { stomach, } \\
\text { hepatitis, } \\
\text { muscular } \\
\text { relaxative, and } \\
\text { cough }\end{array}$ & Infusion (I) & 17 & 4 & 6 & 0.80 \\
\hline
\end{tabular}


Table 3: Continued.

\begin{tabular}{lccc}
\hline Family/species & $\begin{array}{c}\text { Vernacular } \\
\text { name }\end{array}$ & Application $\begin{array}{c}\text { Preparation } \\
\text { (administration) }\end{array}$ listed NCS NP RI \\
\hline
\end{tabular}

25. CARYOCARACEAE

25.1. Caryocar brasiliense A. St.-Hil.

\section{CELASTRACEAE}

26.1. Maytenus ilicifolia Mart.ex Reissek

\section{CECROPIACEAE}

27.1. Cecropia pachystachya Trécul

\section{CLUSIACEAE}

28.1. Kielmeyera aff. grandiflora (Wawra) Saddi 29. COMBRETACEAE

29.1. Terminalia argentea Mart.

29.2. Terminalia catappa L. 30. COMMELINACEAE

30.1. Commelina benghalensis L.

30.2. Commelina nudiflora L.

30.3. Dichorisandra hexandra (Aubl.) Standl.

\section{CONVOLVULACEAE}

31.1. Cuscuta racemosa Mart.

31.2. Ipomoea batatas (L.) Lam.

31.3. Ipomoea (Desr.) Roem. \& asarifolia Schult

\section{COSTACEAE}

32.1. Costus spicatus (Jacq.) Sw.

\section{CRASSULACEAE}

33.1. Kalanchoe pinnata (Lam.) Pers.

\section{CUCURBITACEAE}

34.1. Cayaponia tayuya (Cell.) Cogn.

34.2. Citrullus vulgaris Schrad.

34.3. Cucumis anguria $\mathrm{L}$. diabetes,

Pequizeiro

hypertension,

labyrinthitis, and

obesity

uric acid,

bronchitis

Espinheira-

santa

diarrhea, stomach, gastritis, flu, and cough

cholesterol, blood cleanser, diabetes, pain,

Embaúba hypertension, leukemia, pneumonia, kidneys, and cough

Pau-santo

anemia

Pau-de-bicho

itching, diabetes, and cough

Sete-copa

conjunctivitis

Capoeraba

Erva-de-santaluzia

Cana-de-

macaco

hemorrhoids

wound healing and conjunctivitis

flu, hypertension, and kidneys

Cipó-dechumbo

Batata-doce

Batatinha-dobrejo

Caninha-dobrejo

Folha-dafortuna

allergy, bronchitis blood cleanser, and flu

Raiz-de-bugre

Melância

blood cleanser pain, and hepatitis

Máxixe $\begin{array}{lllll}\text { Infusion (I) } & 38 & 6 & 9 & 1.20\end{array}$

$\begin{array}{llll}11 & 4 & 4 & 0.67\end{array}$

$\begin{array}{lllll}\text { Infusion (I) } & 8 & 5 & 7 & 0.97\end{array}$

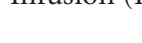

$\begin{array}{cccccc}\text { pain } & \text { Infusion (I) } & 1 & 1 & 1 & 0.17 \\ \begin{array}{c}\text { hearth } \\ \begin{array}{c}\text { Stomach and } \\ \text { worms }\end{array}\end{array} & \text { Infusion (I) } & 1 & 1 & 1 & 0.17 \\ \text { Infusion (I) } & 4 & 2 & 2 & 0.33\end{array}$

bladder diuretic, inflammation uterina, muscular relaxative, and

Infusion (I) $\quad 40 \quad 3 \quad 5 \quad 0.63$ kidneys

$\begin{array}{lllll}\begin{array}{l}\text { Infusion and } \\ \text { juice (I) }\end{array} & 11 & 2 & 4 & 0.47\end{array}$ bladder colic

\begin{tabular}{lllll} 
Infusion (I) & 17 & 2 & 3 & 0.40 \\
Infusion (I) & 2 & 1 & 2 & 0.23 \\
Infusion (I) & 1 & 1 & 1 & 0.17 \\
\hline
\end{tabular}


TABle 3: Continued.

\begin{tabular}{|c|c|c|c|c|c|c|c|}
\hline Family/species & $\begin{array}{c}\text { Vernacular } \\
\text { name }\end{array}$ & Application & $\begin{array}{c}\text { Preparation } \\
\text { (administration) }\end{array}$ & $\begin{array}{c}\text { Uses } \\
\text { listed }\end{array}$ & NCS & NP & RI \\
\hline 34.4. Cucumis sativus $\mathrm{L}$. & Pepino & hypertension & Maceration (I) & 1 & & & \\
\hline 34.5. Cucurbita maxima Duchesne ex Lam. & Abóbora & Pain and worms & Infusion (I) & 4 & 2 & 2 & 0.33 \\
\hline 34.6. Luffa sp & Bucha & $\begin{array}{l}\text { Anemia and } \\
\text { kidneys }\end{array}$ & Infusion (I) & 7 & 2 & 2 & 0.33 \\
\hline 34.7. Momordica charantia L. & $\begin{array}{l}\text { Melão-de-são- } \\
\text { caetano }\end{array}$ & $\begin{array}{l}\text { bronchitis dengue, } \\
\text { stomach, fever, } \\
\text { flu, hepatitis, } \\
\text { swelling in } \\
\text { pregnant woman, } \\
\text { malaria, muscular } \\
\text { relaxative, and } \\
\text { worms }\end{array}$ & Infusion (I) & 50 & 6 & 10 & 1.27 \\
\hline 34.8. Siolmatra brasiliensis (Cogn.) Baill. & Taiuá & Ulcer & Infusion (I) & 6 & 1 & 1 & 0.17 \\
\hline \multicolumn{8}{|l|}{ 35. CYPERACEAE } \\
\hline 35.1. Bulbostylis capillaris (L.) C.B. Clarke & Barba-de-bode & $\begin{array}{l}\text { diuretic, stomach, } \\
\text { kidneys, and } \\
\text { worms }\end{array}$ & Infusion (I) & 12 & 3 & 4 & 0.57 \\
\hline 35.2. Cyperus rotundus $\mathrm{L}$. & Tiririca & Pain & Infusion (I) & 1 & 1 & 1 & 0.17 \\
\hline \multicolumn{8}{|l|}{ 36. DILLENIACEAE } \\
\hline 36.1. Curatella americana L. & Lixeira & $\begin{array}{c}\text { wound healing, } \\
\text { colic, diarrhea, } \\
\text { flu, kidneys, and } \\
\text { cough }\end{array}$ & Infusion (I, E) & 24 & 5 & 6 & 0.90 \\
\hline 36.2. Davilla elliptica A. St.-Hil. & Lixeira-de-cipó & kidneys & & 3 & 1 & 1 & 0.17 \\
\hline 36.3. Davilla nitida (Vahl.) Kubitzki & Lixeirinha & $\begin{array}{l}\text { delivery help, } \\
\text { liver, hernia, and } \\
\text { kidneys }\end{array}$ & Infusion (I) & 10 & 3 & 4 & 0.57 \\
\hline \multicolumn{8}{|l|}{ 37. DIOSCOREACEAE } \\
\hline 37.1. Dioscorea sp. & $\begin{array}{l}\text { Cará-do- } \\
\text { cerrado }\end{array}$ & boil & Infusion (I) & 25 & 1 & 1 & 0.17 \\
\hline 37.2. Dioscorea trifida L & Cará & blood cleanser & Infusion (I) & 6 & 1 & 1 & 0.17 \\
\hline \multicolumn{8}{|l|}{ 38. EBENACEAE } \\
\hline 38.1. Diospyros hispida A. DC. & Olho-de-boi & Pain and leprosy & Infusion (I) & 5 & 2 & 2 & 0.33 \\
\hline \multicolumn{8}{|l|}{ 39. EQUISETACAE } \\
\hline 39.1. Equisetum arvense L. & Cavalinha & $\begin{array}{l}\text { gastritis and } \\
\text { kidneys }\end{array}$ & Infusion (I) & 8 & 2 & 2 & 0.33 \\
\hline \multicolumn{8}{|l|}{ 40. ERYTHROXYLACEAE } \\
\hline 40.1 Erythroxylum aff. Daphnites Mart. & $\begin{array}{l}\text { Vasoura-de- } \\
\text { bruxa }\end{array}$ & syphilis & Infusion (I) & 1 & 1 & 1 & 0.17 \\
\hline \multicolumn{8}{|l|}{ 41. EUPHORBIACEAE } \\
\hline 41.1. Croton antisyphiliticus Mart. & Curraleira & $\begin{array}{c}\text { Hypertension and } \\
\text { uterine } \\
\text { inflammation }\end{array}$ & Infusion (I) & 6 & 2 & 2 & 0.33 \\
\hline 41.2. Croton sp. & $\begin{array}{l}\text { Curraleira- } \\
\text { branca }\end{array}$ & $\begin{array}{c}\text { uterine } \\
\text { inflammation }\end{array}$ & Infusion (I) & 3 & 1 & 1 & 0.17 \\
\hline 41.3. Croton urucurana Baill. & Sangra-d’água & $\begin{array}{l}\text { cancer prostate } \\
\text { cancer healing, } \\
\text { diabetes, stomach, } \\
\text { gastritis, uterine } \\
\text { inflammation, } \\
\text { kidneys, and ulcer }\end{array}$ & Maceration (I) & 37 & 5 & 9 & 1.10 \\
\hline 41.4. Euphorbia aff. Thymifolia L. & Trinca-pedra & kidneys & Infusion (I) & 3 & 1 & 1 & 0.17 \\
\hline 41.5. Euphorbia prostrata Aiton & Fura-pedra & kidneys & Infusion (I) & 4 & 1 & 1 & 0.17 \\
\hline
\end{tabular}


Table 3: Continued.

\begin{tabular}{|c|c|c|c|c|c|c|c|}
\hline Family/species & $\begin{array}{c}\text { Vernacular } \\
\text { name }\end{array}$ & Application & $\begin{array}{c}\text { Preparation } \\
\text { (administration) }\end{array}$ & $\begin{array}{c}\text { Uses } \\
\text { listed }\end{array}$ & $\mathrm{NCS}$ & NP & RI \\
\hline 41.6. Euphorbia tirucalli L & Aveloz & $\begin{array}{l}\text { cancer uterine } \\
\text { inflammation }\end{array}$ & Maceration (I) & 3 & 2 & 2 & 0.33 \\
\hline 41.7. Jatropha sp. & Capa-rosa & diabetes & Infusion (I) & 10 & 1 & 1 & 0.17 \\
\hline 41.8. Jatropha elliptica (Poh) Oken & $\begin{array}{l}\text { Purga-de- } \\
\text { lagarto }\end{array}$ & allergy & Infusion (I) & 38 & 1 & 1 & 0.17 \\
\hline 41.9. Jatropha aff. Gossypiifolia L. & Pinhão-roxo & $\begin{array}{l}\text { wound healing, } \\
\text { prostrate cancer, } \\
\text { itching, blood } \\
\text { cleanser, stroke, } \\
\text { snakebite, } \\
\text { syphilis, worms, } \\
\text { and vitiligo }\end{array}$ & Maceration(I, E) & 7 & 6 & 10 & 1.27 \\
\hline 41.10. Jatropha urens L. & Cansansão & diabetes & $\begin{array}{l}\text { Maceration (I, } \\
\text { E) }\end{array}$ & 6 & 1 & 1 & 0.17 \\
\hline 41.11. Manihot esculenta Crantz & $\begin{array}{l}\text { Mandioca- } \\
\text { braba }\end{array}$ & itching & $\begin{array}{l}\text { Maceration (I, } \\
\text { E) }\end{array}$ & 2 & 1 & 1 & 0.17 \\
\hline 41.12. Manihot utilissima Pohl. & Mandioca & itching & $\begin{array}{l}\text { Maceration (I, } \\
\text { E) }\end{array}$ & 7 & 1 & 1 & 0.17 \\
\hline 41.13. Ricinus communis L. & Mamona & $\begin{array}{l}\text { wound healing } \\
\text { and blood } \\
\text { cleanser }\end{array}$ & $\begin{array}{l}\text { Maceration (I, } \\
\text { E) }\end{array}$ & 8 & 2 & 2 & 0.33 \\
\hline 41.14. Synadenium grantii Hook. f. & Cancerosa & $\begin{array}{l}\text { gastritis, prostate } \\
\text { cancer stomach, } \\
\text { and pneumonia }\end{array}$ & $\begin{array}{l}\text { Maceration (I, } \\
\text { E) }\end{array}$ & 12 & 3 & 4 & 0.57 \\
\hline \multicolumn{8}{|l|}{ 42. FABACEAE } \\
\hline 42.1. Acosmium dasycarpum (Volgel) Yakovlev & Cinco-folha & $\begin{array}{l}\text { column, blood } \\
\text { cleanser, pain, and } \\
\text { kidneys }\end{array}$ & Infusion (I) & 19 & 2 & 4 & 0.47 \\
\hline 42.2. Acosmium subelegans (Mohlenbr.) Yakovlev & $\begin{array}{l}\text { Quina- } \\
\text { gensiana }\end{array}$ & $\begin{array}{l}\text { wound healing, } \\
\text { blood cleanser, } \\
\text { pain, liver, uterine } \\
\text { inflammation, } \\
\text { delivery relapse, } \\
\text { and kidneys }\end{array}$ & Decoction (I) & 16 & 5 & 7 & 0.97 \\
\hline 42.3. Albizia niopoides (Spr. ex Benth.) Burkart. & Angico-branco & bronhitis & Decoction (I) & 1 & 1 & 1 & 0.17 \\
\hline 42.4. Amburana cearensis (Allemão) A. C. Sm. & Imburana & cough & Decoction (I) & 13 & 1 & 1 & 0.17 \\
\hline 42.5. Anadenanthera colubrina (Vell.) Brenan & Angico & $\begin{array}{l}\text { asthma, wound } \\
\text { healing, } \\
\text { expectorant, } \\
\text { uterine } \\
\text { inflammation, } \\
\text { pneumonia, and } \\
\text { cough }\end{array}$ & Decoction (I) & 12 & 5 & 6 & 0.90 \\
\hline 42.6. Andira anthelminthica Benth. & Angelim & diabetes & Decoction (I) & 3 & 1 & 1 & 0.17 \\
\hline 42.7. Bauhinia variegata $\mathrm{L}$. & Unha-de-boi & kidneys & Decoction (I) & 4 & 1 & 1 & 0.17 \\
\hline 42.8. Bauhinia ungulata L. & Pata-de-vaca & diabetes & Infusion (I) & 11 & 1 & 1 & 0.17 \\
\hline 42.9. Bauhinia glabra Jacq. & $\begin{array}{l}\text { Cipó-tripa-de- } \\
\text { galinha }\end{array}$ & $\begin{array}{c}\text { diarrhea, } \\
\text { dysentery, and } \\
\text { pain }\end{array}$ & Infusion (I) & 7 & 3 & 3 & 0.50 \\
\hline 42.10. Bauhinia rubiginosa Bong. & $\begin{array}{l}\text { Tripa-de- } \\
\text { galinha }\end{array}$ & kidneys & Infusion (I) & 2 & 1 & 1 & 0.17 \\
\hline 42.11. Bauhinia rufa (Bong.) Steud. & Pata-de-boi & diabetes & Infusion (I) & 1 & 1 & 1 & 0.17 \\
\hline
\end{tabular}


TABle 3: Continued.

\begin{tabular}{|c|c|c|c|c|c|c|c|}
\hline Family/species & $\begin{array}{l}\text { Vernacular } \\
\text { name }\end{array}$ & Application & $\begin{array}{c}\text { Preparation } \\
\text { (administration) }\end{array}$ & $\begin{array}{l}\text { Uses } \\
\text { listed }\end{array}$ & NCS & NP & RI \\
\hline 42.12. Bowdichia virgilioides Kunth & Sucupira & $\begin{array}{l}\text { blood cleanser, } \\
\text { paom, stomach, } \\
\text { nose bleeding, } \\
\text { cough, and worms }\end{array}$ & Bottle (I) & 20 & 4 & 6 & 0.80 \\
\hline 42.13. Caesalpinia ferrea Mart. & Jucá & $\begin{array}{l}\text { wound healing, } \\
\text { stomach, bone } \\
\text { fractures, and } \\
\text { inflammation of } \\
\text { uterine }\end{array}$ & $\begin{array}{l}\text { Maceration (I, } \\
\text { E) }\end{array}$ & 15 & 3 & 4 & 0.57 \\
\hline 42.14. Cajanus bicolor DC. & Feijão-andu & $\begin{array}{l}\text { diarrhea, stomach } \\
\text { and worms }\end{array}$ & Infusion (I) & 8 & 2 & 3 & 0.40 \\
\hline 42.15. Cassia desvauxii Collad. & Sene & $\begin{array}{c}\text { constipation, } \\
\text { pain, fever, uterine } \\
\text { inflammation, } \\
\text { and labyrinthitis }\end{array}$ & Infusion (I) & 18 & 4 & 5 & 0.73 \\
\hline 42.16. Chamaecrista desvauxii (Collad.) Killip & $\begin{array}{l}\text { Sene-do- } \\
\text { campo }\end{array}$ & $\begin{array}{l}\text { constipation, } \\
\text { blood cleanser, } \\
\text { pain, and fever }\end{array}$ & Infusion (I) & 10 & 2 & 4 & 0.47 \\
\hline 42.17. Copaifera sp. & Pau-d'óleo & $\begin{array}{l}\text { wound healing, } \\
\text { kidneys, ulcer }\end{array}$ & Infusion (I) & 8 & 3 & 3 & 0.50 \\
\hline 42.18. Copaifera langsdorffii var. glabra (Vogel) Benth. & Copaiba & $\begin{array}{l}\text { bronchitis } \\
\text { prostate cancer } \\
\text { stroke, pain, } \\
\text { throat, and } \\
\text { tuberculosis }\end{array}$ & $\begin{array}{l}\text { Maceration and } \\
\text { syrup (I) }\end{array}$ & 13 & 5 & 6 & 0.90 \\
\hline 42.19. Copaifera marginata Benth. & Guaranazinho & ulcer & Infusion (I) & 4 & 1 & 1 & 0.17 \\
\hline 42.20. Desmodium incanum DC. & Carrapicho & $\begin{array}{l}\text { bladder itching, } \\
\text { diarrhea, pain, } \\
\text { hepatitis, and } \\
\text { kidneys }\end{array}$ & Infusion (I) & 18 & 5 & 6 & 0.90 \\
\hline 42.21. Dimorphandra mollis Benth. & $\begin{array}{l}\text { Fava-de-santo- } \\
\text { inácio }\end{array}$ & $\begin{array}{l}\text { bronchitis wound } \\
\text { healing, pain, flu, } \\
\text { hypertension, } \\
\text { pneumonia, } \\
\text { rheumatism, } \\
\text { cough, and worms }\end{array}$ & Infusion (I) & 21 & 6 & 9 & 1.20 \\
\hline 42.22. Dioclea latifolia Benth. & $\begin{array}{l}\text { Fruta-olho-de- } \\
\text { boi }\end{array}$ & stroke & Infusion (I) & 3 & 1 & 1 & 0.17 \\
\hline 42.23. Dioclea violacea Mart. Zucc. & $\begin{array}{l}\text { Coronha-de- } \\
\text { boi }\end{array}$ & osteoporosis & Infusion (I) & 6 & 2 & 2 & 0.33 \\
\hline 42.24. Dipteryx alata Vogel & Cumbarú & $\begin{array}{c}\text { stroke } \\
\text { bronchitis } \\
\text { cicartrizante, } \\
\text { diarrhea, } \\
\text { dysentery, pain, } \\
\text { throat, flu, } \\
\text { snakebite, and } \\
\text { cough }\end{array}$ & Infusion (I) & 43 & 4 & 9 & 1.00 \\
\hline 42.25. Galactia glaucescens Kunth & Três-folhas & $\begin{array}{l}\text { column, pain, } \\
\text { bone fractures, } \\
\text { and kidneys }\end{array}$ & Infusion (I) & 8 & 4 & 4 & 0.67 \\
\hline 42.26. Hymenaea courbaril L. & Jatobá-mirim & $\begin{array}{l}\text { bladder bronchitis } \\
\text { flu, pneumonia, } \\
\text { and cough }\end{array}$ & $\begin{array}{c}\text { Syrup and } \\
\text { decoction (I) }\end{array}$ & 36 & 3 & 5 & 0.63 \\
\hline
\end{tabular}


Table 3: Continued.

\begin{tabular}{|c|c|c|c|c|c|c|c|}
\hline Family/species & $\begin{array}{c}\text { Vernacular } \\
\text { name }\end{array}$ & Application & $\begin{array}{c}\text { Preparation } \\
\text { (administration) }\end{array}$ & $\begin{array}{c}\text { Uses } \\
\text { listed }\end{array}$ & NCS & NP & RI \\
\hline 42.27. Hymenaea stigonocarpa Mart. ex Hayne & $\begin{array}{l}\text { Jatoba-do- } \\
\text { cerrado }\end{array}$ & $\begin{array}{c}\text { bronchitis } \\
\text { prostate cancer } \\
\text { pain, fertilizer, flu, } \\
\text { and cough }\end{array}$ & $\begin{array}{c}\text { Syrup and } \\
\text { decoction (I) }\end{array}$ & 31 & 5 & 6 & 0.90 \\
\hline 42.28. Indigofera suffruticosa Mill. & Anil & ulcer & Infusion (I) & 2 & 1 & 1 & 0.17 \\
\hline 42.29. Inga vera Willd. & Ingá & $\begin{array}{l}\text { Laxative and } \\
\text { kidneys }\end{array}$ & Infusion (I) & 5 & 2 & 2 & 0.33 \\
\hline 42.30. Machaerium hirtum (Vell.) Stellfeld & $\begin{array}{l}\text { Espinheira- } \\
\text { santa-nativa }\end{array}$ & ulcer & Infusion (I) & 2 & 1 & 1 & 0.17 \\
\hline 42.31. Melilotus officinalis (L) Pall. & Trevo-cheiroso & $\begin{array}{l}\text { bone fractures } \\
\text { and thyroid }\end{array}$ & Infusion (I) & 5 & 2 & 2 & 0.33 \\
\hline 42.32. Mimosa debilis var. vestita (Benth.) Barneby & Dorme-dorme & soothing & Infusion (I) & 2 & 1 & 1 & 0.17 \\
\hline 42.33. Mucuna pruriens (L.) DC. & Macuna & stroke & Infusion (I) & 2 & 1 & 1 & 0.17 \\
\hline 42.34. Peltophorum dubium (Spreng.) Taub. & Cana-fistula & gastritis & Infusion (I) & 5 & 1 & 1 & 0.17 \\
\hline 42.35. Platycyamus regnellii Benth. & Pau-porrete & anemia & Infusion (I) & 1 & 1 & 1 & 0.17 \\
\hline 42.36. Pterodon pubescens (Benth.) Benth. & $\begin{array}{l}\text { Sucupira- } \\
\text { branca }\end{array}$ & $\begin{array}{l}\text { worms, pain, and } \\
\text { stomach }\end{array}$ & $\begin{array}{c}\text { SYRope, } \\
\text { decoction and } \\
\text { maceration }(\mathrm{I})\end{array}$ & 2 & 3 & 3 & 0.50 \\
\hline 42.37. Senna alata (L.) Roxb. & Mata-pasto & $\begin{array}{l}\text { throat, worms, } \\
\text { and vitiligo }\end{array}$ & Infusion (I) & 6 & 3 & 3 & 0.50 \\
\hline 42.38. Senna occidentalis (L.) Link & Fedegoso & $\begin{array}{l}\text { blood cleanser, } \\
\text { pain, flu, cough, } \\
\text { and worms }\end{array}$ & Infusion (I) & 42 & 3 & 5 & 0.63 \\
\hline 42.39. Stryphnodendron obovatum Benth. & Barbatimão 1 & wound healing & $\begin{array}{c}\text { Syrup and } \\
\text { decoction (I, E) }\end{array}$ & 57 & 1 & 1 & 0.17 \\
\hline 42.40. Stryphnodendron adstringens (Mart.) Coville & Barbatimão 2 & $\begin{array}{c}\text { bladder } \\
\text { bronchitis, colic, } \\
\text { stomach, bone } \\
\text { fractures, uterine } \\
\text { inflammation, } \\
\text { relaxative } \\
\text { muscular, and } \\
\text { ulcer }\end{array}$ & $\begin{array}{c}\text { Syrup and } \\
\text { decoction }(\mathrm{I}, \mathrm{E})\end{array}$ & 15 & 4 & 9 & 1.00 \\
\hline 42.41. Tamarindus indica $\mathrm{L}$. & Tamarindo & $\begin{array}{l}\text { anxiety pain, } \\
\text { thooth, laxative, } \\
\text { osteoporosis, } \\
\text { syphilis, and } \\
\text { worms }\end{array}$ & $\begin{array}{c}\text { Maceration and } \\
\text { juice (I) }\end{array}$ & 30 & 6 & 7 & 1.07 \\
\hline \multicolumn{8}{|l|}{ 43. FLACOURTIACEAE } \\
\hline 43.1. Casearia silvestris Sw. & Guaçatonga & $\begin{array}{l}\text { Epilepsy and } \\
\text { kidneys }\end{array}$ & Infusion (I) & 3 & 2 & 2 & 0.33 \\
\hline \multicolumn{8}{|l|}{ 44. GINKGOACEAE } \\
\hline 44.1. Ginkgo biloba L. & Ginco-biloba & vertebral & Infusion (I) & 1 & 1 & 1 & 0.17 \\
\hline \multicolumn{8}{|l|}{ 45. HERRERIACEAE } \\
\hline 45.1. Herreria salsaparilha Mart. & Salsaparilha & $\begin{array}{l}\text { column, blood } \\
\text { cleanser, muscular } \\
\text { relaxative, and } \\
\text { kidneys }\end{array}$ & Infusion (I) & 12 & 3 & 4 & 0.57 \\
\hline \multicolumn{8}{|l|}{ 46. HIPPOCRATEACEAE } \\
\hline 46.1. Salacia aff. elliptica (Mart. ex Schult.) G. Don & $\begin{array}{l}\text { Saputa-do- } \\
\text { brejo }\end{array}$ & pain & Infusion (I) & 6 & 1 & 1 & 0.17 \\
\hline
\end{tabular}


TABle 3: Continued.

\begin{tabular}{|c|c|c|c|}
\hline Family/species & $\begin{array}{l}\text { Vernacular } \\
\text { name }\end{array}$ & Application & $\begin{array}{c}\text { Preparation Uses } \\
\text { (administration) listed NCS NP RI }\end{array}$ \\
\hline
\end{tabular}

47. IRIDACEAE

47.1. Eleutherine bulbosa (Mill.) Urb.

\section{LAMIACEAE}

48.1. Hyptis cf. hirsuta Kunth

48.2. Hyptis paludosa St.-Hil.ex Benht.

48.3. Hyptis sp.

48.4. Hyptis suaveolens (L.) Poit.

48.5. Leonotis nepetifolia (L.) R. Br.

48.6. Marsypianthes chamaedrys (Vahl) Kuntze

48.7. Melissa officinalis L

48.8. Mentha crispa L.

48.9. Mentha pulegium L.

48.10. Mentha spicata L.

48.11. Mentha x piperita L.

48.12. Mentha $x$ villosa Huds.

48.13. Ocimum kilimandscharicum Baker ex Gürke

48.14. Ocimum minimum L.

48.15. Origanum majorana L.

48.16. Origanum vulgare L.

48.17. Plectranthus amboinicus (Lour.) Spreng.

48.18. Plectranthus barbatus Andrews

48.19. Plectranthus neochilus Schltr.

pain,

Palmeirinha

hemorrhoids, cough, and blood cleanser

Hortelã-do-
campo
Alevante

Hortelã-bravo

Tapera-velha

Cordão-desão-francisco

Hortelãpimenta

Hortelã-

rasteira

Alfavacaquinha

Manjericão

Manjerona

Orégano

Hortelã-dafolha-gorda

Boldobrasileiro

Boldinho diabetes, stomach, flu, cough, and worms

cold

Diabetes and cough

pain, stomach, flu, constipation, kidneys, and worms

column, hearth, blood cleanser, stomach, fever, gastritis, flu, hypertension, labyrinthitis, muscular

relaxative, and kidneys

flu, hypertension, and cough soothing

anemia, liver, cough, and worms

bronchitis soothing fever, flu, cold, and cough bronchitis flu, wound healing, stomach, and worms

bronchitis flu, cough and worms

stomach, flu, cold, and worms

flu

kidneys, sinusitis, and worms

heart cough bronchitis flu, uterine inflammation, and cough

pain, stomach, liver, and malaise
Infusion (I) $\quad 11 \quad 2 \quad 4 \quad 0.47$

Infusion (I) $\quad 23 \quad 5 \quad 5 \quad 0.83$

$\begin{array}{lllll}\text { Infusion (I) } & 4 & 1 & 1 & 0.17\end{array}$

$\begin{array}{lllll}\text { Infusion (I) } & 6 & 2 & 2 & 0.33\end{array}$

$\begin{array}{lllll}\text { Infusion (I) } \quad 42 & 5 & 6 & 0.90\end{array}$

$\begin{array}{lllll}\text { Infusion (I) } & 38 & 7 & 11 & 1.43\end{array}$

Infusion (I) $\quad 8 \quad 3 \quad 3 \quad 0.50$

$\begin{array}{lllll}\text { Infusion (I) } & 2 & 1 & 1 & 0.17\end{array}$

$\begin{array}{lllll}\text { Infusion (I) } & 16 & 4 & 4 & 0.67\end{array}$

$\begin{array}{lllll}\text { Infusion (I) } & 59 & 3 & 6 & 0.70\end{array}$

$\begin{array}{lllll}\text { Infusion (I) } & 24 & 4 & 5 & 0.73\end{array}$

Infusion (I) $\quad 42 \quad 3 \quad 4 \quad 0.57$

$\begin{array}{lllll}\text { Infusion (I) } & 86 & 3 & 4 & 0.57\end{array}$

$\begin{array}{lllll}\text { Infusion (I) } & 2 & 1 & 1 & 0.17\end{array}$

$\begin{array}{lllll}\text { Infusion (I) } & 7 & 3 & 3 & 0.50\end{array}$

$\begin{array}{lllll}\text { Infusion (I) } & 4 & 1 & 1 & 0.17\end{array}$

$\begin{array}{lllll}\text { Infusion (I) } & 1 & 1 & 1 & 0.17\end{array}$

$\begin{array}{lllll}\underset{\text { Infusion and }}{\text { syrup (I) }} & 7 & 3 & 4 & 0.57\end{array}$

Maceration (I) $\quad 99 \quad 2 \quad 4 \quad 0.47$

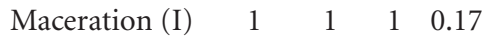


TABle 3: Continued.

Family/species

48.20. Rosmarinus officinalis $\mathrm{L}$.

\section{LAURACEAE}

49.1. Cinnamomum camphora (L.) Nees \& Eberm.

49.2. Cinnamomum zeylanicum Breyne

49.3. Persea americana Mill.

\section{LECYTHIDACEAE}

50.1. Cariniana rubra Gardner ex Miers

51. LOGANIACEAE

51.1. Strychnos pseudoquina A. St.-Hil.

\section{LORANTHACEAE}

52.1. Psittacanthus calyculatus (D.C.) G. Don

\section{LYTHRACEAE}

53.1. Adenaria floribunda Kunth

53.2. Lafoensia pacari A. St.-Hil.

\section{MALPIGHIACEAE}

54.1. Byrsonima orbignyana A. Juss.

54.2. Byrsonima sp.

54.3. Byrsonima verbascifolia (L.) DC.
Vernacular name

Alecrim

Cânfora

Canela-daindia

Abacateiro obesity, and cough
diuretic, hypertension, and kidneys

bladder wound healing, colic, pain, uterine inflammation, rheumatism, cough, and ulcer

anemia, wound healing, cholesterol, blood cleanser, pain, stomach, bone fractures, flu, uterine pneumonia, muscle relaxant, cough, ulcer, and worms

Erva-depassarinho stroke, pain, flu, and pneumonia

Veludovermelho

Mangavabraba

Angiquinho

Semaneira

Murici-docerrado

kidneys

wound healing, diarrhea, pain, stomach, gastritis, kidneys, and ulcer $\begin{array}{cc}\text { Preparation } & \text { Uses } \\ \text { administration) } & \text { listed }\end{array}$ NCS NP RI

Infusion and maceration (I) $\quad \begin{array}{lllll}31 & 6 & 10 & 1.27\end{array}$

$\begin{array}{lll}6 & 10 & 1.27\end{array}$ inflammation,

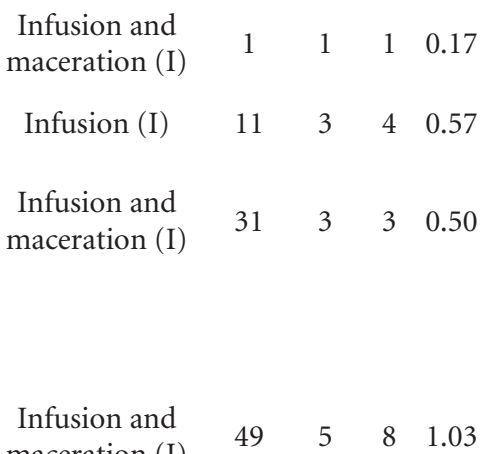

Decoction and maceration (I, $\quad 107 \quad 8 \quad 14 \quad 1.73$ E)

Infusion and maceration (I)

$\begin{array}{llll}14 & 3 & 4 & 0.57\end{array}$

$\begin{array}{llll}3 & 1 & 1 & 0.17\end{array}$

Decoction and maceration (I, $\quad \begin{array}{lllll}73 & 5 & 7 & 0.97\end{array}$ E)

$\begin{array}{lllll}\begin{array}{l}\text { Decoction and } \\ \text { maceration (I) }\end{array} & 2 & 1 & 1 & 0.17\end{array}$ $\begin{array}{lllll}\text { Infusion (I) } & 1 & 1 & 1 & 0.17\end{array}$ $\begin{array}{lllll}\text { Infusion (I) } & 3 & 2 & 2 & 0.33\end{array}$ 
Table 3: Continued.

\begin{tabular}{|c|c|c|c|c|c|c|c|}
\hline Family/species & $\begin{array}{c}\text { Vernacular } \\
\text { name }\end{array}$ & Application & $\begin{array}{c}\text { Preparation } \\
\text { (administration) }\end{array}$ & $\begin{array}{c}\text { Uses } \\
\text { listed }\end{array}$ & NCS & NP & RI \\
\hline & & $\begin{array}{c}\text { uterine } \\
\text { inflammation }\end{array}$ & & & & & \\
\hline 54.4. Camarea ericoides A. St.-Hil. & Arniquinha & wound healing & Infusion (I) & 11 & 1 & 1 & 0.17 \\
\hline 54.5. Galphimia brasiliensis (L.) A. Juss. & $\begin{array}{l}\text { Mercúrio-do- } \\
\text { campo }\end{array}$ & $\begin{array}{l}\text { wound healing, } \\
\text { itching, thooth, } \\
\text { and bone fractures }\end{array}$ & Infusion (I) & 7 & 3 & 4 & 0.57 \\
\hline 54.6. Heteropterys aphrodisiaca O. Mach. & $\begin{array}{l}\text { Nó-de- } \\
\text { cachorro }\end{array}$ & $\begin{array}{l}\text { brain, wound } \\
\text { healing, blood } \\
\text { cleanser, } \\
\text { impotence, } \\
\text { muscular } \\
\text { relaxative, and } \\
\text { rheumatism }\end{array}$ & Decoction (I) & 23 & 5 & 6 & 0.90 \\
\hline 54.7. Malpighia emarginata DC. & Cereja & wound healing & Infusion (I) & 5 & 1 & 1 & 0.17 \\
\hline 54.8. Malpighia glabra L. & Aceroleira & $\begin{array}{l}\text { bronchitis dengue, } \\
\text { stomach, fever, } \\
\text { and flu }\end{array}$ & Infusion (I) & 24 & 4 & 5 & 0.73 \\
\hline \multicolumn{8}{|l|}{ 55. MALVACEAE } \\
\hline 55.1. Brosimum gaudichaudii Trécul & Mama-cadela & stomach & Infusion (I) & 13 & 1 & 1 & 0.17 \\
\hline 55.2. Gossypium barbadense L. & $\begin{array}{l}\text { Algodão-de- } \\
\text { quintal }\end{array}$ & $\begin{array}{l}\text { blood cleanser, } \\
\text { stomach, vitiligo, } \\
\text { inflammation, } \\
\text { and gonorrhea }\end{array}$ & Infusion (I) & 47 & 5 & 5 & 0.83 \\
\hline 55.3. Guazuma ulmifolia var. tomentosa (Kunth) K. Schum. & Chico-magro & $\begin{array}{c}\text { diarrhea, kidneys, } \\
\text { bronchitis wound } \\
\text { healing }\end{array}$ & $\begin{array}{l}\text { Infusion and } \\
\text { decoction (I) }\end{array}$ & 10 & 4 & 4 & 0.67 \\
\hline 55.4. Hibiscus pernambucensis Bertol. & $\begin{array}{l}\text { Algodão-do- } \\
\text { brejo }\end{array}$ & $\begin{array}{l}\text { wound healing, } \\
\text { colic, flu, and } \\
\text { uterine } \\
\text { inflammation }\end{array}$ & Infusion (I) & 2 & 3 & 4 & 0.57 \\
\hline 55.5. Hibiscus rosa-sinensis $\mathrm{L}$. & Primavera & pain & Infusion (I) & 2 & 1 & 1 & 0.17 \\
\hline 55.6. Hibiscus sabdariffa L. & $\begin{array}{l}\text { Quiabo-de- } \\
\text { angola, } \\
\text { Hibisco }\end{array}$ & $\begin{array}{l}\text { anxiety hearth, } \\
\text { flu, tachycardia, } \\
\text { kidneys, colic, } \\
\text { runny, diarrhea, } \\
\text { pain, uterine } \\
\text { inflammation, } \\
\text { labyrinthitis, } \\
\text { snakebite, and } \\
\text { pneumonia }\end{array}$ & Infusion (I) & 18 & 10 & 13 & 1.87 \\
\hline 55.7. Helicteres sacarolha A. St.-Hil. & $\begin{array}{l}\text { Semente-de- } \\
\text { macaco }\end{array}$ & $\begin{array}{l}\text { Hypertension and } \\
\text { ulcer }\end{array}$ & Infusion (I) & 2 & 2 & 2 & 0.33 \\
\hline 55.8. Malva sylvestris L. & Malva-branca & $\begin{array}{l}\text { wound healing, } \\
\text { conjunctivitis, } \\
\text { runny, blood } \\
\text { cleanser, diuretic, } \\
\text { boil, uterine } \\
\text { inflammation, } \\
\text { and rheumatism }\end{array}$ & Infusion (I) & 31 & 7 & 8 & 1.23 \\
\hline 55.9. Malvastrum corchorifolium (Desr.) Britton ex Small & Malva & $\begin{array}{c}\text { tonsillitis wound } \\
\text { healing, pain, and } \\
\text { uterine } \\
\text { inflammation }\end{array}$ & Infusion (I) & 13 & 4 & 4 & 0.67 \\
\hline 55.10. Sida rhombifolia L. & Guaxuma & obesity & Infusion (I) & 5 & 1 & 1 & 0.17 \\
\hline \multicolumn{8}{|l|}{ 56. MELASTOMATACEAE } \\
\hline 56.1. Leandra purpurascens (DC.) Cogn. & Pixirica & rheumatism & Infusion (I) & 1 & 1 & 1 & 0.17 \\
\hline
\end{tabular}


TABle 3: Continued.

\begin{tabular}{|c|c|c|c|c|c|c|c|}
\hline Family/species & $\begin{array}{l}\text { Vernacular } \\
\text { name }\end{array}$ & Application & $\begin{array}{c}\text { Preparation } \\
\text { (administration) }\end{array}$ & $\begin{array}{c}\text { Uses } \\
\text { listed }\end{array}$ & NCS & NP & RI \\
\hline 56.2. Tibouchina clavata (Pers.) Wurdack & Cibalena & pain & Infusion (I) & 3 & 1 & 1 & 0.17 \\
\hline 56.3. Tibouchina urvilleana (DC.) Cogn. & $\begin{array}{l}\text { Buscopam-de- } \\
\text { casa }\end{array}$ & stomach & Infusion (I) & 1 & 1 & 1 & 0.17 \\
\hline \multicolumn{8}{|l|}{ 57. MELIACEAE } \\
\hline 57.1. Azadirachta indica A. Juss. & Neem & diabetes & $\begin{array}{c}\text { Infusion and } \\
\text { decoction }(I, E)\end{array}$ & 1 & 1 & 1 & 0.17 \\
\hline 57.2. Cedrela odorata L. & Cedro & wound healing & Infusion (I) & 3 & 1 & 1 & 0.17 \\
\hline \multicolumn{8}{|l|}{ 58. MENISPERMACEAE } \\
\hline 58.1. Cissampelos sp. & $\begin{array}{l}\text { Orelha-de- } \\
\text { onça }\end{array}$ & $\begin{array}{l}\text { Column and } \\
\text { kidneys }\end{array}$ & Infusion (I) & 3 & 2 & 2 & 0.33 \\
\hline \multicolumn{8}{|l|}{ 59. MORACEAE } \\
\hline 59.1. Artocarpus integrifolia L.f. & Jaca & diuretic & Infusion (I) & 1 & 1 & 1 & 0.17 \\
\hline 59.2. Chlorophora tinctoria (L.) Gaudich. ex Benth. & Taiúva & $\begin{array}{l}\text { osteoporosis and } \\
\text { muscular } \\
\text { relaxative }\end{array}$ & Infusion (I) & 2 & 2 & 2 & 0.33 \\
\hline 59.3. Dorstenia brasiliensis Lam. & Carapiá & $\begin{array}{l}\text { wound healing, } \\
\text { colic, thooth, } \\
\text { blood cleanser, } \\
\text { dysentery, pain, } \\
\text { flu, laxative, } \\
\text { menstruation, } \\
\text { pneumonia, } \\
\text { relapse delivery, } \\
\text { and kidneys }\end{array}$ & Infusion (I) & 41 & 7 & 12 & 0.50 \\
\hline 59.4. Ficus brasiliensis Link. & Figo & gastritis & Infusion (I) & 4 & 1 & 1 & 0.17 \\
\hline 59.5. Ficus pertusa L. f. & Figueirinha & stomach & Infusion (I) & 5 & 1 & 1 & 0.17 \\
\hline \multicolumn{8}{|l|}{ 60. MUSACEAE } \\
\hline 60.1. Musa x paradisiaca L. & $\begin{array}{l}\text { Bananeira-de- } \\
\text { umbigo }\end{array}$ & $\begin{array}{l}\text { bronchitis anemia } \\
\text { and pain }\end{array}$ & $\begin{array}{l}\text { Infusion and } \\
\text { syrup (I) }\end{array}$ & 9 & 3 & 3 & 0.50 \\
\hline \multicolumn{8}{|l|}{ 61. MYRTACEAE } \\
\hline 61.1. Eucalyptus citriodora Hook. & Eucálipto & $\begin{array}{c}\text { bronchitis } \\
\text { diabetes, fever, flu, } \\
\text { sinusitis, and } \\
\text { cough }\end{array}$ & $\begin{array}{l}\text { Infusion and } \\
\text { syrup (I) }\end{array}$ & 22 & 3 & 6 & 0.70 \\
\hline 61.2. Eugenia pitanga (O. Berg) Kiaersk. & Pitanga & $\begin{array}{l}\text { pain, throat, flu, } \\
\text { and kidneys }\end{array}$ & Infusion (I) & 10 & 3 & 4 & 0.57 \\
\hline 61.3. Psidium guajava L. & Goiabeira & diarrhea & Infusion (I) & 19 & 1 & 1 & 0.17 \\
\hline 61.4. Psidium guineense Sw. & Goiaba-áraça & $\begin{array}{l}\text { pain, diarrhea, } \\
\text { and hypertension }\end{array}$ & Infusion (I) & 11 & 3 & 3 & 0.50 \\
\hline 61.5. Syzygium aromaticum (L.) Merr. \& L. M. Perry & Cravo-da-india & Throat and cough & Infusion (I) & 5 & 1 & 2 & 0.23 \\
\hline 61.6. Syzygium jambolanum (Lam.) DC. & Azeitona-preta & cholesterol & Decoction $(\mathrm{I}, \mathrm{E})$ & 4 & 1 & 1 & 0.17 \\
\hline \multicolumn{8}{|l|}{ 62. NYCTAGINACEAE } \\
\hline 62.1. Boerhavia coccinea L. & Amarra-pinto & $\begin{array}{l}\text { bladder icterus, } \\
\text { inflammation } \\
\text { uterina, and } \\
\text { kidneys }\end{array}$ & Infusion (I) & 22 & 2 & 4 & 0.47 \\
\hline 62.2. Mirabilis jalapa L. & Maravilha & $\begin{array}{l}\text { heart, pain, and } \\
\text { hypertension }\end{array}$ & Infusion (I) & 8 & 2 & 3 & 0.40 \\
\hline \multicolumn{8}{|l|}{ 63. OLACACEAE } \\
\hline $\begin{array}{l}\text { 63.1. Ximenia americana L. } \\
\text { 64. OPILIACEAE }\end{array}$ & \multicolumn{6}{|c|}{ 64. OPILIACEAE } & 0.33 \\
\hline 64.1. Agonandra brasiliensis Miers ex Benth. \& Hook f. & Pau-marfim & $\begin{array}{c}\text { uterine } \\
\text { inflammation }\end{array}$ & Decoction (I, E) & 1 & 1 & 1 & 0.17 \\
\hline
\end{tabular}


Table 3: Continued.

\begin{tabular}{|c|c|c|c|c|c|c|c|}
\hline Family/species & $\begin{array}{l}\text { Vernacular } \\
\text { name }\end{array}$ & Application & $\begin{array}{c}\text { Preparation } \\
\text { (administration) }\end{array}$ & $\begin{array}{l}\text { Uses } \\
\text { listed }\end{array}$ & NCS & NP & RI \\
\hline \multicolumn{8}{|l|}{ 65. ORCHIDACEAE } \\
\hline 65.1. Vanilla palmarum (Salzm. ex Lindl.) Lindl. & Baunilha & hypertension & Infusion (I) & 2 & 1 & 1 & 0.17 \\
\hline 65.2. Oncidium cebolleta (Jacq.) Sw. & Orquidea & pain & Infusion (I) & 2 & 1 & 1 & 0.17 \\
\hline \multicolumn{8}{|l|}{ 66. OXALIDACEAE } \\
\hline 66.1. Averrhoa carambola L. & Carambola & hypertension & Infusion (I) & 8 & 1 & 1 & 0.17 \\
\hline 66.2. Oxalis aff. hirsutissima Mart. ex Zucc. & Azedinha & obesity & Infusion (I) & 9 & 1 & 1 & 0.17 \\
\hline \multicolumn{8}{|l|}{ 67. PAPAVERACEAE } \\
\hline 67.1. Argemone mexicana L. & Cardo-santo & hypertension & Infusion (I) & 8 & 1 & 1 & 0.17 \\
\hline \multicolumn{8}{|l|}{ 68. PASSIFLORACEAE } \\
\hline 68.1. Passiflora alata Curtis & Maracujá & & Infusion (I) & 9 & 1 & 1 & 0.17 \\
\hline 68.2. Passiflora cincinnata Mast. & $\begin{array}{l}\text { Maracujá-do- } \\
\text { mato }\end{array}$ & $\begin{array}{c}\text { soothing } \\
\text { hypertension }\end{array}$ & Infusion (I) & 5 & 2 & 2 & 0.33 \\
\hline \multicolumn{8}{|l|}{ 69. PEDALIACEAE } \\
\hline 69.1 Sesamum indicum L. & Gergelim & $\begin{array}{l}\text { stomach, liver, } \\
\text { gastritis, ulcer, } \\
\text { and worms }\end{array}$ & $\begin{array}{l}\text { Infusion and } \\
\text { maceration (I) }\end{array}$ & 12 & 2 & 5 & 0.53 \\
\hline \multicolumn{8}{|l|}{ 70. PHYLLANTHACEAE } \\
\hline 70.1. Phyllanthus niruri L. & Quebra-pedra & kidneys & Infusion (I) & 32 & 1 & 1 & 0.17 \\
\hline \multicolumn{8}{|l|}{ 71. PHYTOLACCACEAE } \\
\hline 71.1. Petiveria alliacea L. & Guiné & rheumatism & Infusion (I, E) & 4 & 1 & 1 & 0.17 \\
\hline \multicolumn{8}{|l|}{ 72. PIPERACEAE } \\
\hline 72.1. Piper callosum Ruiz \& Pav & $\begin{array}{l}\text { Ventre- } \\
\text { livre/elixir } \\
\text { paregórico }\end{array}$ & kidneys & Infusion (I) & 1 & 1 & 1 & 0.17 \\
\hline 72.2. Piper cuyabanum C. DC. & Jaborandi & $\begin{array}{l}\text { pain, stomach, } \\
\text { and loss of hair }\end{array}$ & Infusion (I, E) & 10 & 3 & 3 & 0.50 \\
\hline 72.3. Pothomorphe umbellata (L.) Miq. & Pariparoba & $\begin{array}{l}\text { blood cleanser, } \\
\text { stomach, liver, } \\
\text { and pneumonia }\end{array}$ & Infusion (I) & 11 & 3 & 3 & 0.50 \\
\hline \multicolumn{8}{|l|}{ 73. PLANTAGINACEAE } \\
\hline 73.1. Plantago major L. & Tanchagem & $\begin{array}{l}\text { heart, pain, and } \\
\text { laxative }\end{array}$ & Infusion (I) & 16 & 3 & 3 & 0.50 \\
\hline \multicolumn{8}{|l|}{ 74. POACEAE } \\
\hline 74.1. Andropogon bicornis L. & $\begin{array}{l}\text { Capim-rabo- } \\
\text { de-lobo }\end{array}$ & $\begin{array}{c}\text { uterine } \\
\text { inflammation }\end{array}$ & Infusion (I) & 3 & 1 & 1 & 0.17 \\
\hline 74.2. Coix lacryma-jobi L. & $\begin{array}{l}\text { Lácrimas-de- } \\
\text { nossa-senhora }\end{array}$ & kidneys & Infusion (I, E) & 4 & 1 & 1 & 0.17 \\
\hline 74.3. Cymbopogon citratus (DC.) Stapfc & Capim-cidreira & $\begin{array}{l}\text { soothing blood } \\
\text { cleanser, pain, } \\
\text { stomach, } \\
\text { expectorant, fever, } \\
\text { flu, hypertension, } \\
\text { muscular } \\
\text { relaxative, } \\
\text { kidneys, } \\
\text { tachycardia, and } \\
\text { cough }\end{array}$ & $\begin{array}{l}\text { Infusion and } \\
\text { juice (I) }\end{array}$ & 49 & 5 & 12 & 1.30 \\
\hline 74.4. Cymbopogon nardus (L.) Rendle. & $\begin{array}{l}\text { Capim- } \\
\text { citronela }\end{array}$ & $\begin{array}{l}\text { flu, cough, and } \\
\text { tuberculosis }\end{array}$ & Infusion (E) & 11 & 2 & 2 & 0.33 \\
\hline 74.5. Digitaria insularis (L.) Mez ex Ekman & $\begin{array}{l}\text { Capim- } \\
\text { amargoso }\end{array}$ & $\begin{array}{l}\text { wound healing, } \\
\text { stomach, bone } \\
\text { fractures, and } \\
\text { rheumatism }\end{array}$ & Infusion (I) & 14 & 3 & 4 & 0.57 \\
\hline
\end{tabular}


Table 3: Continued.

\begin{tabular}{|c|c|c|c|c|c|c|c|}
\hline Family/species & $\begin{array}{c}\text { Vernacular } \\
\text { name }\end{array}$ & Application & $\begin{array}{c}\text { Preparation } \\
\text { (administration) }\end{array}$ & $\begin{array}{c}\text { Uses } \\
\text { listed }\end{array}$ & NCS & NP & RI \\
\hline 74.6. Eleusine indica (L.) Gaertn. & $\begin{array}{l}\text { Capim-pé-de- } \\
\text { galinha }\end{array}$ & $\begin{array}{l}\text { Hypertension and } \\
\text { swelling in } \\
\text { pregnant woman }\end{array}$ & Infusion (I) & 6 & 2 & 2 & 0.33 \\
\hline 74.7. Imperata brasiliensis Trin. & Capim-sapé & $\begin{array}{l}\text { diabetes, pain, } \\
\text { hepatitis, kidneys, } \\
\text { and vitiligo }\end{array}$ & Infusion (I) & 12 & 5 & 5 & 0.83 \\
\hline 74.8. Melinis minutiflora P. Beauv. & $\begin{array}{l}\text { Capim- } \\
\text { gordura }\end{array}$ & $\begin{array}{l}\text { dengue, blood } \\
\text { cleanser, stroke, } \\
\text { flu, kidneys, } \\
\text { sinusitis, cough, } \\
\text { and tumors }\end{array}$ & Infusion (I) & 31 & 7 & 8 & 1.23 \\
\hline 74.9. Oryza sativa $\mathrm{L}$. & Arroz & bladder & Infusion (I) & 1 & 1 & 1 & 0.17 \\
\hline 74.10. Saccharum officinarum L. & $\begin{array}{l}\text { Cana-de- } \\
\text { açúcar }\end{array}$ & $\begin{array}{l}\text { kidneys, anemia, } \\
\text { and hypertension }\end{array}$ & Infusion (I) & 2 & 3 & 3 & 0.50 \\
\hline 74.11. Zea mays L. & Milho & bladder kidneys & Infusion (I) & 3 & 2 & 2 & 0.33 \\
\hline \multicolumn{8}{|l|}{ 75. POLYGALACEAE } \\
\hline 75.1. Polygala paniculata L. & Bengué & rheumatism & Infusion (I) & 6 & 1 & 1 & 0.17 \\
\hline \multicolumn{8}{|l|}{ 76. POLYGONACEAE } \\
\hline 76.1. Coccoloba cujabensis Wedd. & Uveira & diuretic & Infusion (I) & 1 & 1 & 1 & 0.17 \\
\hline 76.2. Polygonum cf. punctatum Elliott & Erva-de-bicho & $\begin{array}{l}\text { wound healing, } \\
\text { dengue, stomach, } \\
\text { fever, flu, and } \\
\text { hemorrhoids }\end{array}$ & Infusion (I) & 41 & 5 & 6 & 0.90 \\
\hline 76.3. Rheum palmatum L. & Ruibarbo & $\begin{array}{l}\text { blood cleanser, } \\
\text { dysentery, pain, } \\
\text { and snakebite }\end{array}$ & Infusion (I) & 6 & 4 & 4 & 0.67 \\
\hline 76.4. Triplaris brasiliana Cham. & Novatero & diabetes & Infusion (I) & 1 & 1 & 1 & 0.17 \\
\hline \multicolumn{8}{|l|}{ 77. POLYPODIACEAE } \\
\hline 77.1. Phlebodium decumanum (Willd.) J. Sm. & $\begin{array}{l}\text { Rabo-de- } \\
\text { macaco }\end{array}$ & $\begin{array}{l}\text { diuretic, hepatitis, } \\
\text { and kidneys }\end{array}$ & Infusion (I) & 9 & 2 & 3 & 0.40 \\
\hline 77.2. Pteridium aquilinum (L.) Kuhn & Samambaia & $\begin{array}{l}\text { colic, blood } \\
\text { cleanser, and } \\
\text { rheumatism }\end{array}$ & Infusion (I) & 8 & 3 & 3 & 0.50 \\
\hline 77.3. Pteridium sp. & $\begin{array}{l}\text { Samambaia- } \\
\text { de-cipo }\end{array}$ & rheumatism & Infusion (I) & 1 & 1 & 1 & 0.17 \\
\hline \multicolumn{8}{|l|}{ 78. PONTEDERIACEAE } \\
\hline 78.1. Eichhornia azurea (Sw.) Kunth & Aguapé & ulcer & Infusion (I) & 3 & 1 & 1 & 0.17 \\
\hline \multicolumn{8}{|l|}{ 79. PORTULACACEAE } \\
\hline 79.1. Portulaca oleracea L. & Onze-horas & hypertension & Infusion (I) & 3 & 1 & 1 & 0.17 \\
\hline \multicolumn{8}{|l|}{ 80. PROTEACEAE } \\
\hline 80.1. Roupala montana Aubl. & Carne-de-vaca & $\begin{array}{l}\text { muscular } \\
\text { relaxative }\end{array}$ & Infusion (I) & 2 & 1 & 1 & 0.17 \\
\hline \multicolumn{8}{|l|}{ 81. PUNICACEAE } \\
\hline 81.1. Punica granatum L. & Romã & $\begin{array}{l}\text { colic, diarrhea, } \\
\text { pain, throat, } \\
\text { inflammation } \\
\text { uterina, and } \\
\text { kidneys }\end{array}$ & $\begin{array}{l}\text { Infusion and } \\
\text { maceration (I, } \\
\text { E) }\end{array}$ & 41 & 3 & 6 & 0.70 \\
\hline \multicolumn{8}{|l|}{ 82. RHAMNACEAE } \\
\hline 82.1. Rhamnidium elaeocarpum Reissek & Cabriteiro & $\begin{array}{l}\text { anemia, diarrhea, } \\
\text { diuretic, pain, } \\
\text { stomach, and } \\
\text { worms }\end{array}$ & Infusion (I) & 37 & 5 & 6 & 0.90 \\
\hline
\end{tabular}


TABle 3: Continued.

\begin{tabular}{|c|c|c|c|c|c|c|c|}
\hline Family/species & $\begin{array}{c}\text { Vernacular } \\
\text { name }\end{array}$ & Application & $\begin{array}{c}\text { Preparation } \\
\text { (administration) }\end{array}$ & $\begin{array}{c}\text { Uses } \\
\text { listed }\end{array}$ & NCS & NP & RI \\
\hline \multicolumn{8}{|l|}{ 83. ROSACEAE } \\
\hline 83.1. Rosa alba L. & Rosa-branca & $\begin{array}{l}\text { wound healing, } \\
\text { pain, and uterine } \\
\text { inflammation }\end{array}$ & $\begin{array}{l}\text { Infusion and } \\
\text { maceration (I, } \\
\text { E) }\end{array}$ & 6 & 3 & 3 & 0.50 \\
\hline 83.2. Rosa graciliflora Rehder \& E. H. Wilson & Rosa-amarela & pain & $\begin{array}{l}\text { Infusion and } \\
\text { maceration (I, } \\
\text { E) }\end{array}$ & 1 & 1 & 1 & 0.17 \\
\hline 83.3. Rubus brasiliensis Mart. & Amoreira & $\begin{array}{c}\text { cholesterol, } \\
\text { hypertension, } \\
\text { labyrinthitis, } \\
\text { menopause, } \\
\text { obesity, } \\
\text { osteoporosis, and } \\
\text { kidneys }\end{array}$ & $\begin{array}{l}\text { Infusion and } \\
\text { tintura (I) }\end{array}$ & 38 & 6 & 7 & 1.07 \\
\hline \multicolumn{8}{|l|}{ 84. RUBIACEAE } \\
\hline 84.1. Chiococca alba (L.) Hitchc. & Cainca & $\begin{array}{l}\text { pain, flu, and } \\
\text { rheumatism }\end{array}$ & Infusion (I) & 8 & 3 & 3 & 0.50 \\
\hline 84.2. Cordiera edulis (Rich.) Kuntze & Marmelada & worms & $\begin{array}{c}\text { Maceration and } \\
\text { syrup (I) }\end{array}$ & 3 & 1 & 1 & 0.17 \\
\hline 84.3. Cordiera macrophylla (K. Schum.) Kuntze & $\begin{array}{l}\text { Marmelada- } \\
\text { espinho }\end{array}$ & worms & $\begin{array}{c}\text { Maceration and } \\
\text { syrup (I) }\end{array}$ & 1 & 1 & 1 & 0.17 \\
\hline 84.4. Cordiera sessilis (Vell.) Kuntze & $\begin{array}{l}\text { Marmelada- } \\
\text { bola }\end{array}$ & Flu and worms & $\begin{array}{c}\text { Maceration and } \\
\operatorname{syrup}(\mathrm{I})\end{array}$ & 4 & 2 & 2 & 0.33 \\
\hline 84.5. Coutarea hexandra (Jacq.) K. Schum. & Murtinha & diarrhea & Infusion (I) & 1 & 1 & 1 & 0.17 \\
\hline 84.6. Genipa americana L. & Jenipapo & $\begin{array}{l}\text { appendicitis } \\
\text { bronchitis } \\
\text { diabetes and } \\
\text { kidneys }\end{array}$ & $\begin{array}{l}\text { Infusion and } \\
\text { syrup (I) }\end{array}$ & 8 & 4 & 4 & 0.67 \\
\hline 84.7. Guettarda viburnoides Cham. \& Schltdl. & Veludo-branco & $\begin{array}{l}\text { blood cleanser } \\
\text { and ulcer }\end{array}$ & Infusion (I) & 5 & 2 & 2 & 0.33 \\
\hline 84.8. Palicourea coriacea (Cham.) K. Schum. & $\begin{array}{l}\text { Douradinha- } \\
\text { do-campo }\end{array}$ & $\begin{array}{l}\text { prostate cancer } \\
\text { hearth, blood } \\
\text { cleanser, diuretic, } \\
\text { flu, hypertension, } \\
\text { insomnia, } \\
\text { relaxative } \\
\text { muscular, and } \\
\text { kidneys }\end{array}$ & Infusion (I) & 62 & 7 & 9 & 1.30 \\
\hline 84.9. Palicourea rigida Kunth & Doradão & $\begin{array}{l}\text { Kidneys and } \\
\text { cough }\end{array}$ & $\begin{array}{l}\text { Infusion and } \\
\text { decoction (I) }\end{array}$ & 5 & 2 & 2 & 0.33 \\
\hline 84.10. Rudgea viburnoides (Cham.) Benth. & Erva-molar & $\begin{array}{l}\text { column, thooth, } \\
\text { blood cleanser, } \\
\text { dysentery, } \\
\text { rheumatism, and } \\
\text { kidneys }\end{array}$ & Infusion (I) & 44 & 5 & 6 & 0.90 \\
\hline 84.11. Tocoyena formosa (Cham. \& Schltdl.) K. Schum. & Jenipapo-bravo & kidneys & Infusion (I) & 1 & 1 & 1 & 0.17 \\
\hline 84.12. Uncaria tomentosa (Willd. ex Roem. \& Schult.) DC. & Unha-de-gato & $\begin{array}{l}\text { intoxication, } \\
\text { rheumatism, and } \\
\text { kidneys }\end{array}$ & Infusion (I) & 10 & 3 & 3 & 0.50 \\
\hline \multicolumn{8}{|l|}{ 85. RUTACEAE } \\
\hline 85.1. Citrus aurantiifolia (Christm.) Swingle & Lima & $\begin{array}{l}\text { soothing hearth, } \\
\text { and hypertension }\end{array}$ & Infusion (I) & 8 & 2 & 3 & 0.40 \\
\hline 85.2. Citrus limon (L.) Osbeck & Limão & $\begin{array}{l}\text { colic, diabetes, } \\
\text { pain, liver, flu, } \\
\text { hypertension, and } \\
\text { cough }\end{array}$ & Infusion (I) & 17 & 5 & 7 & 0.97 \\
\hline
\end{tabular}


Table 3: Continued.

\begin{tabular}{|c|c|c|c|c|c|c|c|}
\hline Family/species & $\begin{array}{l}\text { Vernacular } \\
\text { name }\end{array}$ & Application & $\begin{array}{c}\text { Preparation } \\
\text { (administration) }\end{array}$ & $\begin{array}{l}\text { Uses } \\
\text { listed }\end{array}$ & NCS & NP & RI \\
\hline 85.3. Citrus sinensis (L.) Osbeck & Laranja & $\begin{array}{l}\text { soothing wound } \\
\text { healing, fever, flu, } \\
\text { pneumonia, and } \\
\text { thyroid }\end{array}$ & Infusion (I) & 30 & 4 & 6 & 0.80 \\
\hline 85.4. Ruta graveolens L. & Arruda & $\begin{array}{c}\text { colic, } \\
\text { conjunctivitis, } \\
\text { pain, stomach, } \\
\text { fever, gastritis, } \\
\text { nausea, and } \\
\text { laxative muscular }\end{array}$ & Infusion (I) & 57 & 4 & 8 & 0.93 \\
\hline 85.5. Spiranthera odoratissima A.St.-Hil. & Manacá & rheumatism & Infusion (I) & 6 & 1 & 1 & 0.17 \\
\hline 85.6. Zanthoxylum cf. rhoifolium Lam. & $\begin{array}{l}\text { Mamica-de- } \\
\text { porca }\end{array}$ & $\begin{array}{l}\text { diabetes, diarrhea, } \\
\text { hemorrhoids, and } \\
\text { muscular } \\
\text { relaxative }\end{array}$ & Decoction (I, E) & 12 & 4 & 4 & 0.67 \\
\hline \multicolumn{8}{|l|}{ 86. SALICACEAE } \\
\hline 86.1. Casearia silvestris Sw. & Chá-de-frade & $\begin{array}{l}\text { blood cleanser, } \\
\text { pain, and fever }\end{array}$ & Infusion (I) & 10 & 1 & 3 & 0.30 \\
\hline \multicolumn{8}{|l|}{ 87. SAPINDACEAE } \\
\hline 87.1. Dilodendron bipinnatum Radlk. & Mulher-pobre & bone fractures & Infusion (I) & 5 & 2 & 2 & 0.33 \\
\hline 87.2. Magonia pubescens A. St.-Hil. & Timbó & $\begin{array}{c}\text { uterine } \\
\text { inflammation } \\
\text { wound healing, } \\
\text { pain, and cough }\end{array}$ & $\begin{array}{l}\text { Maceration (I, } \\
\text { E) }\end{array}$ & 7 & 2 & 3 & 0.40 \\
\hline 87.3. Serjania erecta Radk. & Cinco-pontas & $\begin{array}{l}\text { column, muscular } \\
\text { relaxative, and } \\
\text { kidneys }\end{array}$ & Infusion (I) & 9 & 2 & 3 & 0.40 \\
\hline 87.4. Talisia esculenta (A. St.-Hil.) Radlk. & Pitomba & $\begin{array}{l}\text { column, pain, and } \\
\text { rheumatism }\end{array}$ & Infusion (I) & 6 & 2 & 3 & 0.40 \\
\hline \multicolumn{8}{|l|}{ 88. SAPOTACEAE } \\
\hline 88.1. Pouteria glomerata (Miq.) Radlk. & $\begin{array}{l}\text { Laranjinha-do- } \\
\text { mato }\end{array}$ & fever & Infusion (I) & 1 & 1 & 1 & 0.17 \\
\hline 88.2. Pouteria ramiflora (Mart.) Radlk. & Fruta-de-viado & Ulcer and kidneys & Infusion (I) & 1 & 2 & 2 & 0.33 \\
\hline \multicolumn{8}{|l|}{ 89. SCROPHULARIACEAE } \\
\hline 89.1. Bacopa sp. & Vicki-de-batata & kidneys & Infusion (I) & 2 & 1 & 1 & 0.17 \\
\hline 89.2. Scoparia dulcis L. & Vassorinha & $\begin{array}{l}\text { bladder wound } \\
\text { healing, hearth, } \\
\text { blood cleanser, } \\
\text { diabetes, pain, } \\
\text { bone fractures, } \\
\text { swelling in } \\
\text { pregnant woman, } \\
\text { pneumonia, } \\
\text { kidneys, syphilis, } \\
\text { and cough }\end{array}$ & Infusion (I) & 81 & 7 & 12 & 1.50 \\
\hline \multicolumn{8}{|l|}{ 90. SIMAROUBACEAE } \\
\hline 90.1. Simaba ferruginea A. St.-Hil. & Calunga & $\begin{array}{l}\text { anemia, wound } \\
\text { healing, diabetes, } \\
\text { digestive, pain, } \\
\text { stomach, obesity, } \\
\text { ulcer, and worms }\end{array}$ & Maceration (I) & 31 & 7 & 9 & 1.30 \\
\hline 90.2. Simarouba versicolor A. St.-Hil. & Pé-de-perdiz & $\begin{array}{l}\text { wound healing } \\
\text { and uterine } \\
\text { inflammation }\end{array}$ & Decoction $(\mathrm{I}, \mathrm{E})$ & 4 & 2 & 2 & 0.33 \\
\hline
\end{tabular}


TABle 3: Continued.

\begin{tabular}{|c|c|c|c|c|c|c|c|}
\hline Family/species & $\begin{array}{c}\text { Vernacular } \\
\text { name }\end{array}$ & Application & $\begin{array}{c}\text { Preparation } \\
\text { (administration) }\end{array}$ & $\begin{array}{c}\text { Uses } \\
\text { listed }\end{array}$ & NCS & NP & RI \\
\hline \multicolumn{8}{|l|}{ 91. SIPARUNACEAE } \\
\hline 91.1. Siparuna guianensis Aubl. & Negramina & pain, fever, and flu & Infusion (I) & 20 & 2 & 3 & 0.40 \\
\hline \multicolumn{8}{|l|}{ 92. SMILACACEAE } \\
\hline 92.1. Smilax aff. brasiliensis Spreng. & Japecanga & $\begin{array}{l}\text { Column and } \\
\text { rheumatism }\end{array}$ & Infusion (I) & 5 & 1 & 2 & 0.23 \\
\hline \multicolumn{8}{|l|}{ 93. SOLANACEAE } \\
\hline 93.1. Capsicum sp. & Pimenta & $\begin{array}{c}\text { Pain and } \\
\text { hemorrhoids }\end{array}$ & Infusion (I, E) & 14 & 2 & 2 & 0.33 \\
\hline 93.2. Nicotiana tabacum L. & Fumo & thyroid & Infusion (I, E) & 2 & 1 & 1 & 0.17 \\
\hline 93.3. Physalis $\mathrm{sp}$. & $\begin{array}{l}\text { Tomate-de- } \\
\text { capote }\end{array}$ & hepatitis & Infusion (I) & 1 & 1 & 1 & 0.17 \\
\hline 93.4. Solanum americanum Mill. & Maria-pretinha & worms & Infusion (I) & 3 & 1 & 1 & 0.17 \\
\hline 93.5. Solanum lycocarpum A. St.-Hil. & Fruta-de-lobo & Gastritis and ulcer & $\begin{array}{l}\text { Infusion and } \\
\text { maceration (I) }\end{array}$ & 6 & 1 & 2 & 0.23 \\
\hline 93.6. Solanum sp. & Jurubeba & $\begin{array}{c}\text { column, stomach, } \\
\text { and liver }\end{array}$ & Infusion (I) & 8 & 2 & 3 & 0.40 \\
\hline 93.7. Solanum sp. & Urtiga & boi & Infusion (I) & 1 & 1 & 1 & 0.17 \\
\hline 93.8. Solanum melongena L. & Berinjela & cholesterol & $\begin{array}{l}\text { Infusion and } \\
\text { maceration (I) }\end{array}$ & 2 & 1 & 1 & 0.17 \\
\hline 93.9. Solanum tuberosum L. & Batata-inglesa & Pain and gastritis & $\begin{array}{l}\text { Infusion and } \\
\text { maceration (I, } \\
\text { E) }\end{array}$ & 13 & 2 & 2 & 0.33 \\
\hline 93.10. Solanum viarum Dunal. & Joá-manso & Hemorrhoids & Infusion (I) & 7 & 1 & 1 & 0.17 \\
\hline \multicolumn{8}{|l|}{ 94. TILIACEAE } \\
\hline 94.1. Apeiba tibourbou Aubl. & Jangadeira & liver & Decoction (I, E) & 1 & 1 & 1 & 0.17 \\
\hline 94.2. Luehea divaricata Mart. & Açoita-cavalo & $\begin{array}{l}\text { uric acid, column, } \\
\text { blood cleanser, } \\
\text { throat, flu, } \\
\text { hemorrhoids, } \\
\text { intestine, } \\
\text { pneumonia, } \\
\text { muscular } \\
\text { relaxative, } \\
\text { kidneys, cough, } \\
\text { and tumors }\end{array}$ & $\begin{array}{l}\text { Decoction and } \\
\text { syrup (I) }\end{array}$ & 58 & 7 & 12 & 1.50 \\
\hline \multicolumn{8}{|l|}{ 95. ULMACEAE } \\
\hline 95.1. Trema micrantha (L.) Blume & Piriquiteira & wound healing & Decoction (I, E) & 1 & 1 & 1 & 0.17 \\
\hline \multicolumn{8}{|l|}{ 96. VERBENACEAE } \\
\hline 96.1. Casselia mansoi Schau & $\begin{array}{l}\text { Saúde-da- } \\
\text { mulher }\end{array}$ & $\begin{array}{l}\text { thooth, blood } \\
\text { cleanser, uterine } \\
\text { inflammation, } \\
\text { and menstruation }\end{array}$ & Infusion (I) & 9 & 3 & 4 & 0.57 \\
\hline 96.2. Duranta repens L. & Pingo-de-ouro & diabetes & Infusion (I, E) & 3 & 1 & 1 & 0.17 \\
\hline 96.3. Lantana camara L. & Cambará & cold and cough & Decoction (I) & 22 & 2 & 2 & 0.33 \\
\hline 96.4. Lippia alba (Mill.) N. E. Br. ex Britton \& P. Wilson & Erva-cidreira & $\begin{array}{l}\text { soothing hearth, } \\
\text { thooth, blood } \\
\text { cleanser, pain, flu, } \\
\text { hypertension, } \\
\text { tachycardia, and } \\
\text { cough }\end{array}$ & Infusion (I) & 75 & 5 & 9 & 1.10 \\
\hline
\end{tabular}


TABle 3: Continued.

\begin{tabular}{|c|c|c|c|c|c|c|c|}
\hline Family/species & $\begin{array}{l}\text { Vernacular } \\
\text { name }\end{array}$ & Application & $\begin{array}{c}\text { Preparation } \\
\text { (administration) }\end{array}$ & $\begin{array}{l}\text { Uses } \\
\text { listed }\end{array}$ & NCS & NP & RI \\
\hline 96.5. Phyla sp. & Chá-mineiro & $\begin{array}{l}\text { conjunctivitis, } \\
\text { blood cleanser, } \\
\text { pain, fever, } \\
\text { muscular } \\
\text { relaxative, } \\
\text { rheumatism, and } \\
\text { kidneys }\end{array}$ & Infusion (I) & 19 & 4 & 7 & 0.87 \\
\hline 96.6. Priva lappulacea (L.) Pers. & Pega-pega & $\begin{array}{l}\text { Stomach and } \\
\text { sinusitis }\end{array}$ & Infusion (I) & 2 & 2 & 2 & 0.33 \\
\hline 96.7. Stachytarpheta aff. cayennensis (Rich.) Vahl & Gervão & $\begin{array}{l}\text { bronchitis blood } \\
\text { cleanser, stomach, } \\
\text { liver, bone } \\
\text { fractures, gastritis, } \\
\text { flu, constipation, } \\
\text { relaxative } \\
\text { muscular, cough, } \\
\text { and worms }\end{array}$ & Infusion (I) & 80 & 6 & 11 & 1.33 \\
\hline 96.8. Stachytarpheta sp. & Rabo-de-pavão & $\begin{array}{l}\text { relaxative } \\
\text { muscular }\end{array}$ & Infusion (I) & 3 & 1 & 1 & 0.17 \\
\hline 96.9. Vitex cymosa Bert.ex Spregn. & Tarumeiro & $\begin{array}{l}\text { blood cleanser, } \\
\text { diarrhea, pain, } \\
\text { and stomach }\end{array}$ & Infusion (I) & 8 & 3 & 4 & 0.57 \\
\hline \multicolumn{8}{|l|}{ 97. VIOLACEAE } \\
\hline 97.1. Anchietea salutaris A. St.-Hil. & Cipó-suma & $\begin{array}{c}\text { column, blood } \\
\text { cleanser, fever, } \\
\text { intoxication, and } \\
\text { vitiligo }\end{array}$ & Infusion (I) & 18 & 4 & 5 & 0.73 \\
\hline 97.2. Hybanthus calceolaria (L.) Schulze-Menz. & Poaia-branca & cough & Infusion (I) & 1 & 1 & 1 & 0.17 \\
\hline \multicolumn{8}{|l|}{ 98. VITACEAE } \\
\hline 98.1. Cissus cissyoides $\mathrm{L}$. & $\begin{array}{l}\text { Insulina-de- } \\
\text { ramo }\end{array}$ & diabetes & Infusion (I) & 10 & 1 & 1 & 0.17 \\
\hline 98.2. Cissus gongylodes Burch. ex Baker & Cipó-de-arráia & $\begin{array}{l}\text { relaxative } \\
\text { muscular }\end{array}$ & Infusion (I) & 1 & 1 & 1 & 0.17 \\
\hline 98.3. Cissus sp. & Rabo-de-arráia & hypertension & Infusion (I) & 3 & 2 & 2 & 0.33 \\
\hline 98.4. Cissus sp. & $\begin{array}{l}\text { Sofre-do-rim- } \\
\text { quem-quer }\end{array}$ & $\begin{array}{l}\text { inflammation } \\
\text { uterina, relaxative } \\
\text { muscular, and } \\
\text { kidneys }\end{array}$ & Infusion (I) & 5 & 3 & 3 & 0.50 \\
\hline \multicolumn{8}{|l|}{ 99. VOCHYSIACEAE } \\
\hline 99.1. Callisthene fasciculata Mart. & Carvão-branco & $\begin{array}{l}\text { Hepatitis and } \\
\text { icterus }\end{array}$ & Decoction (I, E) & 10 & 2 & 2 & 0.33 \\
\hline 99.2. Qualea grandiflora Mart. & Pau-terra & Diarrhea and pain & Decoction $(\mathrm{I}, \mathrm{E})$ & 5 & 2 & 2 & 0.33 \\
\hline 99.3. Qualea parviflora Mart. & Pau-terrinha & diarrhea & & 1 & 1 & 1 & 0.17 \\
\hline 99.4. Salvertia convallariodora A. St.-Hil. & Capotão & $\begin{array}{l}\text { diarrhea, diuretic, } \\
\text { hemorrhoids, and } \\
\text { relaxative } \\
\text { muscular }\end{array}$ & Decoction (I, E) & 4 & 4 & 4 & 0.67 \\
\hline 99.5. Vochysia cinnamomea Pohl & Quina-doce & flu & & 3 & 1 & 1 & 0.17 \\
\hline 99.6. Vochysia rufa Mart. & Pau-doce & $\begin{array}{l}\text { blood cleanser, } \\
\text { diabetes, diarrhea, } \\
\text { laxative, obesity, } \\
\text { kidneys, cough, } \\
\text { and worms }\end{array}$ & $\begin{array}{l}\text { Decoction, } \\
\text { Infusion }(\mathrm{I}, \mathrm{E})\end{array}$ & 25 & 6 & 8 & 1.13 \\
\hline
\end{tabular}


TABle 3: Continued.

\begin{tabular}{|c|c|c|c|c|c|c|c|}
\hline Family/species & $\begin{array}{c}\text { Vernacular } \\
\text { name }\end{array}$ & Application & $\begin{array}{c}\text { Preparation } \\
\text { (administration) }\end{array}$ & $\begin{array}{l}\text { Uses } \\
\text { listed }\end{array}$ & NCS & $\mathrm{NP}$ & RI \\
\hline \multicolumn{8}{|l|}{ 100. LILIACEAE } \\
\hline 100.1. Aloe barbadensis Mill. & Babosa & $\begin{array}{l}\text { Cancer, prostate } \\
\text { cancer, wound } \\
\text { healing, diabetes, } \\
\text { stomach, bone } \\
\text { fractures, gastritis, } \\
\text { hepatitis, laxative, } \\
\text { and rheumatism }\end{array}$ & $\begin{array}{l}\text { Syrup and } \\
\text { maceration (I, } \\
\text { E) }\end{array}$ & 87 & 5 & 9 & 1.10 \\
\hline \multicolumn{8}{|l|}{ 101. ZAMIACEAE } \\
\hline 101.1. Zamia boliviana (Brongn.) A. DC. & Maquiné & stomach & Infusion (I) & 2 & 1 & 1 & 0.17 \\
\hline \multicolumn{8}{|l|}{ 102. ZINGIBERACEAE } \\
\hline 102.1. Alpinia speciosa (J. C. Wendl.) K. Schum. & Colônia & $\begin{array}{l}\text { soothing hearth, } \\
\text { fever, flu, and } \\
\text { hypertension }\end{array}$ & Infusion (I) & 36 & 4 & 5 & 0.73 \\
\hline 102.2. Curcuma longa L. & Açafrão & $\begin{array}{l}\text { column, diuretic, } \\
\text { pain, stomach, } \\
\text { and hepatitis }\end{array}$ & $\begin{array}{l}\text { Infusion and } \\
\text { maceration (I) }\end{array}$ & 18 & 4 & 5 & 0.73 \\
\hline 102.3. Zingiber officinale Roscoe & Gengibre & $\begin{array}{l}\text { pain, flu, sinusitis, } \\
\text { and cough }\end{array}$ & $\begin{array}{c}\text { Infusion and } \\
\text { maceration (I) }\end{array}$ & 26 & 2 & 4 & 0.47 \\
\hline
\end{tabular}

I: Internal, E: External; NSC: Number of body systems treated by species; NCS: number of body systems. NP: Number of properties of the species; RI: Relative importance of the species.

TABLE 4: Species with the highest values of relative importance.

\begin{tabular}{|c|c|c|c|c|}
\hline Family & Species & Application/citation & $\mathrm{RF}$ & RI \\
\hline Apocynaceae & $\begin{array}{l}\text { Himatanthus obovatus (Müll. } \\
\text { Arg.) Woodson }\end{array}$ & $\begin{array}{l}\text { anemia (1), wound healing ( } 7) \text {, cholesterol (3), blood cleanser } \\
\text { (9), pain (4), nose bleeding (1), hypertension (4), uterine } \\
\text { inflammation (5), labyrinthitis (6), muscle relaxant (2), } \\
\text { worms (1), vitiligo (1), and pneumonia (1) }\end{array}$ & 45 & 1.87 \\
\hline Malvaceae & Hibiscus sabdariffa $\mathrm{L}$ & $\begin{array}{l}\text { anxiety/heart (1), flu (1), tachycardia (1), kidneys (1), cramps } \\
\text { (3), discharge (1), diarrhea (1), pain (1), inflammation uterine } \\
\text { (2), labyrinthitis (3), snakebite (1), and pneumonia (2) }\end{array}$ & 18 & 1.87 \\
\hline Asteraceae & Solidago microglossa DC. & $\begin{array}{l}\text { wound healing (53), blood cleanser (11), pain (2), bone } \\
\text { fractures (1), hypertension (1), uterine inflammation ( } 3 \text {, } \\
\text { muscle relaxant (6), kidneys (3), and worms (2) }\end{array}$ & 82 & 1.8 \\
\hline Loganiaceae & Strychnos pseudoquina A. St.-Hil. & $\begin{array}{l}\text { anemia (46), wound healing (3), cholesterol (1), blood } \\
\text { cleanser (16), pain (13), stomach ( } 3) \text {, bone fractures ( } 1) \text {, flu } \\
\text { (2), uterine inflammation ( } 1) \text {, pneumonia ( } 1) \text {, muscle relaxant } \\
\text { (1), cough (10), ulcer (1), and worms (8) }\end{array}$ & 107 & 1.73 \\
\hline Moraceae & Dorstenia brasiliensis Lam. & $\begin{array}{l}\text { wound healing (1), colic ( } 1) \text {, tooth ache (1), blood cleanser } \\
\text { (4), dysentery (1), pain ( } 7) \text {, flu (2), laxative ( } 3) \text {, menstruation } \\
\text { (1), pneumonia (6), relapse delivery (13), and kidneys (1) }\end{array}$ & 41 & 1.5 \\
\hline Plantaginaceae & Scoparia dulcis L. & $\begin{array}{l}\text { heart (6), blood cleanser (1), diabetes (1), pain (16), bone } \\
\text { fractures (47), swelling in pregnant woman (4), pneumonia } \\
(1) \text {, kidneys, ( } 1 \text { ) syphilis (3), and cough (1) }\end{array}$ & 55 & 1.5 \\
\hline Malvaceae & Luehea divaricata Mart. & $\begin{array}{l}\text { uric acid (18), vertebral column (2), blood cleanser (1), throat } \\
\text { (1), flu (1), hemorrhoids ( } 7) \text {, intestine (1), pneumonia (8), } \\
\text { muscle relaxant (2), kidneys (3), cough (10), and tumors (4) }\end{array}$ & 58 & 1.5 \\
\hline
\end{tabular}

RF: Relative frequency; RI: Relative importance of the species.

traditional use as a blood cleansing, wound healing, and other conditions associated with infections, which seems to point to its possible antibiotic activity. Indeed, some studies have demonstrated the in vitro activity of its different extracts against promastigotes of Leishmania donovani [38]. A few others also showed experimentally its antiviral, antitumor activities, cellular proliferation activities, and inflammatory and immune response [39, 40]. On the basis of these aforementioned, it is possible that its use in the folk medicine may be related to its ability to modulate the immune system, which may enhance physiological mechanisms involved in resolving inflammation, pain, and wound healing. 
TABLE 5: Categories of diseases, indications, form of use, preparation and the informant consensus factor of the main medicinal plants from Nossa Senhora Aparecida do Chumbo District, Poconé, Mato Grosso, Brazil.

\begin{tabular}{|c|c|c|c|c|c|c|}
\hline $\begin{array}{l}\text { Disease category/CID, 10th } \\
\text { ed. }\end{array}$ & Medicinal plants & Main indications & $\begin{array}{l}\text { Main forms } \\
\text { of use }\end{array}$ & $\begin{array}{c}\text { Part utilized/ } \\
\text { State of the } \\
\text { plant }\end{array}$ & Species/citations & ICF \\
\hline $\begin{array}{l}\text { Injuries, poisoning, and } \\
\text { certain other consequences } \\
\text { of external causes_- XIX }\end{array}$ & $\begin{array}{c}\text { Scoparia dulcis L. } \\
\text { Solidago microglossa } \\
\text { D. C Lafoensia pacari } \\
\text { A. St.-Hil. }\end{array}$ & $\begin{array}{l}\text { inflammation and } \\
\text { pain }\end{array}$ & $\begin{array}{l}\text { Inf, Dec, } \\
\text { Mac, and Tin }\end{array}$ & $\begin{array}{l}\mathrm{L}, \mathrm{Wp}, \mathrm{Rt}(\mathrm{Fr} \\
\text { Dr })\end{array}$ & $65 / 286$ & 0.78 \\
\hline $\begin{array}{l}\text { Mental and behavioural } \\
\text { disorders - V }\end{array}$ & $\begin{array}{l}\text { Chamomilla recutita } \\
\text { (L.) Rauschert. }\end{array}$ & soothing & Dec and Inf & $\mathrm{L}(\mathrm{In}, \mathrm{Sc})$ & $20 / 85$ & 0.77 \\
\hline $\begin{array}{l}\text { Symptoms, signs, and } \\
\text { abnormal clinical and } \\
\text { laboratory findings not } \\
\text { elsewhere classified-XVIII }\end{array}$ & $\begin{array}{l}\text { Macrosiphonia } \\
\text { longiflora (Desf.) } \\
\text { Müll. Arg. }\end{array}$ & blood depurative & $\begin{array}{c}\text { Inf, Dec, and } \\
\text { Mac }\end{array}$ & $\mathrm{Rz}(\mathrm{Fr}, \mathrm{Dr})$ & $176 / 713$ & 0.75 \\
\hline $\begin{array}{l}\text { Diseases of the } \\
\text { genitourinary system } \\
\text {-XIV }\end{array}$ & $\begin{array}{l}\text { Palicourea coriacea } \\
\text { (Cham.) K. Schum. }\end{array}$ & Kidneys and diuretic & $\begin{array}{c}\text { Inf, Dec, and } \\
\text { Syr }\end{array}$ & $\mathrm{L}(\mathrm{Fr}, \mathrm{Dr})$ & $132 / 533$ & 0.75 \\
\hline $\begin{array}{l}\text { Diseases of the digestive } \\
\text { system-XI }\end{array}$ & $\begin{array}{c}\text { Plectranthus barbatus } \\
\text { Andrews }\end{array}$ & $\begin{array}{l}\text { stomach, pain, liver, } \\
\text { and malaise }\end{array}$ & $\begin{array}{c}\text { Dec, Inf, } \\
\text { Mac, and Juc }\end{array}$ & $\mathrm{L}(\mathrm{Fr}, \mathrm{Dr})$ & $113 / 428$ & 0.74 \\
\hline $\begin{array}{l}\text { Other infectious and } \\
\text { parasitic diseases-I }\end{array}$ & $\begin{array}{l}\text { Chenopodium } \\
\text { ambrosioides L. }\end{array}$ & verminose & $\begin{array}{l}\text { Inf, Mac, and } \\
\text { Juc }\end{array}$ & $\mathrm{L}(\mathrm{Fr}, \mathrm{Dr})$ & $82 / 300$ & 0.73 \\
\hline $\begin{array}{l}\text { Diseases of the respiratory } \\
\text { system-X }\end{array}$ & Mentha pulegium L. & $\begin{array}{l}\text { flu, bronchitis, colds, } \\
\text { and cough }\end{array}$ & $\begin{array}{c}\text { Dec, Inf, } \\
\text { Mac, and Syr }\end{array}$ & $\mathrm{L}(\mathrm{Fr}, \mathrm{Dr})$ & $88 / 303$ & 0.71 \\
\hline $\begin{array}{l}\text { Pregnancy, childbirth, and } \\
\text { the puerperium-XV }\end{array}$ & $\begin{array}{l}\text { Dorstenia brasiliensis } \\
\text { Lam. }\end{array}$ & childbirth & $\begin{array}{l}\text { Dec, Inf, and } \\
\text { Syr }\end{array}$ & $\mathrm{Rz}$ (Fr, Dr) & $9 / 28$ & 0.70 \\
\hline $\begin{array}{l}\text { Diseases of the circulatory } \\
\text { system-IX }\end{array}$ & $\begin{array}{l}\text { Alpinia speciosa (J. C. } \\
\text { Wendl.) K. Schum. }\end{array}$ & $\begin{array}{l}\text { Hypertension and } \\
\text { heart }\end{array}$ & Inf and Mac & $\mathrm{L}(\mathrm{Fr}, \mathrm{Dr})$ & $56 / 180$ & 0.69 \\
\hline $\begin{array}{l}\text { Some disorders originating } \\
\text { in the perinatal } \\
\text { period-XVI }\end{array}$ & Bidens pilosa $\mathrm{L}$. & Hepatitis and enteric & Dec and Inf & $\mathrm{L}(\mathrm{In}, \mathrm{Sc})$ & $3 / 7$ & 0.67 \\
\hline $\begin{array}{l}\text { Diseases of blood and } \\
\text { blood forming organs and } \\
\text { certain disorders involving } \\
\text { the immune system-III }\end{array}$ & $\begin{array}{c}\text { Strychnos } \\
\text { pseudoquina A. } \\
\text { St.-Hil. }\end{array}$ & anemia & $\begin{array}{c}\text { Inf, Mac, and } \\
\text { Syr }\end{array}$ & $\mathrm{B}(\mathrm{Fr}, \mathrm{Dr})$ & $15 / 38$ & 0.62 \\
\hline $\begin{array}{l}\text { Diseases of the eye and the } \\
\text { surrounding } \\
\text { structures_-VII }\end{array}$ & Malva sylvestris $\mathrm{L}$. & $\begin{array}{l}\text { Discharge and } \\
\text { conjuctivitis }\end{array}$ & Inf and Tin & $\mathrm{L}(\mathrm{Fr}, \mathrm{Dr})$ & $6 / 14$ & 0.61 \\
\hline $\begin{array}{l}\text { Diseases of endocrine of } \\
\text { nutritional and metabolic } \\
\text { origins_-IV }\end{array}$ & Cissus cissyoides $\mathrm{L}$. & diabetes & Inf & $\mathrm{L}(\mathrm{Fr}, \mathrm{Dr})$ & $47 / 109$ & 0.57 \\
\hline $\begin{array}{l}\text { Diseases of the ear and } \\
\text { mastoid process-VIII }\end{array}$ & $\begin{array}{l}\text { Himatanthus obovatus } \\
\text { (Müll. Arg.) Woodson }\end{array}$ & labyrinthitis & $\operatorname{Inf}$ & $\mathrm{L}(\mathrm{Fr}, \mathrm{Dr})$ & $7 / 15$ & 0.57 \\
\hline $\begin{array}{l}\text { Diseases of musculoskeletal } \\
\text { and connective } \\
\text { tissue-XIII }\end{array}$ & $\begin{array}{l}\text { Solidago microglossa } \\
\text { DC. }\end{array}$ & bone fractures & $\begin{array}{c}\text { Dec, Inf, } \\
\text { Mac, and Tin }\end{array}$ & $\mathrm{L}(\mathrm{Fr}, \mathrm{Dr})$ & $70 / 146$ & 0.52 \\
\hline $\begin{array}{l}\text { Diseases of the skin and } \\
\text { subcutaneous tissue-XII }\end{array}$ & $\begin{array}{c}\text { Dioscorea brasiliensis } \\
\text { Willd. }\end{array}$ & furuncules & $\begin{array}{l}\text { Dec, Inf, } \\
\text { Mac, Tin, } \\
\text { and Out }\end{array}$ & $\mathrm{Rz}(\mathrm{Fr}, \mathrm{Dr})$ & $29 / 51$ & 0.44 \\
\hline Neoplasia (tumors)_-II & Aloe barbadensis Mill. & wound healing & $\begin{array}{l}\text { Dec, Inf, } \\
\text { Mac, Tin, } \\
\text { and Out }\end{array}$ & $\mathrm{L}(\mathrm{Fr}, \mathrm{Dr})$ & $22 / 38$ & 0.43 \\
\hline $\begin{array}{l}\text { Diseases of the nervous } \\
\text { system-VI }\end{array}$ & $\begin{array}{l}\text { Macrosiphonia } \\
\text { longiflora (Desf.) } \\
\text { Müll. Arg. }\end{array}$ & leakage & $\operatorname{Inf}$ & & $14 / 16$ & 0.13 \\
\hline
\end{tabular}

CID, 10th ed. categories of diseases in chapters according to International Classification of Diseases and Related Health Problems, 10th. edition [25]; ICF: informant consesus factor; Inf: infusion, Dec: decoction, Syr: syrup, Mac: maceration, Sal: salad, Tin: tinture, Juc: juice, Out: others (compression and bath). L: leave; Wp: whole plant; Rt: root; Rz: rhizome; B: bark. State of the plant: Fr: fresh; Dr: dried. 
We did not encounter any literature pertaining to its use in anemia, nosebleeding, muscle relaxant, deworming, or vitiligo treatment. Its indications as a blood cleansing and as antihypercholesterolemic are important targets for future biomedical research.

Hibiscus sabdariffa calyces are used in many parts of the world to make cold and hot drinks as well as in folk medicine [41]. Due to its many health-enhancing benefits, extensive works have been carried to validate its traditional therapeutic claims. In fact, its medicinal importance is widely acknowledged in many traditional herbal systems [42].

The benefits associated with the use of $H$. sabdariffa may in part be due to its high content of beneficial phytochemical constituents. These include alkaloids, L-ascorbic acid, anisaldehyde, anthocyanin, $\beta$-carotene, $\beta$-sitosterol, citric acid, cyanidin-3-rutinoside, delphinidin, galactose, gossypetin, hibiscetin, mucopolysaccharide, pectin, protocatechuic acid, polysaccharide, quercetin, stearic acid, and flavonoids [42, 43]. Studies have highlighted the role of polyphenol acids, flavonoids, and anthocyanins that may act as antioxidants or through other mechanisms that may contribute to its cardioprotective activity [44, 45].

In additions to folkloric use of $H$. sabdariffa noted in this study, other previous reports have indicated its use in the treatment of liver disease, hypocholesterolemic, antispasmodic, intestinal antiseptic, sedative, and as mild laxative $[42,46]$. The most extensively studied is its antihypertensive activity. This effect was confirmed in several in vitro and animal studies [47-49]. The hypotensive effect of H. sabdariffa and its constituents may be mediated, at least partially, by a cholinergic and/or histaminergic mechanism and it has been confirmed to act via inhibitiory action on angiotensin I converting enzyme, vasorelaxation [50], and diuretic action [51]. For detailed review on this aspect, see [41]. In addition to literature reports on the medicinal uses of this plant, we also report here its indications in the treatment of anxiety and labyrinthitis and as anti-snake venom. To the best of our knowledge, these indications remained to be proven experimentally.

In concordance with the traditional use of $H$. sabdariffa in the treatment of uterine inflammation and pain, its aqueous ethanol extract was shown experimentally to presents anti-inflammatory, uterine antispasmodic activities, and attenuation of intestinal spasm [52-54]. In addition to its confirmed pharmacological activities, its antiobese/weightreducing [50, 55], hepatoprotective [56-58], anticancer $[46,59,60]$, free-radical scavenging [61], antioxidant [42], immunomodulatory [62], lipid-lowering [43, 63] effects and attenuation of oxidants-mediated complications in diabetes [64] have been well documented. Besides, the plant extract is characterized by a very low degree of toxicity [41]. Moreover, apart from its medicinal uses, the plant seed oil was also shown to be a good source of lipidsoluble antioxidants, particularly $\gamma$-tocopherol, thus it could have important industrial applications [65].

Solidago microglossa is popularly known in Brazil as "arnica," "arnica-do-mato," "arnica-silvestre," "erva-federal," "arnica-vulgar," "erva-lanceta," and "rabo-de-rojão" [66]. It is usually confused with Arnica montana L., a native of the mountainous regions of Europe, due to the similarity in their medicinal flowers and having the same color (yellow), S. microglossa is not cultivated in Brazil due to it low adaptation to the tropical conditions [66]. In our study, S. microglossa was indicated for treatment of 15 different diseases corresponding to 8 classes of CID, 10th ed. and had a total of 49 citations. The key citations for this plant were its use in wound healing and blood cleansing. Other popular indications found in this study were similar to those previously reported, especially its use in the treatment of wounds, acne, bruises, and stomach-related ailments [67].

Several classes of compounds and metabolites have been isolated from $S$. microglossa, especially phenols, acetophenones, carotenoids, lactones (helenalin and dihydrohelenalin) [68, 69], flavonoids [70, 71] saponins [72], and polyacetylenes [70]. The cicatrizant activity of the plant's extract has been confirmed experimentally [73]. Although not mentioned directly by respondents in this study, some lines of evidence suggest important antibiotic activity with the use of $S$. microglossa, which can justify its indication for uterine inflammation. Morel et al. [74] showed that the essential oil of $S$. microglossa and three of its components (quercetrin, $\alpha$-espinasterol, and solidagenone) are capable of significantly inhibiting the growth of Staphylococcus aureus, Staphylococcus epidermidis, Klebsiella pneumoniae, Escherichia coli, Salmonella setubal, Bacillus subtilis, Pseudomonas aeruginosa, Saccharomyces cerevisiae, and Candida albicans [74]. In addition, cicatrizant activity was observed with the administration of the plant's extract [73]. Its use in ameliorating renal ailments, blood cleansing, and hypotensive and antiparasitic activities may be associated with the presence in high concentrations of tannins $[75,76]$ and flavonoids in this species [76-79]. Its indication for muscle relaxation may also derive from its antispasmodic effect [80]. Further studies are warranted in these regards.

Other pharmacological properties not mentioned here, but have been established in preclinical studies, include hypoglycemic effect [81] and antitumor activity. In fact, the latter effect has attracted intense interest in the discovery of new chemotherapeutic agents. The extract of S. microglossa demonstrated antiproliferative effect (but not mutagenic) against young shoot cells of onion (Allium cepa) strain [82]. Some of these activities may be related to the presence of secondary metabolites such as helenalin [83].

Although Strychnos pseudoquina is referred to locally as "quinas", similar to the local name used for species such as Cinchona sp. (source of quinine), it has been shown to be inactive against Plasmodium berghei [84] contrary to its popular use in folk medicine elsewhere [84]. Theoretically, some of the indications may result from the classification bias in the community due to an erroneous popular cultural belief that plants referred to as "quinas" are useful for "anemic" patients infected with malaria parasite. This perhaps helps to explain why the highest indication for this plant in our study was to treat anemia.

Among the components isolated from S. pseudoquina metabolites are isoramnetin, strychnobiflavone, and 11diaboline metoxidiaboline [85]. Silva et al. [86] demonstrated the gastroprotective effect of $S$. pseudoquina in models 
of gastric lesions induced by nonsteroidal anti-inflammatory agents and some necrotizing agents, thus confirming its indication for gastric ulcer and stomach disorders as noted in this present study. On the other hand, its indication in wound healing has not been experimentally confirmed at least in the diabetic wound model in rats [87] or in local hemorrhage induced by Bothrops jararaca venom [88]. Other medicinal uses indicated like "blood depurative" and analgesic effect may be subject of future investigation as a potential agent with antinociceptive and metabolic disorders ameliorating effects. Regarding its toxicity, Santos et al. [81] showed that only the methanol extract (but not dichloromethane) from the leaves of $S$. pseudoquina have mutagenic effect in Salmonella strains TA98 (-S9) and TA100 (+ S9, -S9) and that it induces formation of micronuclei after acute treatment [81].

Dorstenia brasiliensis, known as "Carapiá" is a perennial herb of the early geological point of view, typical of the fields in southern Brazil, Paraguay, Uruguay, and Argentina $[89,90]$. Phytochemical analysis of roots of $D$. brasiliensis indicated the presence of dorstenic acid A and B (triterpenoids), isopimarane-type diterpenoid, and six different types of coumarins. The two triterpenoids showed moderate cytotoxicity against leukemia cells (L-1210 and HL-60) [91]. Furthermore, some authors have suggested that its use in cutaneow disease (such as psoriases and vitiligo) may be associated with the presence of furanocoumarins in the species of Dorstenia [92]. Bartericin A and $\mathrm{B}$, stigmasterol, isobavachalcone, 4-hydroxylonchocarpin, dorsmanin F, 6,8-diprenyleridictyol, quercetin, quercitrin, amentoflavone [93], psoralen, bergapten (from rhizome), and umbelliferone [94] are some of the compounds isolated this medicinal plant.

Some few pharmacological studies have demonstrated analgesic and anti-inflammatory activities of $D$. brasiliensis in animal models [95]. These data corroborated the popular use of $D$. brasiliensis as an analgesic. There is dearth of information confirming its use in the popular medicine use as an anti-inflammatory agent. Moreover, $D$. brasiliensis may possesses some biologically active compounds similar to other Dorstenia species from the same genus and may thus share similar pharmacological profile. The following compounds and pharmacological activities have been reported in other Dorstenia species: chalcones (D. prorepens and $D$. zenkeri) [96], furocoumarins (D. bahiensis and D. bryoniifolia), triterpenes (D. bahiensis, D. bryoniifolia, D. carauntae, $D$. cayapiaa, and D. heringerii) [97]. This is a point to be noted for future research. Some authors have investigated its potential use as antivenom, antiinfective, anti-rheumatic $[96,97]$ while others established its antitrichomonal [93], antitussive [98], antioxidant [93, 99] and antileishmanial [100] activities.

Scoparia dulcis, popularly known as "vassourinha", grows wild in backyards, gardens, and fields in Brazil. Phytochemical studies have identified the presence of more than 12 interesting pharmacologically active compounds in this species, namely, scoparic acid A [101], isodulcinol, 4-epi-scopadulcic acid B, dulcidiol, scopanolal, dulcinol/scopadulciol, scopadiol [102], scoparinol [103], scopadulcic acid B [104-106], glutinol [107] and scopadulin [105]. Scopadulcic acid B inhibited the effects of tumor promoter 12-O-tetradecanoylphorbol-13-acetate (TPA) in vitro and in vivo, and also suppressed the promoting effect of TPA on skin tumor formation, demonstrating stronger effect than antitumor-promoting terpenoids, such as glycyrrhetinic acid [104]. In fact, its cytotoxicity has been investigated against antitumor activity [102] and nerve growth factor-mediated neurite outgrowth and neurodegenerative disorders [103, 108].

The analgesic and anti-inflammatory activities of ethanol extracts of $S$. dulcis and glutinol have been demonstrated in writhing induced by acetic acid and carrageenan-induced paw edema, respectively [107]. However, S. dulcis extracts were ineffective in the central pain models (tail flick) and paw edema induced by dextran. Another secondary metabolite, scoparinol, also showed significant analgesic and anti-inflammatory activity [109]. In regard to its toxicological effects, it is worthwhile to mention that glutinol and scoparinol markedly potentiated pentobarbital-induced sedation and duration of sleeping time in these two studies mentioned above.

In contrast to its toxicity, $S$. dulcis seems to possess potential hepatoprotective activity in different models, which have been attributed to its free-radical scavenging potential activities [110-113]. Corroborating with antibiotic use for some infections (like gonorrhea), some authors have investigated inhibition of multidrug resistance (MDR) bacteria, fungi $[114,115]$, leishmanial parasite [116], and herpes simplex virus type 1 growths [96].

Paradoxically, despite the low citation in gastric ulcer and diabetes treatments in this study, the antiulcer and antihyperglycemic activities of this species are well documented. Inhibitory activities of $S$. dulcis extracts was demonstrated in pylorus ligature model, histamine- or bethanechol-stimulated gastric secretion, and acute gastric lesions induced by indomethacin $[117,118]$. S. dulcis was also demonstrated to inhibit both proton pump $\left(\mathrm{H}^{+}, \mathrm{K}^{+}-\right.$ ATPase) and proton transport into gastric vesicles [105]. In regard to its antihyperglycemic effect, experimental evidences demonstrated that $S$. dulcis extracts reduced blood glucose, glycosylated haemoglobin, prevented decrease in the body weight, and improved glucose tolerance similarly with glibenclamide [119]. Even in the insulin resistance stage, $S$. dulcis-treated L6 myotubes were found to be more capable of stimulating glucose transport than insulin treatment [120]. In addition, scoparic acid D was able to stimulate insulin secretion and receptor binding in streptozotoci- (STZ-) induced diabetic rats [121].

Luehea divaricata is a native tree of the Brazilian Cerrado popularly known as "açoita-cavalo". Just as popularly indicated, some studies have reported the following pharmacological activities of L. divaricata: the leaves as used as diuretic, the stems as anti-inflammatory, the bark and aerial parts are used for healing skin wounds, pimples, and for vaginal washes [122, 123].

Phytochemical screening of $L$. divaricata reported the presence of flavonoids, tannins and saponins and afforded the presence of 3b-p-hydroxybenzoyl-tormentic acid [124], 
maslinic acid [122], vitexin and glucopyranosylsitosterol, and (-)-epicatechin [123].

The presence of flavonoids and metabolites such as the vitexin $[125,126]$ and maslinic acid $[127,128]$ may be associated with the popular indication of its antiinflammatory properties formation of urate (18) and antitumor (4). Extracts of $L$. divaricata has been shown to have antioxidant activity and analgesic property [129], lack toxicity in vivo [130], or mutagenicity [131]. Its extract also showed cytotoxicity against tumor cell lines [123]. Due to the high level of citation for the treatment of urate aleviation (18), we believe that its antigout or uricosuric activity may be an important target of pharmacological interest. Another indication prominently cited by the respondents is the use of $L$. divaricata in the treatment of lung diseases and upper airway. However, there is no scientific evidence on its regulatory activity on cough, while its antibiotic properties also vary. Some authors have demonstrated its inhibitory effect on the growth of dermatophytes [132] but not in other fungi species $[123,129]$. In addition, the extract of $L$. divaricata was shown to strongly inhibit the growth of S. aureus, S. epidermitis, K. pneumonia, and E. coli in a study [129] but showed only moderately in another study elsewhere [123].

It is worth mentioning that although Lafoensia pacari A.St.-Hil. had low relative importance value, all the same, it is among the three plants with the highest informant consesus factor in addition to being a native plant in the region. The other two (S. dulcis and S. microglossa) have been discussed previously.

L. pacari popularly called "mangava-brava", belongs to the family Lythraceae, is a tree native to the Brazilian Cerrado [133]. It is commonly used for gastrointestinal disorders, wound healing, diarrhea, and kidney problems. In our study, it was referenced for the treatment of seven disorders distributed into five classes of CID, 10th ed. Preliminary phytochemical studies of methanol extract of the stem bark of $L$. pacari revealed the presence of free steroids, saponins, tannins catechins, pyrogalic tannins (in particular, ellagic acid), triterpenoids, simple phenols, strong and weak fixed acids, alkali, and quaternary amino acids [134-136]. Acute toxicity studies or subchronic oral administration of extracts of $L$. pacari did not indicate any harmful effects [137]. However, it is also indicated for its adverse reactions and used as an abortifacient, diarrheic, weight loss, and tachycardia. Among the 42 citations for L. pacari, 29 were for the treatment of ulcer, and four and two for gastritis and stomach, respectively. These indications have been confirmed with the use of methanol crude extract of $L$. pacari and its major active components, ellagic acid, in different experimental ulcer models [138-143]. In addition, the antiulcer activity of the methanol extract (capsules) of L. pacari was confirmed in the clinical trial with 55 patients with dyspepsia [144].

We did not encounter any studies concerning its activities in wound healing, antidiarrheal or alleviation of kidney disorders. This phenomenon of plant selection by local people for certain indications may be, for instance, to consolidate best practice of the medicinal properties of the plants at the expense of using other plants substitute for these indications. In fact, the broad community access to Amazon or Pantanal biome, and the close relationship with the indigenous native populations, promotes a variety of possibilities of ethnobotanical indications. Examples of other popular uses of $L$. pacari that have been experimentally confirmed includes weight loss [145], anorectic effect [142], antipyretic activity [146], anti-inflammatory [147], antiallergic [148], and analgesic property [149].

It is also worth mentioning other studies focused on the medicinal uses of $L$. pacari, including its potent antifungal activity [150], have demonstrated that the main compound responsible is found in the methanol extract of this plant. A patent application of lotion with the infusion prepared from the leaves of $L$. pacari, as a component of the formulation was also solicited [151]. To the best of our knowledge, there is currently no available literature concerning its claims as wound healing, antidiarrheal, or in kidney disorders.

\section{Conclusions}

The present study identified the several plant species and their medicinal uses in NSACD highlighting significant cultural diversity in the Pantanal region. In fact, one of the important components of this community is the contribution of Amerindian culture, which highlights its importance in the identification of indigenous popular knowledge relevance in the identification of native popular knowledge.

Analytically, the data were categorized according to the highest values of relative importance and consensus among informants, ensuring the best evidence for ethnobotanical bioprospecting of medicinal plants. Thus, we identified seven native species with the highest relative importance, which are $H$. obovatus, $H$. sabdariffa, S. microglossa, S. pseudoquina and $D$.brasiliensis, S. dulcis, and L. divaricata including L. pacari. The three plants with the highest value of consensus among informants were S. dulcis, S. microglossa, and L. pacari.

The preservation of local culture, the practice of traditional medicinal plant species themselves represent important strategies for sustenance of popular knowledge of CAM in the local systems of health care and environmental education. Moreover, ethnobotanical and pharmacological studies provide information essential for guidance in bioprospecting for new drugs of plant origin in the consolidation of therapeutic practices of the community.

\section{Acknowledgments}

The authors thank all the informants and staffs of Family Health Programme of NSACD, for the assistance and contributions made throughout ethnobotanical fieldwork, FAPEMAT and CNPq for granting scholarships, researcher, Dr. Rosilene Rodrigues Silva, UFMT Herbarium and Vali Joana Pott (MSc.) of CGMS Herbarium of Federal University of Mato Grosso do Sul, Campo Grande, for technical assistance in identification of plant species, National Institute for Science and Technology in Wetlands (INAU), National Council 
for Scientific and Technological Development CNPq/MCT, and Pantanal Research Center (CPP) for funding the research work.

\section{References}

[1] OMS, Organización Mundial DE La Salud. Estrategia de la OMS sobre medicina tradicional 2002-2005, OMS, Geneva, Switzerland, 2002.

[2] Brasil, "Ministério da Saúde. Portaria n 971. Aprova a Política Nacional de Práticas Integrativas e Complementares no SUS," Diário Oficial [da] República Federativa do Brasil, Poder Executivo, Brasília, DF, 2006.

[3] U. Cakilcioglu and I. Turkoglu, "An ethnobotanical survey of medicinal plants in Sivrice," Journal of Ethnopharmacology, vol. 132, no. 1, pp. 165-175, 2010.

[4] Brasil, "Flora, vegetação, etnobotânica-conservação de recursos vegetais no pantanal," Cuiabá, 2006.

[5] Mato Grosso, "Plano plurianual 2004-2007 do Governo do Estado," Projeto de lei. Seplan, MT. 2005.

[6] M. C. M. Amorozo, "Uso e diversidade de plantas medicinais em Santo Antônio do Leverger, MT," Acta Botanica Brasílica, vol. 16, no. 2, pp. 189-203, 2002.

[7] G. Guarim Neto, "O saber tradicional pantaneiro: as plantas medicinais e a Educação Ambiental," REMEA. Julho a dezembro, FURG/PPGEA. 2006.

[8] A. C. D. Diegues, O Mito Moderno da Natureza Intocada, Hucitec, São Paulo, Brazil, 1998.

[9] Poconé, "Plano Municipal de Saúde de Poconé. Prefeitura Muncipal de Poconé. Secretaria municipal de Saúde," Poconé - MT, 2010.

[10] R. L. Scheaffer, W. Mendnhall, and L. Ott, Elementos de Muestreo, Editora Iberoamericana, México, 1987.

[11] H. Bolfarine and W. O. Bussab, Elementos de amostragem, Edgar Blucher, São Paulo, Brazil, 2005.

[12] Brasil, "Ministério do Desenvolvimento, Indústria e Comércio," Sistema Aliceweb: informações sobre o comércio exterior brasileiro. Brasília, 2007.

[13] P. S. Levy and S. Lemeshow, Sampling of populations. Methods and Applications, John Wiley \& Sons, New York, NY, USA, 2008.

[14] M. Pio Correa, "Dicionário das plantas úteis do Brasil e das exóticas cultivadas," Instituto Brasileiro de Desenvolvimento Florestal, IBDF, Rio de Janeiro, 6 v.il. 1926-1969.

[15] A. C. Diegues, "Etnoconservação na natureza: enfoques alternativos," in Etnoconservação, novos rumos para a conservação da natureza nos trópicos, A. C. Diegues, Ed., pp. 1-46, Hucitec Nupaub-USP, São Paulo, Brazil, 2000.

[16] A. M. Borba and M. Macedo, "Medicinal plants used for oral health in the Santa Cruz neighborhood, Chapada dos Guimarães, Mato Grosso State, Brazil," Acta Botanica Brasilica, vol. 20, no. 4, pp. 771-782, 2006.

[17] M. C. Pasa, J. J. Soares, and G. Guarim Neto, "Estudo etnobotânico na comunidade de Conceição-Açu (alto da bacia do rio Aricá Açu, MT, Brasil)," Acta Botanica Brasilica, vol. 19, no. 2, pp. 195-207, 2004.

[18] M. G. De La Cruz, Plantas Medicinais de Mato Grosso-A Farmacopéia Popular dos Raizeiros, Ed. Carlini e Caniato Editorial, 2008.

[19] V. J. Pott and A. Pott, Plantas do Pantanal, EMBRAPA-CPAP, Brasília, Brazil, 1994.
[20] A. Cronquist, The evolution classification of flowering plants, The New York Botanical Garden, New York, NY, USA, 2nd edition, 1988.

[21] Missouri Botanical Garden - MOBOT, April 2010, http:// www.tropicos.org/.

[22] B. C. Bennett and G. T. Prance, "Introduced plants in the indigenous pharmacopoeia of northern South America," Economic Botany, vol. 54, no. 1, pp. 90-102, 2000.

[23] G. L. de Oliveira, A. F. M. de Oliveira, and L. H. C. Andrade, "Medicinal plants used in the urban community of Muribeca, Northeast Brazil," Acta Botanica Brasilica, vol. 24, no. 2, pp. 571-577, 2010.

[24] Brasil, "Classificação Internacional de Doenças e de Problemas Relacionados a Saúde,” Décima Revisão - CID-10, DATASUS. 2008.

[25] D. M. Eisenberg, R. B. Davis, S. L. Ettner et al., "Trends in alternative medicine use in the United States, 19901997: results of a follow-up national survey," Journal of the American Medical Association, vol. 280, no. 18, pp. 15691575, 1998.

[26] G. A. Taddei-Bringas, M. A. Santillana-Macedo, J. A. Romero-Cancio, and M. B. Romero-Téllez, "Acceptance and use of therapeutic medical plants in family medical care," Salud Publica de Mexico, vol. 41, no. 3, pp. 216-220, 1999.

[27] T. H. Bekalo, S. D. Woodmatas, and Z. A. Woldemariam, "An ethnobotanical study of medicinal plants used by local people in the lowlands of Konta Special Woreda, southern nations, nationalities and peoples regional state, Ethiopia," Journal of Ethnobiology and Ethnomedicine, vol. 5, article no. 26, 2009.

[28] I. G. C. Bieski, Plantas Medicinais e Aromáticas no Sistema Único de Saúde da Região Sul de Cuiabá-MT, Secretaria Municipal de Saúde de Cuiabá-MT, Lavras Minas Gerais Brazil, 2005.

[29] G. S. Vendruscolo and L. A. Mentz, "Study of use citations agreement and importance of medicinal used species and families to the community of Ponta Grossa neighborhood, Porto Alegre, Rio Grande do Sul State, Brazil," Acta Botanica Brasilica, vol. 20, no. 2, pp. 367-382, 2006.

[30] E. B. Santos, G. S. Dantas, H. B. Santos, M. F. F. Melo Diniz, and F. C. Sampaio, "Etnobotanical studies of medicinal plants for oral conditions in the municipality of João Pessoa, Brazil," Brazilian Journal of Pharmacognosy, vol. 19, no. 1B, pp. 321-324, 2009.

[31] B. Upadhyay, Parveen, A. K. Dhaker, and A. Kumar, "Ethnomedicinal and ethnopharmaco-statistical studies of Eastern Rajasthan, India," Journal of Ethnopharmacology, vol. 129, no. 1, pp. 64-86, 2010.

[32] D. J. Simbo, "An ethnobotanical survey of medicinal plants in Babungo, Northwest Region, Cameroon," Journal of Ethnobiology and Ethnomedicine, vol. 6, article no. 8, 2010.

[33] R. M. Polhill, "Papilionoideae," in Advances in Legume Systematics I, R. M. Polhill and P. H. Raven, Eds., pp. 191208, Royal Botanic Gardens, Kew, 1981.

[34] G. Lewis, B. Schrire, B. MacKinder, and M. Lock, Eds., Legumes of the World, Royal Botanical Gardens, Kew, UK, 2005.

[35] M. A. C. Pilla, M. C. D. M. Amorozo, and A. Furlan, "Acquisition and use of medicinal plants in Martim Francisco district, Mogi Mirim Municipality, São Paulo State, Brazil," Acta Botanica Brasilica, vol. 20, no. 4, pp. 789-802, 2006.

[36] U. P. Albuquerque et al., "Evaluating two quantitative ethnobotanical Techniques," Ethnobotany Research and Applications, vol. 4, pp. 051-060, 2006. 
[37] S. Akerreta, R. Y. Cavero, V. López, and M. I. Calvo, "Analyzing factors that influence the folk use and phytonomy of 18 medicinal plants in Navarra," Journal of Ethnobiology and Ethnomedicine, vol. 3, article no. 16, 2007.

[38] M. L. De Mesquita, J. Desrivot, C. Bories et al., "Antileishmanial and trypanocidal activity of Brazilian Cerrado plants," Memorias do Instituto Oswaldo Cruz, vol. 100, no. 7, pp. 783787, 2005.

[39] G. T. Tan, S. Lee, I. S. Lee et al., "Natural-product inhibitors of human DNA ligase I," Biochemical Journal, vol. 314, no. 3, pp. 993-1000, 1996.

[40] A. J. Vlietinck, T. De Bruyne, S. Apers, and L. A. Pieters, "Plant-derived leading compounds for chemotherapy of human immunodeficiency virus (HIV) infection," Planta Medica, vol. 64, no. 2, pp. 97-109, 1998.

[41] B. H. Ali, N. Al Wabel, and G. Blunden, "Phytochemical, pharmacological and toxicological aspects of Hibiscus sabdariffa L.: a review," Phytotherapy Research, vol. 19, no. 5, pp. 369-375, 2005.

[42] V. Hirunpanich, A. Utaipat, N. P. Morales et al., "Antioxidant effects of aqueous extracts from dried calyx of hibiscus sabdariffa Linn. (roselle) in vitro using rat low-density lipoprotein (LDL)," Biological and Pharmaceutical Bulletin, vol. 28 , no. 3, pp. 481-484, 2005.

[43] O. Carvajal-Zarrabal, S. M. Waliszewski, D. M. BarradasDermitz et al., "The consumption of Hibiscus sabdariffa dried calyx ethanolic extract reduced lipid profile in rats," Plant Foods for Human Nutrition, vol. 60, no. 4, pp. 153-159, 2005.

[44] R. S. Crawford, E. A. Kirk, M. E. Rosenfeld, R. C. LeBoeuf, and A. Chait, "Dietary antioxidants inhibit development of fatty streak lesions in the LDL receptor-deficient mouse," Arteriosclerosis, Thrombosis, and Vascular Biology, vol. 18, no. 9, pp. 1506-1513, 1998.

[45] E. B. Rimm and M. J. Stampfer, "Antioxidants for vascular disease," Medical Clinics of North America, vol. 84, no. 1, pp. 239-249, 2000.

[46] D. X. Hou, X. Tong, N. Terahara, D. Luo, and M. Fujii, "Delphinidin 3-sambubioside, a Hibiscus anthocyanin, induces apoptosis in human leukemia cells through reactive oxygen species-mediated mitochondrial pathway," Archives of Biochemistry and Biophysics, vol. 440, no. 1, pp. 101-109, 2005.

[47] F. B. O. Mojiminiyi, M. Dikko, B. Y. Muhammad et al., "Antihypertensive effect of an aqueous extract of the calyx of Hibiscus sabdariffa," Fitoterapia, vol. 78, no. 4, pp. 292-297, 2007.

[48] M. Haji Faraji and A. H. Haji Tarkhani, "The effect of sour tea (Hibiscus sabdariffa) on essential hypertension," Journal of Ethnopharmacology, vol. 65, no. 3, pp. 231-236, 1999.

[49] A. Herrera-Arellano, S. Flores-Romero, M. A. Chávez-Soto, and J. Tortoriello, "Effectiveness and tolerability of a standardized extract from Hibiscus sabdariffa in patients with mild to moderate hypertension: a controlled and randomized clinical trial," Phytomedicine, vol. 11, no. 5, pp. 375-382, 2004.

[50] M. Sarr, S. Ngom, M. O. Kane et al., "In vitro vasorelaxation mechanisms of bioactive compounds extracted from Hibiscus sabdariffa on rat thoracic aorta," Nutrition and Metabolism, vol. 6, article no. 45, 2009.

[51] V. Prasongwatana, S. Woottisin, P. Sriboonlue, and V. Kukongviriyapan, "Uricosuric effect of Roselle (Hibiscus sabdariffa) in normal and renal-stone former subjects,"
Journal of Ethnopharmacology, vol. 117, no. 3, pp. 491-495, 2008.

[52] A. A. Dafallah and Z. Al-Mustafa, "Investigation of the anti-inflammatory activity of acacia nilotica and hibiscus sabdariffa," American Journal of Chinese Medicine, vol. 24, no. 3-4, pp. 263-269, 1996.

[53] Beltran-Debon et al., "The aqueous extract of Hibiscus sabdariffa calices modulates the production of monocytechemo attractant protein-1 in humans," Phytomedicine, vol. 17, pp. 186-191, 2010.

[54] E.-S. Kao, J.-D. Hsu, C.-J. Wang, S.-H. Yang, S.-Y. Cheng, and H.-J. Lee, "Polyphenols extracted from hibiscus sabdariffa L. inhibited lipopolysaccharide-induced inflammation by improving antioxidative conditions and regulating cyclooxygenase-2 expression," Bioscience, Biotechnology and Biochemistry, vol. 73, no. 2, pp. 385-390, 2009.

[55] O. Carvajal-Zarrabal, P. M. Hayward-Jones, Z. Orta-Flores et al., "Effect of hibiscus sabdariffa L. dried calyx ethanol extract on fat absorption-excretion, and body weight implication in rats," Journal of Biomedicine and Biotechnology, vol. 2009, Article ID 394592, 5 pages, 2009.

[56] B. H. Ali, H. M. Mousa, and S. El-Mougy, "The effect of a water extract and anthocyanins of Hibiscus sabdariffa L. on paracetamol-induced hepatoxicity in rats," Phytotherapy Research, vol. 17, no. 1, pp. 56-59, 2003.

[57] T. H. Tseng, E. S. Kao, C. Y. Chu, F. P. Chou, H. W. Lin Wu, and C. J. Wang, "Protective effects of dried flower extracts of Hibiscus sabdariffa L. against oxidative stress in rat primary hepatocytes," Food and Chemical Toxicology, vol. 35, no. 12, pp. 1159-1164, 1997.

[58] J. Y. Liu, C. C. Chen, W. H. Wang, J. D. Hsu, M. Y. Yang, and C. J. Wang, "The protective effects of Hibiscus sabdariffa extract on CCl 4-induced liver fibrosis in rats," Food and Chemical Toxicology, vol. 44, no. 3, pp. 336-343, 2006.

[59] Y. C. Chang, H. P. Huang, J. D. Hsu, S. F. Yang, and C. J. Wang, "Hibiscus anthocyanins rich extract-induced apoptotic cell death in human promyelocytic leukemia cells," Toxicology and Applied Pharmacology, vol. 205, no. 3, pp. 201-212, 2005.

[60] H. H. Lin, J. H. Chen, W. H. Kuo, and C. J. Wang, "Chemopreventive properties of Hibiscus sabdariffa L. on human gastric carcinoma cells through apoptosis induction and JNK/p38 MAPK signaling activation," Chemico-Biological Interactions, vol. 165, no. 1, pp. 59-75, 2007.

[61] E. O. Farombi and A. Fakoya, "Free radical scavenging and antigenotoxic activities of natural phenolic compounds in dried flowers of Hibiscus sabdariffa L," Molecular Nutrition and Food Research, vol. 49, no. 12, pp. 1120-1128, 2005.

[62] T. O. Fakeye, A. Pal, D. U. Bawankule, and S. P. S. Khanuja, "Immunomodulatory effect of extracts of Hibiscus sabdariffa L. (family malvaceae) in a mouse model," Phytotherapy Research, vol. 22, no. 5, pp. 664-668, 2008.

[63] M. Y. Yang, C. H. Peng, K. C. Chan, Y. I. S. Yang, C. N. Huang, and C. J. Wang, "The hypolipidemic effect of Hibiscus sabdariffa polyphenols via inhibiting lipogenesis and promoting hepatic lipid clearance," Journal of Agricultural and Food Chemistry, vol. 58, no. 2, pp. 850-859, 2010.

[64] C. N. Huang, K. C. Chan, W. T. Lin, S. L. Su, C. J. Wang, and C. H. Peng, "Hibiscus sabdariffa inhibits vascular smooth muscle cell proliferation and migration induced by high glucoses-A mechanism involves connective tissue growth factor signals," Journal of Agricultural and Food Chemistry, vol. 57, no. 8, pp. 3073-3079, 2009.

[65] R. Mohamed, J. Fernández, M. Pineda, and M. Aguilar, "Roselle (Hibiscus sabdariffa) seed oil is a rich source of 
$\gamma$-tocopherol," Journal of Food Science, vol. 72, no. 3, pp. S207-S211, 2007.

[66] H. F. Lorenzi and F. J. A. Matos, Plantas Medicinais do Brasil, nativas e exóticas, Plantarum, São Paulo, Brazil, 1st edition, 2008.

[67] H. Lorenzi, Plantas medicinais no Brasil: nativas e exóticas cultivadas, Instituto Plantarum, Nova Odessa, Brazil, 2000.

[68] A. D. Corrêa, R. Siqueira-Batista, and L. E. M. Quintas, Plantas Medicinais - do Cultivo à Terapêutica-Rio de Janeiro, Editora Vozes, 1998.

[69] F. J. A. Matos, Plantas da medicina popular do Nordeste. Fortaleza, Edições UFC, 1999.

[70] L. Tiansheng, M. A. Menelaou, D. Vargas, F. R. Fronczek, and N. H. Fischer, "Polyacetylenes and diterpenes from Solidago canadensis Phytochemistry," The International Journal of Plant Biochemistry, vol. 32, no. 6, pp. 1483-1488, 1993.

[71] G. Reznicek, J. Jurenitsch, M. Plasun et al., "Four major saponins from Solidago canadensis," Phytochemistry, vol. 30, no. 5, pp. 1629-1633, 1991.

[72] G. Reznicek, J. Jurenitsch, G. Michl, and E. Haslinger, "The first structurally confirmed saponin from solidago gigantea: structure elucidation by modern NMR techniques," Tetrahedron Letters, vol. 30, no. 31, pp. 4097-4100, 1989.

[73] M. A. F. Neto, D. J. Fagundes, M. E. Beletti, N. F. Novo, Y. Juliano, and N. Penha-Silva, "Systemic use of Solidago microglossa DC in the cicatrization of open cutaneous wounds in rats," Brazilian Journal of Morphological Sciences, vol. 21, pp. 204-210, 2004.

[74] A. F. Morel, G. O. Dias, C. Porto, E. Simionatto, C. Z. Stuker, and I. I. Dalcol, "Antimicrobial activity of extractives of Solidago microglossa," Fitoterapia, vol. 77, no. 6, pp. 453455, 2006.

[75] H. Hoste, F. Jackson, S. Athanasiadou, S. M. Thamsborg, and S. O. Hoskin, "The effects of tannin-rich plants on parasitic nematodes in ruminants," Trends in Parasitology, vol. 22, no. 6, pp. 253-261, 2006.

[76] T. Yokozawa, T. Nakagawa, K. I. Lee, E. J. Cho, K. Terasawa, and S. Takeuchi, "Effects of green tea tannin on cisplatininduced nephropathy in LLC-PK1 cells and rats," Journal of Pharmacy and Pharmacology, vol. 51, no. 11, pp. 1325-1331, 1999.

[77] D. Grassi, G. Desideri, G. Croce, S. Tiberti, A. Aggio, and C. Ferri, "Flavonoids, vascular function and cardiovascular protection," Current Pharmaceutical Design, vol. 15, no. 10, pp. 1072-1084, 2009.

[78] Y. Huang, X. Q. Yao, S. Y. Tsang, C. W. Lau, and Z. Y. Chen, "Role of endothelium/nitric oxide in vascular response, to flavonoids and epicatechin," Acta Pharmacologica Sinica, vol. 21, no. 12, pp. 1119-1124, 2000.

[79] C. O. Van Den Broucke and J. A. Lemli, "Spasmolytic activity of the flavonoids from Thymus vulgaris," Pharmaceutisch Weekblad - Scientific Edition, vol. 5, no. 1, pp. 9-14, 1983.

[80] K. G. Kissmam and D. Groth, Plantas infestantes e nocivas, vol. 2, BASF, São Paulo, Brazil, 2nd edition, 1999.

[81] F. V. Santos, I. M. S. Colus, M. A. Silva, W. Vilegas, and E. A. Varanda, "Assessment of DNA damage by extracts and fractions of Strychnos pseudoquina, a Brazilian medicinal plant with antiulcerogenic activity," Food and Chemical Toxicology, vol. 44, no. 9, pp. 1585-1589, 2006.

[82] M. D. Bagatini, J. M. Fachinetto, A. C. F. Da Silva, and S. B. Tedesco, "Cytotoxic effects of infusions (tea) of Solidago microglossa DC. (Asteraceae) on the cell cycle of Allium cepa," Brazilian Journal of Pharmacognosy, vol. 19, no. 2B, pp. 632-636, 2009.
[83] D. Boulanger, E. Brouillette, F. Jaspar et al., "Helenalin reduces Staphylococcus aureus infection in vitro and in vivo," Veterinary Microbiology, vol. 119, no. 2-4, pp. 330-338, 2007.

[84] V. F. Andrade-Neto, M. G. L. Brandão, J. R. Stehmann, L. A. Oliveira, and A. U. Krettli, "Antimalarial activity of Cinchona-like plants used to treat fever and malaria in Brazil," Journal of Ethnopharmacology, vol. 87, no. 2-3, pp. 253-256, 2003.

[85] M. Nicoletti, M. O. F. Goulart, R. A. De Lima, A. E. Goulart, F. Delle Monache, and G. B. M. Bettolo, "Flavonoids and alkaloids from Strychnos pseudoquina," Journal of Natural Products, vol. 47, no. 6, pp. 953-957, 1984.

[86] M. Aparecido Da Silva, B. P. Murino Rafacho, C. A. HirumaLima et al., "Evaluation of Strychnos pseudoquina St. Hil. leaves extract on gastrointestinal activity in mice," Chemical and Pharmaceutical Bulletin, vol. 53, no. 8, pp. 881-885, 2005.

[87] A. C. Honorio-Franca, C. M. Marins, F. Boldrini, and E. L. Franca, "Evaluation of hypoglicemic activity and healing of extract from amongst bark of "Quina do Cerrado" (Strychnos pseudoquina ST. HILL)," Acta Cirurgica Brasileira, vol. 23, pp. 504-510, 2008.

[88] C. M. Nishijima, C. M. Rodrigues, M. A. Silva, M. Lopes-Ferreira, W. Vilegas, and C. A. Hiruma-Lima, "Antihemorrhagic activity of four brazilian vegetable species against Bothrops jararaca venom," Molecules, vol. 14, no. 3, pp. 1072-1080, 2009.

[89] I. B. Noll, Isolamento, identificação e doseamento de furanocumarinas, M.S. thesis, Universidade Federal do Rio Grande do Sul, Porto Alegre, 1984.

[90] C. M. O. Simões et al., Plantas da medicina popular do Rio Grande do Sul, Editora da Universidade, Porto Alegre, 1996.

[91] T. Uchiyama, S. Hara, M. Makino, and Y. Fujimoto, "secoadianane-type triterpenoids from Dorstenia brasiliensis (moraceae)," Phytochemistry, vol. 60, no. 8, pp. 761-764, 2002.

[92] C. A. L. Cardoso, W. Vilegas, A. Barison, and N. K. Honda, "Simultaneous determination of furanocoumarins in infusions and decoctions from "Carapiá" (Dorstenia species) by high-performance liquid chromatography," Journal of Agricultural and Food Chemistry, vol. 50, no. 6, pp. 14651469, 2002.

[93] N. O. A. Omisore, C. O. Adewunmi, E. O. Iwalewa et al., "Antitrichomonal and antioxidant activities of Dorstenia barteri and Dorstenia convexa," Brazilian Journal of Medical and Biological Research, vol. 38, no. 7, pp. 1087-1094, 2005.

[94] C. M. Garcia, Estudo fitoquímico e atividade biológica de Pavonia distinguenda A.ST.- HILL. et NAUDIN E Dorstenia brasiliensis LAM, Ph.D. thesis, Universidade Federal de Santa Maria - RS, 2007.

[95] B. M. Ruppelt, E. F. Pereira, L. C. Gonçalves, and N. A. Pereira, "Pharmacological screening of plants recommended by folk medicine as anti-snake venom-I. Analgesic and anti-inflammatory activities," Memorias do Instituto Oswaldo Cruz, vol. 86, pp. 203-205, 1991.

[96] B. M. Abegaz, B. T. Ngadjui, E. Dongo, B. Ngameni, M. N. Nindi, and M. Bezabih, "Chalcones and other constituents of Dorstenia prorepens and Dorstenia zenkeri," Phytochemistry, vol. 59, no. 8, pp. 877-883, 2002.

[97] J. H. Y. Vilegas, F. M. Lanças, W. Vilegas, and G. L. Pozetti, "Further triterpenes, steroids and furocoumarins from Brazilian medicinal plants of Dorstenia genus (Moraceae)," Journal of the Brazilian Chemical Society, vol. 8, no. 5, pp. 529-535, 1997. 
[98] M. De Fátima Agra, P. F. De Freitas, and J. M. Barbosa-Filho, "Synopsis of the plants known as medicinal and poisonous in Northeast of Brazil," Brazilian Journal of Pharmacognosy, vol. 17, no. 1, pp. 114-140, 2007.

[99] L. Balestrin, J. F. Gaspari Dias, O. G. Miguel, D. S. G. Dall'Stella, and M. D. Miguel, "Contribution to the phytochemical study of Dorstenia multiformis Miquel (Moraceae) with approach in antioxidant activity," Brazilian Journal of Pharmacognosy, vol. 18, no. 2, pp. 230-235, 2008.

[100] M. M. Iwu, J. E. Jackson, J. D. Tally, and D. L. Klayman, "Evaluation of plant extracts for antileishmanial activity using a mechanism-based radiorespirometric microtechnique (RAM)," Planta Medica, vol. 58, no. 5, pp. 436-441, 1992.

[101] M. Kawasaki, T. Hayashi, M. Arisawa et al., "Structure of scoparic acid A, a new labdane-type diterpenoid from A Paraguayan crude drug 'Typycha Kuratu' (Scoparia Dulcis L.)," Chemical and Pharmaceutical Bulletin, vol. 35, no. 9, pp. 3963-3966, 1987.

[102] M. Ahsan, S. K. N. Islam, A. I. Gray, and W. H. Stimson, "Cytotoxic diterpenes from Scoparia dulcis," Journal of Natural Products, vol. 66, no. 7, pp. 958-961, 2003.

[103] Y. Li, X. Chen, M. Satake, Y. Oshima, and Y. Ohizumi, "Acetylated flavonoid glycosides potentiating NGF action from Scoparia dulcis," Journal of Natural Products, vol. 67, no. 4, pp. 725-727, 2004.

[104] H. Nishino, T. Hayashi, M. Arisawa, Y. Satomi, and A. Iwashima, "Antitumor-promoting activity of scopadulcic acid B, isolated from the medicinal plant Scoparia dulcis L," Oncology, vol. 50, no. 2, pp. 100-103, 1993.

[105] T. Hayashi, K. Okamura, M. Kakemi et al., "Scopadulcic acid B, a new tetracyclic diterpenoid from Scoparia dulcis L. Its structure, $\mathrm{H}+, \mathrm{K}+$-adenosine triphosphatase inhibitory activity and pharmacokinetic behaviour in rats," Chemical and Pharmaceutical Bulletin, vol. 38, no. 10, pp. 2740-2745, 1990.

[106] K. Hayashi, S. Niwayama, T. Hayashi, R. Nago, H. Ochiai, and N. Morita, "In vitro and in vivo antiviral activity of scopadulcic acid B from Scoparia dulcis, Scrophulariaceae, against herpes simplex virus type 1," Antiviral Research, vol. 9, no. 6, pp. 345-354, 1988.

[107] S. M. Freire, L. M. Torres, N. F. Roque, C. Souccar, and A. J. Lapa, "Analgesic activity of a triterpene isolated from Scoparia dulcis L. (Vassourinha)," Memorias do Instituto Oswaldo Cruz, vol. 86, pp. 149-151, 1991.

[108] Y. Li and Y. Ohizumi, "Search for constituents with neurotrophic factor-potentiating activity from the medicinal plants of Paraguay and Thailand," Yakugaku Zasshi, vol. 124, no. 7, pp. 417-424, 2004.

[109] M. Ahmed, H. A. Shikha, S. K. Sadhu, M. T. Rahman, and B. K. Datta, "Analgesic, diuretic, and anti-inflammatory principle from Scoparia dulcis," Pharmazie, vol. 56, no. 8, pp. 657-660, 2001.

[110] M. Babincová and P. Sourivong, "Free radical scavenging activity of Scoparia dulcis extract," Journal of Medicinal Food, vol. 4, no. 3, pp. 179-181, 2001.

[111] T. K. Praveen, S. Dharmaraj, J. Bajaj et al., "Hepatoprotective activity of petroleum ether, diethyl ether, and methanol extract of Scoparia dulcis L. against CCl4-induced acute liver injury in mice," Indian Journal of Pharmacology, vol. 41, no. 3, pp. 110-114, 2009.

[112] W. D. Ratnasooriya, J. R. A. C. Jayakody, G. A. S. Premakumara, and E. R. H. S. S. Ediriweera, "Antioxidant activity of water extract of Scoparia dulcis," Fitoterapia, vol. 76, no. 2, pp. 220-222, 2005.

[113] J. C. Tsai, W. H. Peng, T. H. Chiu et al., "Hepatoprotective effect of scoparia dulcis on carbon tetrachloride induced acute liver injury in mice," American Journal of Chinese Medicine, vol. 38, no. 4, pp. 761-775, 2010.

[114] M. Latha, K. M. Ramkumar, L. Pari, P. N. Damodaran, V. Rajeshkannan, and T. Suresh, "Phytochemical and antimicrobial study of an antidiabetic plant: Scoparia dulcis L," Journal of Medicinal Food, vol. 9, no. 3, pp. 391-394, 2006.

[115] M. G. Phan, T. S. Phan, K. Matsunami, and H. Otsuka, "Chemical and biological evaluation on scopadulane-type diterpenoids from Scoparia dulcis of Vietnamese origin," Chemical and Pharmaceutical Bulletin, vol. 54, no. 4, pp. 546549, 2006.

[116] M. S. Gachet, J. S. Lecaro, M. Kaiser et al., "Assessment of anti-protozoal activity of plants traditionally used in Ecuador in the treatment of leishmaniasis," Journal of Ethnopharmacology, vol. 128, no. 1, pp. 184-197, 2010.

[117] M. Babincová, K. Schronerová, and P. Sourivong, "Antiulcer activity of water extract of Scoparia dulcis," Fitoterapia, vol. 79, no. 7-8, pp. 587-588, 2008.

[118] S. Mesía-Vela, M. Bielavsky, L. M. B. Torres et al., "In vivo inhibition of gastric acid secretion by the aqueous extract of Scoparia dulcis L. in rodents," Journal of Ethnopharmacology, vol. 111, no. 2, pp. 403-408, 2007.

[119] L. Pari and S. Venkateswaran, "Hypoglycaemic activity of Scopariadulcis L. extract in alloxan induced hyperglycaemic rats," Phytotherapy Research, vol. 16, pp. 662-664, 2002.

[120] J. E. Beh, J. Latip, M. P. Abdullah, A. Ismail, and M. Hamid, "Scoparia dulcis (SDF7) endowed with glucose uptake properties on L6 myotubes compared insulin," Journal of Ethnopharmacology, vol. 129, no. 1, pp. 23-33, 2010.

[121] L. Pari, M. Latha, and C. A. Rao, "Effect of Scoparia dulcis extract on insulin receptors in streptozotocin induced diabetic rats: Studies on insulin binding to erythrocytes," Journal of Basic and Clinical Physiology and Pharmacology, vol. 15, no. 3-4, pp. 223-240, 2004.

[122] H. Lorenzi, Árvores brasileiras: Manual de identificação e cultivo de plantas arbóreas nativas do Brasil, vol. 1, Plantarum, Nova Odessa, Brazil, 2nd edition, 1998.

[123] J. C. A. Tanaka, C. C. Da Silva, B. P. Dias Filho, C. V. Nakamura, J. E. De Carvalho, and M. A. Foglio, "Chemical constituents of Luehea divaricata Mart. (Tiliaceae)," Quimica Nova, vol. 28, no. 5, pp. 834-837, 2005.

[124] G. M. Barroso, Sistemática de angiospermas do Brasil, vol. 1, EDUSP, São Paulo, Brazil, 1978.

[125] H. J. Choi, J. S. Eun, B. G. Kim, S. Y. Kim, H. Jeon, and Y. Soh, "Vitexin, an HIF- $1 \alpha$ inhibitor, has anti-metastatic potential in PC12 cells," Molecules and Cells, vol. 22, no. 3, pp. 291299, 2006.

[126] J. H. Kim, B. C. Lee, J. H. Kim et al., "The isolation and antioxidative effects of vitexin from Acer palmatum," Archives of Pharmacal Research, vol. 28, no. 2, pp. 195-202, 2005.

[127] Y. W. Hsum, W. T. Yew, P. L. V. Hong et al., "Cancer chemopreventive activity of maslinic acid: suppression of COX-2 expression and inhibition of NF-KB and AP-1 activation in raji cells," Planta Medica, vol. 77, no. 2, pp. 152157, 2011.

[128] C. Li, Z. Yang, C. Zhai et al., "Maslinic acid potentiates the anti-tumor activity of tumor necrosis factor $\alpha$ by inhibiting NF- $\kappa$ B signaling pathway," Molecular Cancer, vol. 9, article no. $73,2010$. 
[129] J. B. Müller, C. S. Ceron, V. T. Kuntz, and P. Pozzatti, "Avaliação da Suscetibilidade Antifúngica e Antibacteriana do Extrato Bruto e Frações das Folhas de Luehea divaricata Martius," in Anais da $58 \nmid$ Reunião Anual da SBPC, Florianópolis, Brazil, 2006.

[130] A. E. Bighetti, M. A. Antônio, A. Possent, M. A. Foglio, M. G. Siqueira, and J. E. Carvalho, "Efeitos da administração aguda e subcrônica da Luehea divaricata Martus et Zuccarini," Lecta, vol. 22, no. 1/2, pp. 53-58, 2004.

[131] L. P. Felício, E. M. Silva, V. Ribeiro et al., "Mutagenic potential and modulatory effects of the medicinal plant Luehea divaricata (Malvaceae) in somatic cells of Drosophila melanogaster: SMART/wing," Genetics and Molecular Research, vol. 10, no. 1, pp. 16-24, 2011.

[132] S. Zacchino, C. Santecchia, S. Lopez et al., "In vitro antifungal evaluation and studies on mode of action of eight selected species from the Argentina flora," Phytomedicine, vol. 5, pp. 389-395, 1998.

[133] R. C. Mendonça, J. M. Felfili, B. M. T. Walter et al., "Flora vascular do cerrado," in Cerrado: ambiente e flora, S. M. Sano and S. P. Almeida, Eds., pp. 289-556, Planaltina, 1998.

[134] S. Solon, L. Lopes, P. T. Sousa-Júnior, and G. SchmedaHirschmann, "Free radical scavening activity of Lafoensia pacari," Journal of Ethnopharmacology, vol. 72, pp. 173-178, 2000.

[135] A. P. Rogerio, C. Fontanari, M. C. C. Melo et al., "Antiinflammatory, analgesic and anti-oedematous effects of Lafoensia pacari extract and ellagic acid," Journal of Pharmacy and Pharmacology, vol. 58, no. 9, pp. 1265-1273, 2006.

[136] A. P. Rogerio, C. Fontanari, É. Borducchi et al., "Antiinflammatory effects of Lafoensia pacari and ellagic acid in a murine model of asthma," European Journal of Pharmacology, vol. 580, no. 1-2, pp. 262-270, 2008.

[137] M. P. Porto et al., "Avaliação tóxico-genética do extrato de Lafoensia pacari em células somáticas de Drosophila melanogaste," in Resumos do 54 Congresso Brasileiro de Genética, 2008.

[138] S. Murakami, Y. Isobe, H. Higima, H. Nagai, M. Muramatu, and S. Otomo, "Inibition of gastric $\mathrm{H}+\mathrm{K}+$ ATPase and acid secretion by ellagic acid," Planta Medica, vol. 57, no. 4, pp. 305-308, 1991.

[139] P. I. Akubue and S. J. Stohs, "Endrin-induced production of nitric oxide by rat peritoneal macrophages," Toxicology Letters, vol. 62, no. 2-3, pp. 311-316, 1992.

[140] L. Ramanathan and N. P. Das, "Inhibitory effects of some natural products on metal-induced lipid oxidation in cooked fish," Biological Trace Element Research, vol. 34, no. 1, pp. 3544, 1992.

[141] N. T. Sartori and D. T. O. Martins, "Screening' farmacológico de plantas popularmente utilizadas como antiúlceras em Mato Gross," in Simpósio de plantas medicinais do Brasil, p. 105, Florianópolis, bRAZIL, 1996.

[142] P. Tamashiro Filho, Avaliação da atividade antiúlcera do extrato bruto metanólico de Lafoensia pacari St. Hil. (mangava brava), M.S. thesis, Universidade Federal de Mato Grosso, Cuiabá, Brazil, 1999.

[143] A. M. S. S. Beserra, Avaliação da atividade gastroprotetora do ácido elágico em modelos animais, M.S. thesis, Universidade Federal de Mato Grosso, Cuiabá, Brazil, 2008.

[144] V. Da Mota Menezes, A. N. Atallah, A. J. Lapa, and W. R. Catapani, "Assessing the therapeutic use of Lafoensia pacari St. Hil. extract (Mangava-Brava) in the eradication of Helicobacter pylori: double-blind randomized clinical trial," Helicobacter, vol. 11, no. 3, pp. 188-195, 2006.
[145] V. M. Tonello, Estrutura de populações de Lafoensia pacari St. Hil. e dados etnobotânicos e fenológicos em Nossa Senhora do Livramento, Mato Grosso, M.S. thesis, Universidade Federal de Mato Grosso, Cuiabá, Brazil, 1997.

[146] D. A. Albuquerque and L. Lopes, "Modulation of DelayedType Hypersensitivity by Lafoensia pacari St. Hil.," Bollettino Chimico Farmaceutico, vol. 2, no. 138, p. 120, 1999.

[147] A. P. Rogério, Estudo da atividade antiinflamatória do extrato etanólico de Lafoensia pacari Jaume St. Hilaire (Lythraceae), M.S. thesis, Universidade de São Paulo, Ribeirão Preto, Brazil, 2002.

[148] A. P. Rogerio, A. Sá-Nunes, and L. H. Faccioli, "The activity of medicinal plants and secondary metabolites on eosinophilic inflammation," Pharmacological Research, vol. 62, no. 4, pp. 298-307, 2010.

[149] M. V. M. Nascimento, P. M. Galdino, I. F. Florentino et al., "Antinociceptive effect of Lafoensia pacari A. St.-Hil. independent of anti-inflammatory activity of ellagic acid," Journal of Natural Medicines, vol. 65, no. 3-4, pp. 448-454, 2011.

[150] I. F. Silva Junior et al., "Avaliação da atividade antifúngica e modo de ação dos extratos da entrecasca, frações e ácido elágico de Lafoensia pacari A. St.-Hil., Lythraceae," Revista Brasileira de Farmacognosia, vol. 20, no. 3, pp. 422-428, 2010.

[151] S.-C. F. A. Silva, "Loção para tratamento capilar e respectivo processo de preparação," N do Pedido: PI9903518-9 A2. Classiicação A61K 7/06. Instituto Nacional de Propriedade Industrial, 1996. 


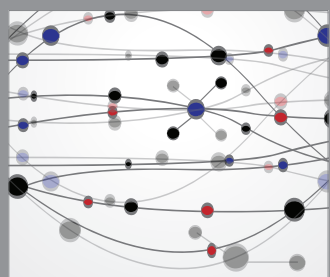

The Scientific World Journal
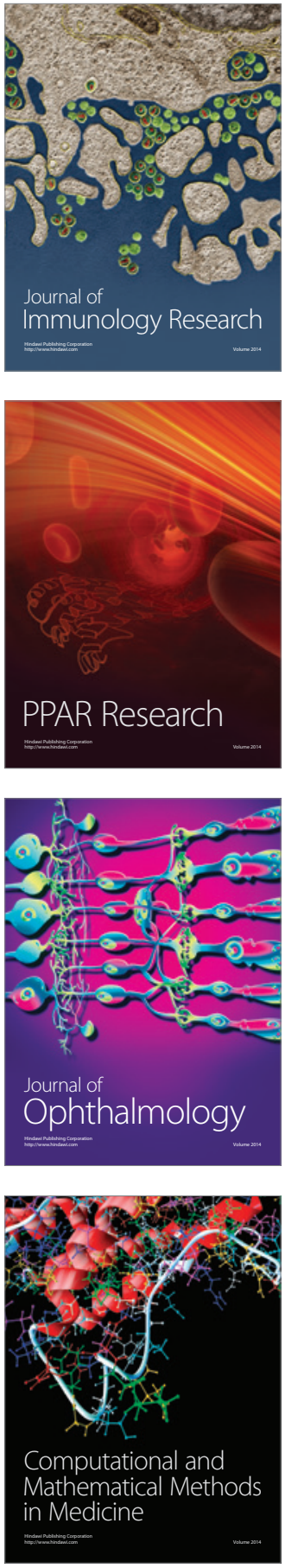

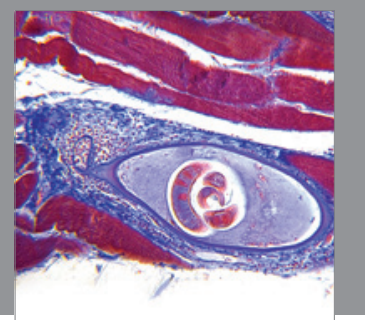

Gastroenterology

Research and Practice
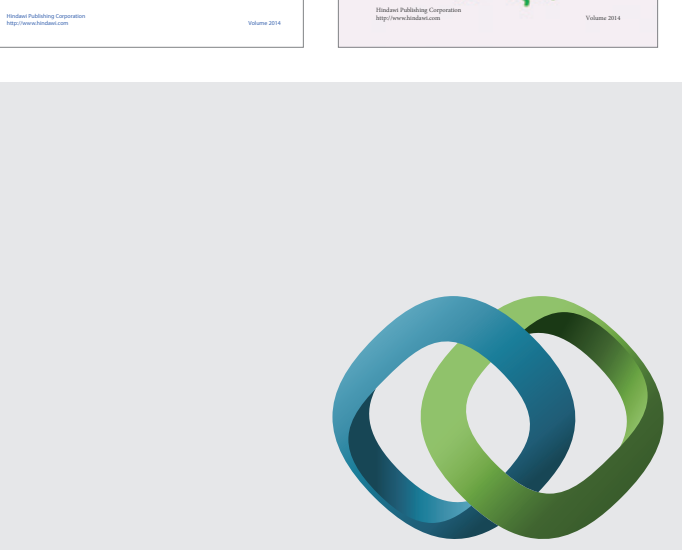

\section{Hindawi}

Submit your manuscripts at

http://www.hindawi.com
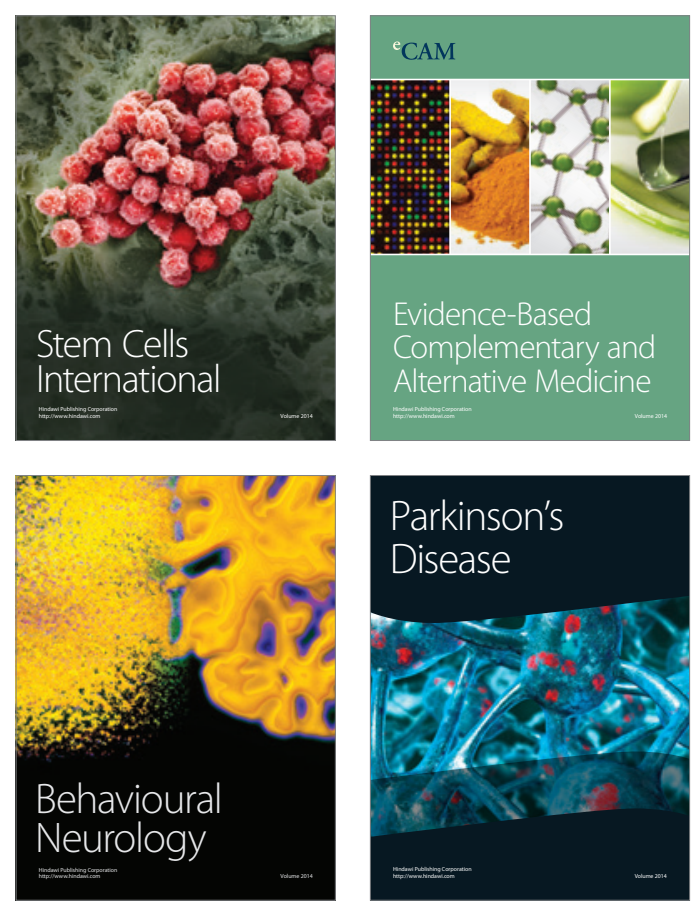

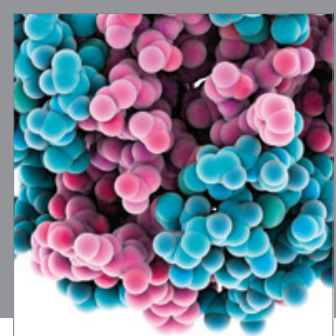

Journal of
Diabetes Research

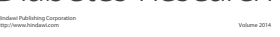

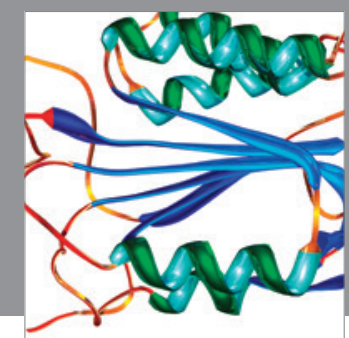

Disease Markers
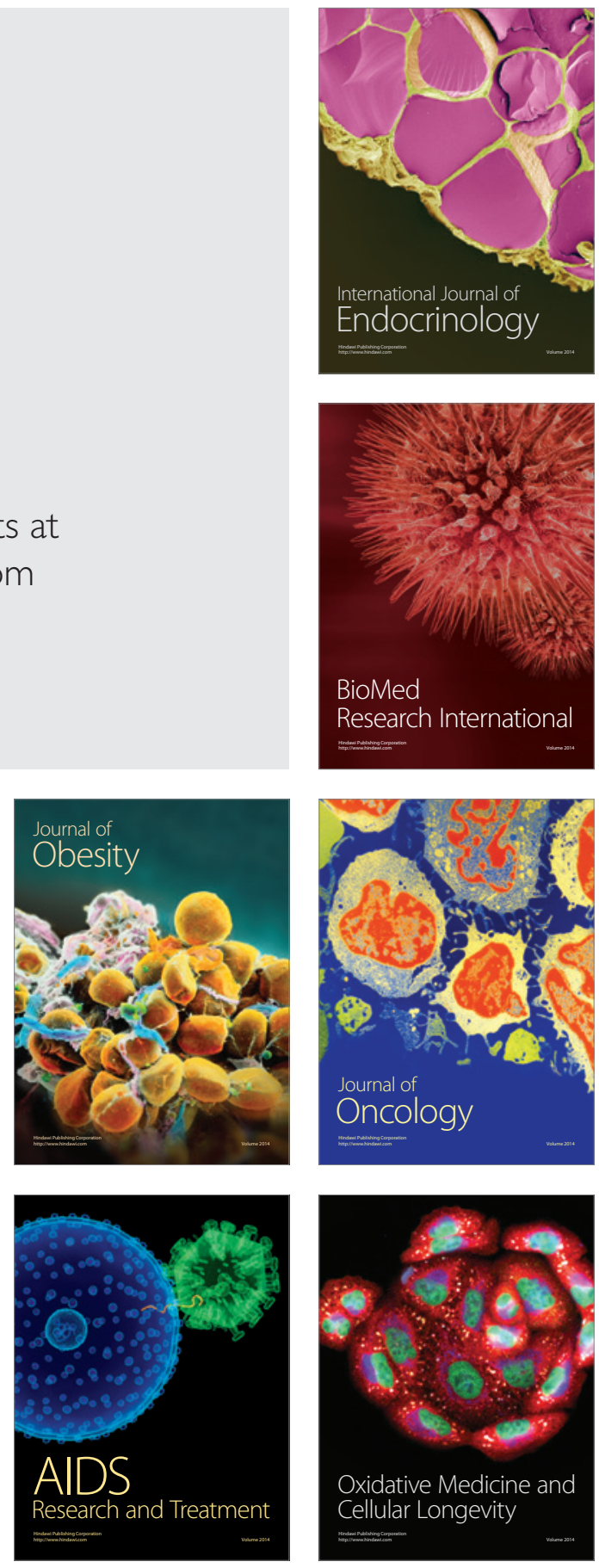